\title{
MÔ HÌNH THỜI GIAN RỜI RAC NHIỀU CHU KỲ TRONG TH! TRƯỜNG CHỨNG KHOÁN
}

\author{
Đinh Nhật Minh \\ May 19, 2012 \\ TRƯỜNG ĐẠI HỌC SƯ PHAM TP. HỒ CHÍ MINH

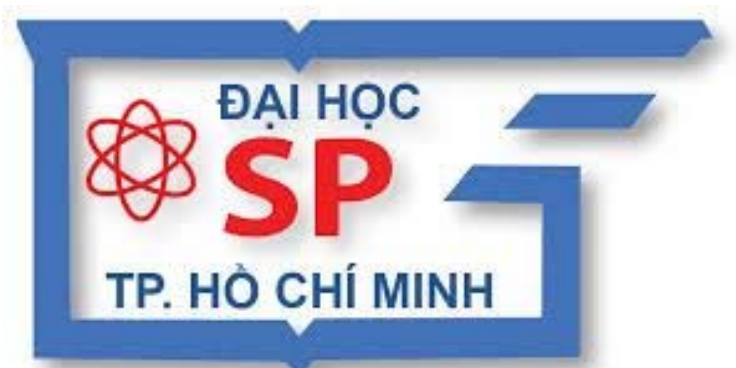 \\ LUẬN VĂN THẠC SĨ TOÁN HỌC \\ http://dlib.hcmue.edu.vn/handle/SPHCM/18346
}




$$
\text { Bộ GIÁO DỤC VÀ ĐÀO TẠO }
$$

TRƯờnG ĐẠI HỌC SƯ PHẠM TP. HỒ CHÍ MINH

\author{
Đinh Nhật Minh
}

MÔ HÌNH THỜI GIAN RỜI RẠC NHIỀU CHU KỲ TRONG TH!̣ TRƯỜNG CHÚNG KHOÁN

\author{
LUẬN VĂN THẠC SĨ TOÁN HỌC
}

Thành phố Hồ Chí Minh - Năm 2012 


$$
\text { Bộ GIÁO DỤC VÀ ĐÀO TạO }
$$

TRƯờNG ĐẠI HỌC SU' PHẠM TP. HỒ CHÍ MINH

\section{Đinh Nhật Minh}

MÔ HÌNH THÒ̀I GIAN RÒ'I RẠC NHIỀU CHU KỲ TRONG TH! TRƯỜNG CHÚNG KHOÁN

Chuyên ngành: Toán Giải tích

Mã số: 604601

\section{LUẬN VĂN THẠC SĨ TOÁN HỌC}

NGUOÒI HƯỚNG DÃ̃N KHOA HỌC TS NGUYẼ̃N CHÍ LONG

Thành phố Hồ Chí Minh - Năm 2012 


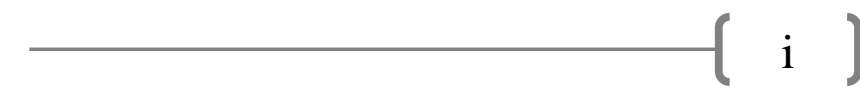

\section{LỜI CÁM ƠN}

Trước khi trình bày nội dung chính của luận văn này, tôi xin bày tỏ lòng biết ơn sâu sắc tới TS NGUYỄN CHÍ LONG đã tận tình chỉ bảo hướng dẫn để tôi có thể hoàn thành luận văn.

Tôi cũng xin bày tỏ lòng biết ơn chân thành tới toàn thể các thầy cô giảng viên trong khoa Toán - Tin học của trường Đại Học Sư Phạm Tp.HCM đã tận tình dạy bảo cho tôi trong quá trình học tập tại khoa.

Tôi cũng xin cám ơn các cán bộ của Phòng Sau Đại Học, trường Đại Học Sư Phạm Tp.HCM đã tạo điều kiện thuận lợi cho tôi cùng các học viên khác có thể học tập và nghiên cứu hiệu quả.

Cuối cùng, tôi xin gửi lời cám ơn tới gia đình, bạn bè đã luôn giúp đỡ, động viên tôi trong suốt quá trình học tập và thực hiện luận văn tốt nghiệp.

Tp. Hồ Chí Minh, tháng 8 năm 2012.

ĐINH NHẬT MINH 


\section{LờI Mở ĐẦ}

Toán học tài chính ra đời hơn 100 năm nay, nhưng đặc biệt phát triển trong khoảng ba bốn thập kỷ này và càng tỏ ra hữu ích trong thực tiễn đời sống kinh tế của các quốc gia và các cộng đồng kinh tế trên thế giới. Nó gắn liền với việc phân tích một cách khoa học những sự kiện tăng trưởng, rủi ro, lạm phát, khủng hoảng tài chính, bảo hiểm,... vốn là những vấn đề tài chính thời sự, nhất là trong cơn suy thoái kinh tế toàn cầu hiện nay.

Ở Việt Nam, việc học và nghiên cứu Toán tài chính được hơn chục năm trở lại đây. Nhiều trường Cao đẳng - Đại học đang xây dựng chương trình học phục vụ cho Toán tài chính. Nên mục đích đầu tiên của bài luận văn là chỉ ra các khái niệm và kết quả cơ bản về Mô hình thời gian rời rạc trong thị trường chứng khoán. Nhằm có thể dự đoán sự biến động giá hay nghiên cứu sâu hơn về Toán tài chính.

Luận văn này sẽ trình bày những kiến thức cơ bản về mô hình chứng khoán thời gian rời rạc một chu kỳ sau đó tập trung mở rộng vào trong mô hình nhiều chu kỳ.

Luận văn gồm 3 chương:

CHƯƠNG 1: MÔ HÌNH CHỨNG KHOÁN MỘT CHU KỲ 
Chương này trình bày mô hình chứng khoán đơn giản nhất, một số khái niệm và nguyên lý căn bản nhằm tạo cơ sở để mở rộng ở các chương sau.

\section{CHUOONG 2: THI TRƯÒNG CHÚNGG KHOÁN NHIỀU CHU KỲ}

Chương này mô tả những yếu tố cơ bản của mô hình thị trường chứng khoán và giới thiệu các khái niệm quan trọng như quá trình cổ tức và mô hình nhị thức.

\section{CHUOONGG 3: QUYỀN CHỌN VÀ HỢP ĐỒNG KÝ KÊT TRƯỚC.}

Chương này đề cập đến các quyền phái sinh.

Trong quá trình làm luận văn này, dù đã cố gắng nhưng vì thời gian làm còn hạn chế nên khó tránh khỏi nhiều thiếu sót. Mong bạn đọc thông cảm. Mọi thắc mắc xin các bạn liên hệ địa chỉ mail: minhmourinho@qmail.com. Mình xin cám ơn. 


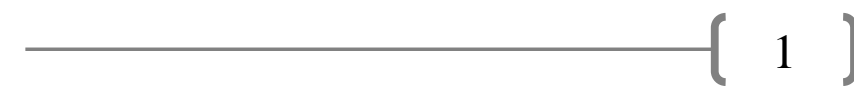

\section{MỤC LỤC}

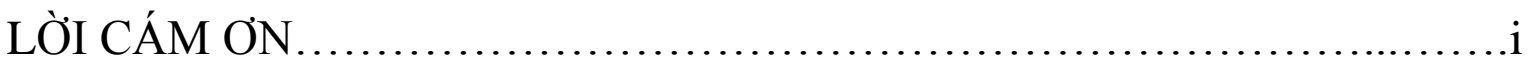

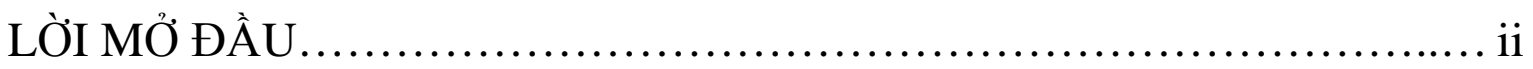

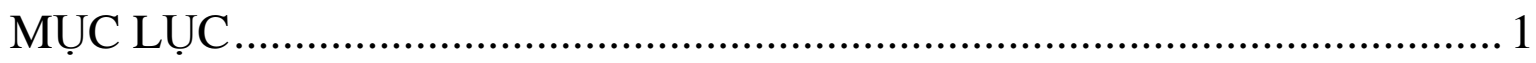

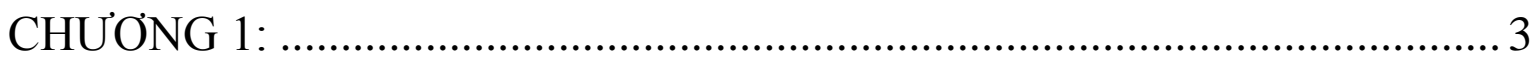

MÔ HÌNH THỊ TRƯờNG CHỨNG KHOÁN MỘT CHU KỲ ........................ 3

1.1 Một số khái niệm, định nghĩa:................................................................... 3

1.2 Thị trường tài chính đầy đủ ............................................................. 6

1.3 Hàm lợi ích và bài toán đầu tư tối ưu ................................................... 11

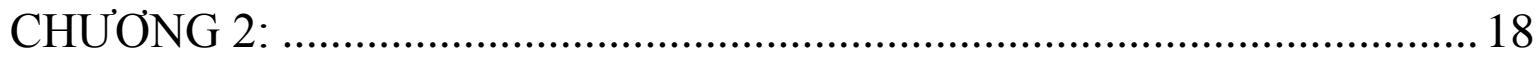

MÔ HÌNH THỊ TRƯỜNG CHỨNG KHOÁN NHIỀU CHU KỲ .................. 18

2.1 Chi tiết mô hình, cấu trúc thông tin và chiến lược kinh doanh .............. 18

2.2 Quá trình lợi tức (return) .......................................................................... 23

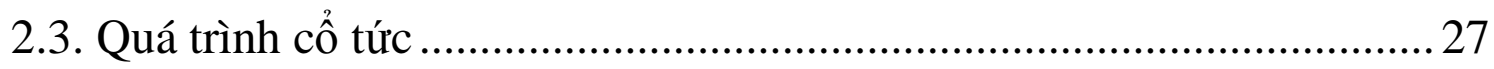

2.4 Kỳ vọng điều kiện và martingale ........................................................ 28

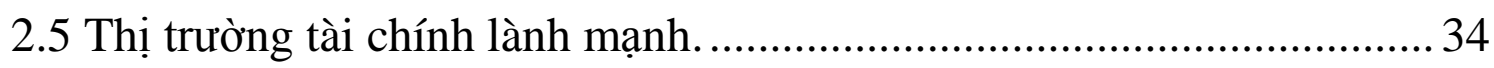

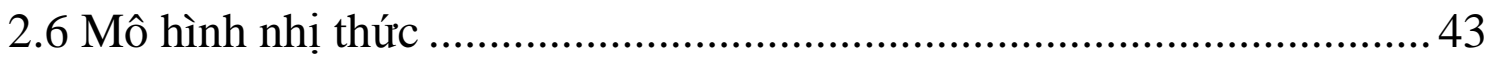

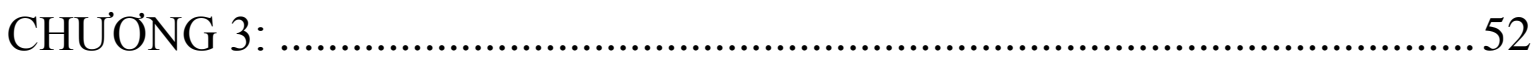

QUYỀN CHỌN VÀ HỢP ĐỒNG KÝ KẾT TRỨ̛C..................................... 52

3.1 Quyền phái sinh................................................................................. 52

3.2 Quyền chọn kiểu châu Âu dưới mô hình nhị thức ................................ 56

3.3 Thị trường đầy đủ và không đầy đủ ..................................................... 58

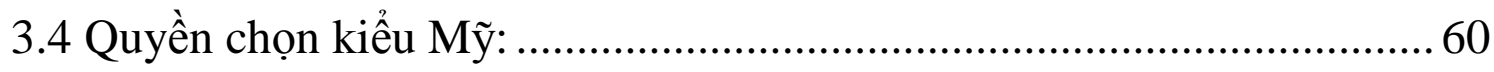

3.5 Giá hợp đồng ký kết trước (forward contract) ..................................... 72

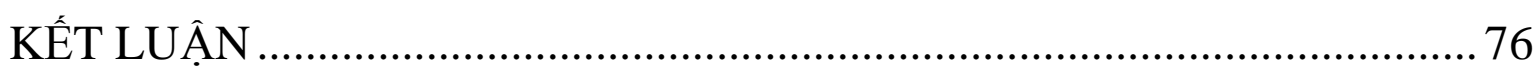


TÀI LIỆU THAM KHẢO.............................................................................. 77 


\section{CHƯONG 1:}

\section{MÔ HÌNH TH!̣ TRƯờNG CHÚNG KHOÁN MộT CHU KỲ}

Các khái niệm và kết quả trong chuơng này đuoợc trính dẫn tù tài liệu [2], [3], [4]

\subsection{Một số khái niệm, định nghĩa:}

Xét mô hình tài chính một chu kỳ với thời gian giao dịch $t=\{0,1\}$. Thời điểm $\mathrm{t}=0$ là thời điểm hiện tại, bắt đầu giao dịch và thời điểm $\mathrm{t}=1$ là thời điểm đáo hạn, kết thúc giao dịch. Thị trương tài chính gồm $N+1$ tài sản nền tảng để đầu tư.

Đó là một tài sản tính dụng trong ngân hàng (hay trái phiếu không rủi ro) $B_{t}, t=0,1$; với lãi suất cố định trong một chu kỳ là $\mathrm{r}$ và $N$ chứng khoán $\left\{S_{t}^{i}\right\}, i=1, \ldots, N ; t=0,1$.

Đối với tài khoản tín dụng $B_{t}$, giả thiết $B_{0}=1$ đơn vị tiền tệ gửi vào ngân hàng tại thời điểm $\mathrm{t}=0$ và sẽ có được $B_{1}=1+r$ đơn vị tiền tệ khi $\mathrm{t}=1$.

Giá của $\mathrm{N}$ chứng khoán tại thời điểm $\mathrm{t}=0$ là $S_{0}^{1}, S_{0}^{2}, \ldots, S_{0}^{N}$ thì được xác định, nhưng giá chứng khoán tại thời điểm $\mathrm{t}=1$ lại phụ thuộc vào một trong $\mathrm{k}$ kịch bản tài chính $\omega_{i}, i=1,2, \ldots, k$ thuộc $\Omega=\left\{\omega_{1}, \omega_{2}, \ldots, \omega_{k}\right\}$.

Giả sử sự xuất hiện của mỗi kịch bản $\omega_{i} \in \Omega$ có xác suất $P\left(\omega_{i}\right)>0, i=1,2, \ldots, k$. Gọi $\mathcal{F}=\mathbb{P}(\Omega)$ là tập hợp tất cả các tập con của $\Omega$ thì $\mathcal{F}$ là trường thông tin lớn nhất của thị trường tài chính đang xét. Lúc đó $S_{1}^{i}, i=1,2, \ldots, N$ là các biến ngẫu nhiên đang xét trên $(\Omega, \mathcal{F}, P)$ và $S_{1}^{i}(\omega)$ là giá chứng khoán thứ i tại thời điểm $\mathrm{t}=1$ khi kịch bản $\omega \in \Omega$ xuất hiện.

\section{Định nghĩa 1.1.1:}

Một phưong án đầu tu là một cặp $(x, \phi)$ trong đó x là tổng số tiền đầu tu ban đầu và $\phi$ là danh muc chứng khoán đầu tur, nó là vecto gồm $N$ thành phần 
$\phi:=\left(\phi^{0}, \phi^{1}, \ldots, \phi^{N}\right)$ với $\phi^{i}$ là số đơn vị cổ phiếu của chứng khoán thứ $i$ được mua tại thờ điểm $t=0$.

Số tiền còn lại sau khi mua $\mathrm{N}$ chứng khoán là:

$$
\phi^{0}=x-\sum_{i=1}^{N} \phi^{i} S_{0}^{i}
$$

sẽ được gửi vào tài khoản tín dụng (hay mua trái phiếu không rủi ro).

\section{Định nghĩa 1.1.2:}

Quá trình giá của phưong án đầu tur $(x, \phi)$ là cặp $\left(V_{0}(x, \phi) ; V_{1}(x, \phi)\right)$.

Trong đó $V_{0}(x, \phi)=x$ và $V_{1}(x, \phi)$ là biến ngẫu nhiên:

$$
V_{1}(x, \phi)=\phi^{0} B_{1}+\sum_{i=1}^{N} \phi^{i} S_{1}^{i}
$$

\section{Định nghĩa 1.1.3:}

Lợi tức của chứng khoán thứ $i, i=1,2, \ldots, N$, ghi là $R^{i}$, và thoả mãn biểu thức sau:

$$
R^{i}=\frac{S_{1}^{i}-S_{0}^{i}}{S_{0}^{i}}
$$

Và $R^{0}$ là lọi tức của chứng khoán tín dụng, đây là hằng số xác định duoong $r$ :

$$
R^{0}=\frac{B_{1}-B_{0}}{B_{0}}=r
$$

\section{Định nghĩa 1.1.4:}

Quá trình lời $G(x, \phi)$ của phuơng án đầu tu $(x, \phi)$ là biến ngẫu nhiên:

$$
G(x, \phi)=\phi^{0} r+\sum_{i=1}^{N} \phi^{i} \Delta S^{i} \text { với } \Delta S^{i}=S_{1}^{i}-S_{0}^{i} .
$$

Và khi biểu diễn lời qua quá trình lợi tức thì:

$$
G(x, \phi)=\phi^{0} R^{0} B_{0}+\sum_{i=1}^{N} \phi^{i} R^{i} S_{0}^{i}
$$

Định nghĩa 1.4.5: 
Trong truoòng hợp mọi hàng hoá trong thị truoòng phải chiết khấu thì quá trình giá của chứng khoán đã chiết khấu là:

$$
\hat{S}_{0}^{i}=S_{0}^{i} \text { và } \hat{S}_{1}^{i}=\frac{1}{B_{1}} S_{1}^{i}
$$

Lúc đó quá trình giá chiết khấu của phuơng án đầu tur $(x, \phi)$ là:

$$
\widehat{V}_{0}(x, \phi)=x \text { và } \hat{V}_{1}(x, \phi)=\phi^{0}+\sum_{i=1}^{N} \phi^{i} \hat{S}_{1}^{i}
$$

Và quá trình lời đã chiết khấu là: $\widehat{G}(x, \phi)=\sum_{i=1}^{N} \phi^{i} \Delta \hat{S}^{i}$

Vói $\Delta \hat{S}^{i}=\hat{S}_{1}^{i}-\hat{S}_{0}^{i}$

Từ các khái niệm trên ta có:

$$
\begin{gathered}
V_{1}(x, \phi)=V_{0}(x, \phi)+G(x, \phi) \\
\hat{V}_{t}=\frac{1}{B_{t}} V_{t}, \quad(t=0,1) \text { và } \hat{V}_{1}(x, \phi)=\hat{V}_{0}(x, \phi)+\widehat{G}(x, \phi)
\end{gathered}
$$

\section{Định nghĩa 1.1.6:}

Thị truoòng tài chính là lành mạnh, nếu trong thị truoòng không tồn tại phuơng án đầu tư $(x, \phi)$ nào thoả mãn cả 3 điều kiện sau:

i. $x=V_{0}(x, \phi)=0$

ii. $V_{1}(x, \phi) \geq 0$ (hoăc $\widehat{G}(x, \phi) \geq 0$ )

iii. $\exists \omega \in \Omega: V_{1}(x, \phi)(\omega)>0$ (hoặc $\widehat{G}(x, \phi)(\omega)>0$ )

\section{Định nghĩa 1.1.7:}

Một độ đo xác suất $Q$ trên $\Omega$ được gọi là độ đo xác suất rủi ro trung tính nếu:

i. $Q(\omega)>0, \forall \omega \in \Omega$ (mỗi kịch bản xảy ra với xác suất duoong) và

ii. $E_{Q}\left[\Delta \hat{S}^{i}\right]=0$ (kỳ vọng của số gia chứng khoán đã chiết khấu lấy theo độ đo $Q$ thì bằng 0) 


\section{Định nghĩa 1.1.8:}

Một quyền tài chính (hay quyền phái sinh) là một biến ngẫu nhiên X xác định trên không gian xác định $(\Omega, \mathcal{F}, P)$ biểu diễn một thu hoạch tại thời điểm đáo hạn $t=1$.

\section{Định nghĩa 1.1.9:}

Cho X là một quyền tài chính. Một phương án đầu tur $(x, \phi)$ được gọi là phưong án đáp úng (a replicating strategy) hay một bảo hộ (hedge) cho $X$ nếu $V_{1}(x, \phi)=X$ tại thời điểm $t=1$.

\section{Định nghĩa 1.1.10:}

Một quyền tài chính X được gọi là đạt được (attainable) hay mua bán được (marketable) nếu có một phuoong án đầu tu $(x, \phi)$ bảo hộ cho X.

\section{Định nghĩa 1.1.11:}

Thị trường tài chính là đầy đủ nếu mọi quyền tài chính $X$ đều có thể tìm được một phương án $(x, \phi)$ bảo hộ cho $X$. Mô hình tài chính không có tính chất này gọi là mô hình tài chính không đầy đủ.

Bây giờ ta phát biểu và chứng minh định lý quan trọng - định lý căn bản về việc định giá tài sản. Đây là một trong những nguyên lý nên tảng của bài toán tài chính

\section{Định lý 1.1.12:}

Thị truờng tài chính không có co hội chênh lệch thị giá nếu và chỉ nếu tồn tại một độ đo xác suất rủi ro trung tính

\subsection{Thị trường tài chính đầy đủ}

\section{Bổ đề 1.2.1 (Bổ đề Farkas):}

Cho ma trận $m$ hàng, $n$ cột $A$ và b là vectơ $m$ chiều thì chỉ có đúng một trong hai hệ (1) và (2) sau có nghiệm:

$$
\left\{\begin{array}{l}
A x=b \\
x \geq 0
\end{array}\right.
$$

Và 


$$
\left\{\begin{array}{l}
b^{T} y<0 \\
A^{T} y \geq 0
\end{array}\right.
$$

\section{Nhận xét 1:}

Từ bổ đề trên, ta có thể kiểm chứng dễ dàng rằng nếu hệ (1) vô nghiệm thì tồn tại $y \in R^{m}$ sao cho: $y A=0$ và $y b>0$.

\section{Mệnh đề 1.2.2:}

Cho $X$ là một quyền tài chính đạt được và $Q$ là độ đo xác suất rủi ro trung tính xác định trên $\Omega$ thì giá x của $X$ được định nghĩa nhu giá của một phuoong án đầu tư đáp úng và có thể xác định tù̀ công thức:

$$
x=E_{Q}\left[\frac{1}{B_{1}} X\right]
$$

Chứng minh:

Gọi $(x, \phi)$ là phương án đầu tư đáp ứng cho $\mathrm{X}$, nghĩa là $V_{1}(x, \phi)=X$.

Từ định nghĩa của quá trình giá đã chiết khấu, ta có:

$$
\begin{aligned}
& \frac{1}{B_{1}} X=\hat{V}_{1}(x, \phi) \\
& \text { Suy ra: } E_{Q}\left[\frac{1}{B_{1}} X\right]=E_{Q}\left[\hat{V}_{1}(x, \phi)\right] \\
& =E_{Q}[x+\widehat{G}(x, \phi)] \\
& =x+E_{Q}\left[\sum_{i=1}^{N} \phi^{i} \Delta \hat{S}^{i}\right] \\
& =x+\sum_{i=1}^{N} \phi^{i} E_{Q}\left[\Delta \hat{S}^{i}\right] \\
& =x \quad\left(\text { do } E_{Q}\left[\Delta \hat{S}^{i}\right]=0\right)
\end{aligned}
$$

Vậy mệnh đề đã được chứng minh. 


\section{Nhận xét 2:}

Mệnh đề 1.2.2 cho ta kết quả đối với mọi độ đo xác suất rủi ro trung tính xác định trên $\Omega$, các giá trị kỳ vọng tính qua công thức (3) là bằng nhau.

Sau đây ta áp dụng bổ đề Farkas để chứng minh một nguyên lý quan trọng khác của thị trường tài chính.

\section{Định lý 1.2.3:}

Giả sủ thị truờng tài chính đang xét là lành mạnh thì thị truờng tài chính là đầy đủ khi và chỉ khi tồn tại duy nhất một độ đo xác suất rủi ro trung tính.

Chứng minh:

$(\Rightarrow)$ :Giả sử thị trường tài chính là lành mạnh và đầy đủ. Theo nguyên lý căn bản định giá tài sản (mục 1.1), thì tồn tại một độ đo xác suất rủi ro trung tính. Để chứng minh tính duy nhất, giả sử có 2 độ đo xác suất rủi ro trung tính $Q_{1}$ và $Q_{2}$ xác định trên $\Omega$, ta cần chứng minh $Q_{1}=Q_{2}$.

Với mỗi i=1,...,k ta xét quyền tài chính có dạng:

$$
X^{i}(\omega)= \begin{cases}B_{1}, & \omega=\omega_{i} \\ 0, & \text { other }\end{cases}
$$

Thì $X^{i}$ là quyền tài chính đạt được, suy ra với mỗi i=1,...,k.

$$
Q_{1}\left(\omega_{i}\right)=E_{Q_{1}}\left[\frac{1}{B_{1}} X^{i}\right]=E_{Q_{2}}\left[\frac{1}{B_{1}} X^{i}\right]=Q_{2}\left(\omega_{i}\right)
$$

Vậy $Q_{1}=Q_{2}$

$(\Leftarrow)$ : Giả sử thị trường tài chính là lành mạnh và chỉ có duy nhất một độ đo xác suất rủi ro trung tính, ta cần chứng minh thị trường là đầy đủ. Để chứng minh điều này ta cần kết quả của 2 bổ đề sau:

\section{Bổ đề 1.2.4:}

Giả sủ thị truoòng tài chính là lành mạnh thì thị truờng này là đầy đủ khi và chỉ khi ma trận $k$ hàng, $N+1$ cột $A$ xác định của phuơng án đầu tu tại thời điểm đáo hạn $t=1$ 
$A=\left[\begin{array}{cccc}B_{1} & S_{1}^{1}\left(\omega_{1}\right) & \cdots & S_{1}^{N}\left(\omega_{1}\right) \\ B_{1} & S_{1}^{1}\left(\omega_{2}\right) & \cdots & S_{1}^{N}\left(\omega_{2}\right) \\ \vdots & \vdots & \ddots & \vdots \\ B_{1} & S_{1}^{1}\left(\omega_{k}\right) & \cdots & S_{1}^{N}\left(\omega_{k}\right)\end{array}\right]$ phải có hạng là $k$.

Chứng minh bổ đề 1.2.4:

Ma trận $\mathrm{A}$ có hạng $\mathrm{k}$ khi và chỉ khi với mỗi $X \in \mathbb{R}^{k}$, thì phương trình

$$
A \phi=X
$$

có nghiệm với $X \in \mathbb{R}^{N+1}$, trong đó $\phi$ có thể xem như một phương án đầu tư $\phi=\left(\phi^{0}, \phi^{1}, \ldots, \phi^{N}\right)^{T}$ và $\mathrm{X}$ là quyền tài chính:

$$
X=\left(V_{1}(x, \phi)\left(\omega_{1}\right), \ldots, V_{1}(x, \phi)\left(\omega_{k}\right)\right)^{T}
$$

Điều này chứng tỏ rằng tìm một phương án đáp ứng cho một quyền tài chính $\mathrm{X}$ là tương đương với việc giải hệ phương trình (4) và do đó phát biểu của bổ đề trên là đúng.

\section{Bổ đề 1.2.5:}

Trong thị truò̀ng tài chính lành mạnh, quyền tài chính X là đạt được khi và chỉ khi $E_{Q}\left[\frac{1}{B_{1}} X\right]$ lấy cùng một giá trị đối với mọi độ đo xác suất rủi ro trung tính $Q$.

Chứng minh bổ đề 1.2.5:

$(\Rightarrow)$ : Giả sử quyền tài chính $X$ là đạt được thì từ mệnh đề 1.2 .2 và Nhận xét 2 , ta có:

$E_{Q}\left[\frac{1}{B_{1}} X\right]=x$ (hằng số) đối với mọi độ đo xác suất rủi ro trung tính $\mathrm{Q}$.

$(\Leftarrow)$ : Giả sử quyên tài chính $X$ là không đạt được, ta cần chứng minh có hai độ đo xác suất rủi ro trung tính $Q_{1}$ và $Q_{2}$ trên $\Omega$ mà:

$$
E_{Q_{1}}\left[\frac{1}{B_{1}} X\right] \neq E_{Q_{2}}\left[\frac{1}{B_{1}} X\right]
$$


Khi X không đạt được thì hệ (4) là không có nghiệm $\phi$. Theo kết quả của bổ đề Farkas và Nhận xét 1 thì ta có một vectơ $n=\left(n_{1}, \ldots, n_{k}\right)$ thoả $n A=0$ và $n X>0$.

Cho trước một độ đo xác suất rủi ro trung tính $Q_{1}$ trên $\Omega$.

Đặt $Q_{2}\left(\omega_{i}\right)=Q_{1}\left(\omega_{i}\right)+\lambda n_{i} B_{1}$, với $\lambda>0$ khá bé sao cho: $Q_{2}\left(\omega_{i}\right)>0, \forall \omega_{i} \in \Omega$

Từ tính chất $n A=0$, ta có:

$\sum_{i=1}^{k} Q_{2}\left(\omega_{i}\right)=\sum_{i=1}^{k} Q_{1}\left(\omega_{i}\right)+\lambda \sum_{i=1}^{k} n_{i} B_{1}=1$

Do đó: $Q_{2}$ cũng là độ đo xác suất trên $\Omega$.

Mặt khác, ta có:

$$
\begin{aligned}
& E_{Q_{2}}\left[\frac{1}{B_{1}} X\right]=\sum_{i=1}^{k} Q_{2}\left(\omega_{i}\right)\left[\frac{1}{B_{1}} X\left(\omega_{i}\right)\right] \\
& =\sum_{i=1}^{k} \frac{1}{B_{1}} Q_{1}\left(\omega_{i}\right) X\left(\omega_{i}\right)+\lambda \sum_{i=1}^{k} n_{i} X\left(\omega_{i}\right) \\
& =E_{Q_{1}}\left[\frac{1}{B_{1}} X\right]+\lambda n X
\end{aligned}
$$

Vì $\lambda N X>0$ nên $E_{Q_{1}}\left[\frac{1}{B_{1}} X\right] \neq E_{Q_{2}}\left[\frac{1}{B_{1}} X\right]$

Vậy bổ đề đã được chứng minh.

Bây giờ ta chứng minh chiều ngược của định lý:

Lấy một quyền tài chính bất kỳ, ta cần chứng minh $\mathrm{X}$ là đạt được.

Thật vậy, vì giả thiết chỉ có duy nhất một độ đo xác suất rủi ro trung tính $Q$ trong thị trường này nên $E_{Q}\left[\frac{1}{B_{1}} X\right]$ có một giá trị duy nhất.

Vậy theo kết quả của bổ đề 1.2.5 thì X là đạt được. Vậy thị trường tài chính là đầy đủ. 
Do đó định lý đã được chứng minh.

\subsection{Hàm lợi ích và bài toán đầu tư tối ưu}

Đối với nhà đầut tư tài chính thì vấn đề quan tâm chính là: Cách nào là tối ưu để đầu tư vào thị trường tài chính?

Lời giải đáp của câu hỏi này phụ thuộc vào mô hình tài chính nào đang xét và chọn lựa phương án đầu tư nào? Tính tối ưu được hiểu chính xác như thế nào? Hay cụ thể là, xác định giá trị đối với mỗi cách biểu diễn phương án đầu tư như thế nào? Giá trị này trong thị trường tài chính thường bị chi phối bởi 3 đặc trưng sau:

1. NĐT thích thu hoạch cao hơn hay là thu thu hoạch thấp hơn đối với một phương án đầu tư.

Đặc trưng này là hiển nhiên. Tuy nhiên, trong thực tế ở thị trường tài chính, lợi ích thu được từ một phương án đầu tư có tính ngẫu nhiên; chẳng hạn, phương án đầu tư 1 có thể đạt được thu hoạch cao khi trạng thái tài chính này xảy ra, nhưng phương án đầu tư 2 lại đạt được thu hoạch cao khi trạng thái tài chính khác xảy ra. Do đó, sẽ không có ý nghĩa khi so sánh hai phương án trên cùng một trạng thái, mà phải xét kỳ vọng của nó, do đó đặc trưng thứ 2 là:

2. NĐT xét giá trị trung bình hay kỳ vọng của từng phương án đầu tư.

3. NĐT thường có tâm lý e ngại rủi ro.

Để rõ đặc trưng này ta xét ví dụ sau:

\section{Ví dụ 1:}

Giả sử NĐT được mời chọn một trong hai phương án 1 và 2 , tương ứng với thu hoạch $X^{1}$ và $X^{2}$. Nếu NĐT chọn phương án 1 sẽ thu hoạch được 100 triệu đồng; còn nếu chọn phương án 2 , thì phải tuân theo quy tắc may rủi sau:

Nếu tung đồng xu (gồm hai mặt $\mathrm{H}$ và $\mathrm{T}$ ) và mặt $\mathrm{H}$ xuất hiện thì $\mathrm{NĐT} \mathrm{thu} \mathrm{được} 200$ triệu đồng, còn nếu mặt $\mathrm{T}$ xuất hiện thì NĐT sẽ không thu được đồng nào. Thông thường, nếu NĐT không phải là tỷ phú, thì có tâm lý chọn phương án 1 để thu hoạch chắc chắn 100 triệu đồng hơn là chọn phương án 2 có thể xảy ra tình trạng trắng tay, nghĩa là NĐT có tâm lý e ngại rủi ro, mặc dù thu hoạch trung bình của hai phương án này như nhau: 
Vì $X^{1}=100$ là tất định và kỳ vọng của nó, $E\left[X^{1}\right]=100$. Còn đối với $X^{2}$ phụ thuộc ngẫu nhiên vào $\mathrm{H}$ hoặc $\mathrm{T} ; X^{2}(H)=200$ và $X^{2}(T)=0$. Do đó nếu đánh giá thu hoạch theo kỳ vọng thì $E\left[X^{2}\right]=\frac{1}{2} \cdot 200+\frac{1}{2} \cdot 0=100$.

Khái niệm e ngại rủi ro thường được sử dụng trong mô hình thông qua các hàm lợi ích (utility functions).

Hàm lợi ích cho ta cách đo lường sự chọn lựa của NĐT phụ thuộc vào tổng vốn hiện có và mức độ e ngại rủi ro, mà NĐT mong muốn là đạt được tổng tài sản về sau lớn hơn. Do đó, hàm lợi ích là hạt nhân của lý thuyết đầu tư tối ưu hiện đại.

\section{Định nghĩa 1.3.1:}

Cho hàm $U: R^{+} \times \Omega \rightarrow R$ được gọi là hàm lợi ích nếu nó thoả mãn hai điều kiện sau:

1. Cố định $\omega \in \Omega$ thì hàm $U(x, \omega)$ là tăng ngặt theo biến $x$, nghĩa là đạo hàm theo biến $x$ của $U$ là $U^{\prime}(x, \omega)>0, \forall x>0$.

2. Cố định $\omega \in \Omega$ thì hàm $U(x, \omega)$ là lõm theo biến $x$, nghĩa là:

$U(\lambda x+(1-\lambda) y, \omega)>\lambda U(x, \omega)+(1-\lambda) U(y, \omega)$

Hay tương đương với $U^{\prime \prime}(x, \omega)<0, \forall x>0$.

Để đơn gian cách biểu diễn, ta thường viết hàm lợi ích dạng theo biến tổng tài sản $\mathrm{x}, U(x, \omega)=U(x(\omega))=U(x)$ và ngầm hiểu nó còn phụ thuộc vào trạng thái $\omega$.

Bây giờ ta xét một biến ngẫu nhiên X biểu diễn thu hoạch của NĐT. Cố định hàm lợi ích U, ta sẽ đo lường thu hoạch của NĐT qua kỳ vọng:

$$
E[U(X)]=\sum_{i=1}^{k} P\left(\omega_{i}\right) U\left(X\left(\omega_{i}\right)\right)
$$

Sẽ biểu diễn thu hoạch này bao hàm ba đặc trưng vừa nêu trên: Đặc trưng thứ nhất phản ánh qua hàm lợi ích thì tăng ngặt, đặc trưng thứ hai là phản ánh qua giá trị trung bình, còn đặc trưng thứ ba là tính e ngại rủi ro, phản ánh qua tính lõm ngặt của hàm lợi ích.

\section{Ví dụ 2:}


Giả sử NĐT đang có tổng tài sản là 5 triệu đồng và thị trường chỉ có một cách đầu tư là mua một loại cổ phiếu: $S_{0}=5$ (triệu). Cũng giả sử tại thời điểm đáo hạn $\mathrm{t}=1$, một trong hai kịch bản trong thị trường có thể xảy ra giống như việc tung đồng xu hai mặt $\mathrm{H}$ và $\mathrm{T}: \Omega=\{H, T\}$ và xác suất $P(H)=P(T)=\frac{1}{2}$.

Nếu kịch bản $\mathrm{H}$ xảy ra (tình hình kinh tế phát triển tốt) thì giá chứng khoán tăng: $S_{1}(H)=9$, nghĩa là tăng thêm 4triệu; còn nếu kịch bản $\mathrm{T}$ xảy ra (tình hình kinh tế khó khăn) thì giá chứng khoán giảm: $S_{1}(T)=1$, nghĩa là giảm 4 triệu. Trong trường hợp này được gọi là công bằng vì kỳ vọng lợi nhuận là:

$$
E[G]=\frac{1}{2} \cdot 4+\frac{1}{2} \cdot(-4)=0
$$

Xét hàm lợi ích $U(x)=\sqrt{x}$. Ta thử tìm hiểu, trên quan điểm đáp ứng nguyên lý cực đại kỳ vọng hàm lợi ích, NĐT sẽ chọn PAĐT hay không chọn?

Nếu NĐT từ chối PA trên, giữ 5 triệu; đối với hàm lợi ích như trên thì $U(x)=U(5)=\sqrt{5}$ (hằng số) nên kỳ vọng của nó là $E[U(5)]=\sqrt{5} \approx 2,24$

Nếu nhà đầu tư chọn phương án đầu tư thì kỳ vọng của hàm lợi ích là:

$$
E[U(x)]=P(H) \cdot U(x(H))+P(T) \cdot U(x(T))=0,5 \cdot \sqrt{9}+0,5 \cdot \sqrt{1}=2<2,24
$$

Vì kỳ vọng lợi ích khi từ chối PAĐT lớn hơn kỳ vọng hàm lợi ích khi chọn PAĐT nên NĐT sẽ từ chối PAĐT.

Một cách tổng quát, NĐT e ngại rủi ro thường từ chối trò chơi công bằng vì kỳ vọng lợi tức là $0 \%$. Nếu kỳ vọng lợi tức lớn hơn $0 \%$ thì NĐT có thể chọn hay không chọn $\mathrm{PAĐT} \mathrm{phụ} \mathrm{thuộc} \mathrm{vào} \mathrm{hàm} \mathrm{lợi} \mathrm{ích} \mathrm{và} \mathrm{tổng} \mathrm{vốn} \mathrm{ban} \mathrm{đầu.} \mathrm{Chẳng} \mathrm{hạn,} \mathrm{nếu}$ xác suất xảy ra của kịch bản $\mathrm{H}, P(H)=\frac{3}{4}$ thay vì $P(H)=\frac{1}{2}$ thì kỳ vọng lợi ích là:

$$
E[U(x)]=\frac{3}{4} \cdot \sqrt{9}+\frac{1}{4} \cdot \sqrt{1}=2,5>2,24
$$

Và do đó NĐT sẽ chọn PAĐT.

Sử dụng kết quả trên, từ việc tìm PAĐT tối ưu trong thị trường tài chính, chuyển sang tìm phương án $(x, \phi)$ sao cho $E\left[U\left(V_{1}(x, \phi)\right)\right]$ đạt giá trị tối ưu. Bài toán này được gọi là bài toán đầu tối ưu. Giá trị tối ưu dĩ nhiên phụ thuộc vào tổng vốn đầu 
tư ban đầu $\mathrm{x}$. Khi vốn đầu tư ban đầu $\mathrm{x}$ càng lớn thì kỳ vọng thu hoạch càng cao. Do đó ta xem vốn đầu tư ban đầu như một tham số của bài toán.

\section{Định nghĩa 1.3.2:}

Một phương án đầu tu $\left(x, \phi^{*}\right)$ được gọi là một nghiệm của bài toán đầu tu tối uuu với vốn ban đầu là $V_{0}=x$ và hàm lợi ích $U$ nếu:

$$
E\left[U\left(V_{1}\left(x, \phi^{*}\right)\right)\right]=\max _{(x, \phi)} E\left[U\left(V_{1}(x, \phi)\right)\right]
$$

\section{Mệnh đề 1.3.3:}

Nếu bài toán đầu tu tối ưu trong thị truòng tài chính đang xét có một nghiệm, thì mô hình tài chính này là lành mạnh.

Chứng minh:

Ta cần chứng minh rằng: nếu thị trường khong lành mạnh thì bài toán đầu tư tối ưu vô nghiệm.

Giả sử thị trường tài chính là không lành mạnh, nghĩa là tồn tại một phương án đầu tư có độ chệnh lệch thị giá $(0, \psi)$. Đối với mỗi phương án đầu tư $(x, \phi)$ chúng ta phải có:

$$
V_{1}(x, \phi+\psi)(\omega)=V_{1}(x, \phi)(\omega)+V_{1}(0, \psi)(\omega)
$$

Trong đó: $(x, \phi+\psi)$ là phương án đầu tư tổng của hai phương án $(x, \phi)$ và $(0, \psi)$, nghĩa là phương án đầu tư mua $\phi^{i}+\psi^{i}$ đơn vị cổ phiếu chứng khoán $S^{i}$. Theo định nghĩa của độ chênh lệch thị giá, phương án này chỉ cần đầu tư vốn ban đầu là $\mathrm{x}$ và bất đẳng thức trên sẽ thoả ngặt với ít nhất một kịch bản $\omega \in \Omega$, do đó với mỗi hàm lợi ích U ta có:

$$
E\left[U\left(V_{1}(x, \phi+\psi)\right)\right]>E\left[U\left(V_{1}(x, \phi)\right)\right]
$$

Điều này chỉ ra rằng, khi thị trường tài chính không lành mạnh, thì đối với mỗi phương án đầu tư $(x, \phi)$, đều có một phương án đầu tư khác, có cùng số đầu tư ban đầu với phương án $(x, \phi)$ nhưng thu hoạch trung bình lại cao hơn. Vậy bài toán đầu tư tối ưu không có nghiệm.

Do đó, mệnh đề đã được chứng minh. 
Theo nguyên lý căn bản định giá phái sinh, thì tính chất lành mạnh của thị trường tài chính tương đương với sự tồn tại một độ đo xác suất rủi ro trung tính. Một độ đo xác suất rủi ro trung tính như vậy được tính qua nghiệm của bài toán đầu tư tối ưu qua mệnh đề sau:

\section{Mệnh đề 1.3.4:}

Gọi $\left(x, \phi^{*}\right)$ là một nghiệm của bài toán đầu tu tối ưu với tổng vốn đầu tu ban đầu là $x$ và hàm lợi ích $U$ thì độ đo $Q$ xác định bởi:

$$
Q(\omega)=\frac{P(\omega) U^{\prime}\left(V_{1}\left(x, \phi^{*}\right)(\omega)\right)}{E\left[U^{\prime}\left(V_{1}\left(x, \phi^{*}\right)\right)\right]}
$$

Là một độ đo xác suất rủi ro trung tính. Trong đó $U$ ' $(x)$ là đạo hàm của $U$ theo $x$.

Độ đo xác suất rủi ro trung tính được xác định trong mệnh đề trên có thể dùng để tính giá trị quyền tài chính. Do đó hai vấn đề cốt lõi là tìm phương án đầu tư tối ưu và định giá quyền tài chính liên hệ chặt chẽ với nhau.

Trong thực tế, việc giải phương trình trong (4) để tìm phương án thông qua $\phi^{i}, i=1,2, \ldots, N$ không hề đơn giản. Một kỹ thuật để giải bài toán là dựa vào độ đo xác suất rủi ro trung tính và phương pháp nhân tử Lagrange. Ý tưởng của phương pháp này là phân tích bài toán đang xét thành hai bài toán con theo hai bước sau:

Bước 1: Xác định cực đại $V_{1}$ của hàm $V \mapsto E[U(V)]$ trên tập hợp chấp nhận được của biến ngẫu nhiên $\mathrm{V}$.

Bước 2: Tìm một phương án đầu tư mà nó có giá trị tại thời điểm $\mathrm{t}=1$, bằng giá trị cực đại $V_{1}$ được xác định ở bước 1 .

Phương án đầu tư tìm được ở bước 2 , chính là phương án tối ưu. Bài toán con ở bước 2 chính là bài toán tìm phương án bảo hộ, mà nó tương đương với việc giải hệ phương trình tuyến tính.

Trước tiên ta xét mô hình tài chính đầy đủ, nghĩa là trong mô hình chỉ tồn tại một độ đo xác suất gốc $\mathrm{P}$ và một độ đo xác suất rủi ro trung tính $\mathrm{Q}$.

Định nghĩa 5:

Tổng tài sản đạt được tù vốn ban đầu $x>0$ được định nghĩa bởi tập sau: 
$\widetilde{W}_{x}=\left\{W \in R^{k}: E_{Q}\left[\frac{1}{B_{1}} W\right]=x\right\}$

Khi $W \in \widetilde{W}_{x}$ thì có một phương án đầu tur $(x, \phi)$ sao cho: $V_{1}(x, \phi)=W$

Bài toán con ở bước 1 chính là bài toán tối ưu:

Tìm cực đại: $E[U(V)]$

Với ràng buộc: $W \in \widetilde{W}_{x}$

DÙng nhân tử Lagrange, với hàm Lagrange

$$
L(W, \lambda)=E[U(V)]-\lambda\left(E_{Q}\left[\frac{1}{B_{1}} W\right]-x\right)
$$

Một nghiệm của bài toán tối ưu có ràng buộc trên là nghiệm của hệ thức có được từ đạo hàm riêng của hàm Lagrange theo các biến $W_{i}=W\left(\omega_{i}\right)$ và $\lambda$ bằng 0 . Trong biểu thức định nghĩa của hàm Lagrange (5), ta phải tính kỳ vọng hai độ đo khác nhau $\mathrm{P}$ và $\mathrm{Q}$. Để tiện cho việc tính toán, ta định nghĩa một biến ngẫu nhiên mới:

$$
L(\omega)=\frac{Q(\omega)}{P(\omega)}(6)
$$

Và gọi là mật độ giá trạng thái (state price density)

Lúc này hàm Lagrange có thể viết:

$$
L(W, \lambda)=\sum_{i=1}^{k} P\left(\omega_{i}\right)\left[U\left(W\left(\omega_{i}\right)\right)-\lambda\left(L\left(\omega_{i}\right) \frac{1}{B_{1}} W\left(\omega_{i}\right)-x\right)\right]
$$

Đạo hàm riêng của hàm Lagrange theo các biến $W_{i}$ bằng 0 , cho ta:

$$
U^{\prime}\left(W\left(\omega_{i}\right)\right)=\lambda \frac{L\left(\omega_{i}\right)}{B_{1}}(7)
$$

Kết hợp với độ đo xác suất $\mathrm{Q}$ xác định trong mệnh 2 thì:

$$
\lambda=E\left[B_{1} U^{\prime}(W)\right]
$$


Vì đạo hàm $U^{\prime}(x)$ của hàm lợi ích là tăng ngặt, do đó tồn tại hàm ngược $I(x)$ của $U^{\prime}(x)$ sao cho:

$U^{\prime}(I(x))=x=I\left(U^{\prime}(x)\right)$, do đó từ (7) suy ra:

$W(\omega)=I\left(\lambda \frac{L(\omega)}{B_{1}}\right)$

Phương trình trên cho ta nghiệm của bài toán tối ưu có ràng buộc khi ta biết chính xác giá trị của $\lambda$.

Công thức (9) không giúp ta tính được $\lambda$ vì nó biểu diễn thông qua biến chưa biến $\mathrm{W}$, tuy nhiên ta lại biết rằng $\mathrm{W}$ phải thoả điều kiện:

$$
E_{Q}\left[\frac{1}{B_{1}} W\right]=x
$$

Thay $\mathrm{W}$ trong (9) vào (10), ta được:

$$
E_{Q}\left[\frac{1}{B_{1}} I\left(\lambda \frac{L(\omega)}{B_{1}}\right)\right]=x
$$

Giả phương trình (11) ta tìm được $\lambda$, rồi thay vào (9) ta tìm được nghiệm của bài toán tối ưu có ràng buộc. Trong trường hợp hàm lợi ích $\mathrm{U}(\mathrm{x})$ trong định nghĩa 1 có thêm tính chất:

(3) $\quad \lim _{x \rightarrow 0} U^{\prime}(x)=+\infty$ và $\lim _{x \rightarrow+\infty} U^{\prime}(x)=0$

Thì nghiệm $\lambda$ của phương trình (11) luôn tồn tại và duy nhất, vì lúc đó hàm $h(\lambda)=E_{Q}\left[\frac{1}{B_{1}} I\left(\lambda \frac{L}{B_{1}}\right)\right]$ là hàm tăng ngặt, liên tục và thoả mãn điều kiện:

$\lim _{x \rightarrow 0} h(\lambda)=+\infty$ và $\lim _{x \rightarrow+\infty} h(\lambda)=0$. 


\section{CHƯONG 2:}

\section{MÔ HÌNH TH!̣ TRƯờNG CHÚNG KHOÁN NHIỀU CHU KỲ}

Các khái niệm và kết quả của chuoong này đuợc trích tù tài liệu [1], [6], [9], [10]

\subsection{Chi tiết mô hình, cấu trúc thông tin và chiến lược kinh doanh}

\subsubsection{Chi tiết mô hình}

Thị trường tài chính nhiều chu kỳ mang tính thực tế hơn mô hình một chu kỳ. Nó được xây dựng từ những yếu tố sau:

- Xét mô hình tài chính $\mathrm{T}$ chu kỳ $(T \in \mathbb{N}, T>1)$ với các thời điểm giao dịch $t=\{0,1, \ldots, T\}$. Thời điểm $t=0$ là thời điểm hiện tại, bắt đầu giao dịch và thời điểm $t=T$ là thời điểm đáo hạn, kết thúc giao dịch.

- Một không gian tài chính (không gian mẫu) $\Omega$ có $k$ phần tử tương ứng với $k$ kịch bản tài chính:

$$
\Omega=\left\{\omega_{1}, \omega_{2}, \ldots, \omega_{k}\right\}
$$

- Một độ đo xác suất $P$ trên $\Omega$ với $P(\omega)>0, \forall \omega \in \Omega$.

- Thị trường tài chính gồm $N+1$ tài sản nền tảng để đầu tư. Đó là một tài khoản tín dụng trong ngân hàng (hay trái phiếu không rủi ro) tương ứng với quá trình tài khoản ngân hàng $B=\left\{B_{t}: t=0,1, \ldots, T\right\}$, và $N$ chứng khoán rủi ro $S^{n},(n=$ $1,2, \ldots, N)$ tương ứng với $N$ quá trình giá

$$
S^{n}=\left\{S_{t}^{n}: t=0,1, \ldots, T\right\},(n=1,2, \ldots, N)
$$

- Một bộ lọc (lọc thông tin) $\mathcal{F}=\left\{\mathcal{F}_{t}: t=0,1, \ldots, T\right\}$

Trong đó:

$B$ là quá trình ngẫu nhiên với $B_{0}=1$ (đơn vị tiền tệ) gửi vào ngân hàng tại thời điểm $t=0$ và $B_{t}(\omega)>0, \omega \in \Omega$.

$B_{t}$ được hiểu như là giá của tài khoản ngân hàng tại thời điểm $t$ khi 1 đơn vị tiền tệ được gửi vào ngân hàng tại thời điểm $t=0$.

Thông thường, trong thực tế $B_{t}$ là dãy không giảm. Trong trường hợp này, ta có:

$$
r_{t}=\frac{B_{t}-B_{t-1}}{B_{t-1}}
$$

$r_{t}$ được gọi là lãi suất trong khoảng thời gian $(t-1, t)$. Ta giả thiết rằng $r_{t}=r$, tức là lãi suât trong mỗi chu kỳ là cố định, do đó $B_{t}=(1+r)^{t}$. 
Đối với $N$ chứng khoán rủi ro. Quá trình giá $S^{n}=\left\{S_{t}^{n}: t=0,1, \ldots, T\right\}$ là không âm và $S_{t}^{n}$ là giá của chứng khoán thứ $n$ tại thời điểm $t$.

Giá của $N$ chứng khoán tại thời điểm $t=0$ là $S_{0}^{1}, S_{0}^{2}, \ldots, S_{0}^{N}$ thì được xác định nhưng giá chứng khoán tại các thời điểm $t$ với $1 \leq t \leq T$ lại phụ thuộc vào một trong $k$ kịch bản tài chính $\omega_{i}, i=1,2, \ldots, k$ thuộc $\Omega=\left\{\omega_{1}, \omega_{2}, \ldots, \omega_{k}\right\}$ và chỉ được biết tại thời điểm $t$.

Với $T=1$, thì mô hình tài chính là một chu kỳ mà ta đã khảo sát ở chương 1 . \

Với $T>1$, thì trong trường hợp này, ta có thêm khái niệm bộ lọc (lọc thông tin) $\mathcal{F}=\left\{\mathcal{F}_{t}: t=0,1, \ldots, T\right\}$ để mô tả thông tin về giá chứng khoán tới nhà đầu tư

\subsubsection{Cấu trúc thông tin}

\section{Định nghĩa 2.1.1:}

Cấu trúc thông tin được mô tả một cách đầy đủ bởi dãy $\mathcal{P}_{0}, \mathcal{P}_{1}, \ldots, \mathcal{P}_{T}$ các phân hoạch của $\Omega$ với:

$$
\begin{aligned}
\text { i. } & \mathcal{P}_{0}=\{\Omega\} \\
\text { ii. } & \mathcal{P}_{T}=\left\{\left\{\omega_{1}\right\},\left\{\omega_{2}\right\}, \ldots,\left\{\omega_{K}\right\}\right\}
\end{aligned}
$$

iii. $\quad$ Mỗi $A \in \mathcal{P}_{t}$ bằng họp một vài phần tủ trong $\mathcal{P}_{t+1}$ với mỗi $t<T$.

\section{Định nghĩa 2.1.2:}

Một chọn lọc F các tập con của $\Omega$ được gọi là $\sigma$-đại số trên $\Omega$ nếu:

$$
\text { i. } \Omega \in \mathcal{F}
$$

ii. Với mỗi $A \in \mathcal{F}$ thì $A^{c} \in \mathcal{F}$.

iii. Vói mọi $A, B \in \mathcal{F}$ thì $A \cup B \in \mathcal{F}$.

- Với mỗi $\sigma$-đại số $\mathcal{F}$ của $\Omega$ tương ứng một phân hoạch duy nhất $\mathcal{P}$ của $\Omega$ và ngược lại.

- Vì thế các mô hình con của cấu trúc thông tin được tạo thành như một dãy $\left\{\mathcal{F}_{t}\right\}$ các đại số. 


\section{Định nghĩa 2.1.3:}

Một họ các $\sigma$-đại số $\mathcal{F}=\left\{\mathcal{F}_{t}: t=0,1, \ldots, T\right\}$ được gọi là bộ lọc (filtration) nếu:

i. $\quad \mathcal{F}_{0}=\{\varnothing, \Omega\}$

ii. $\mathcal{F}_{T}$ chứa tất cả các tập con của $\Omega$.

iii. $\quad \mathcal{F}_{t} \subset \mathcal{F}_{t+1}, \forall t<T$

\subsubsection{Chiến lược đầu tư (trading strategies)}

Định nghĩa 2.1.4:

Một chiến lược đầu tu (hay danh mục đầu tur, chiến lược kinh doanh) là một dãy các vecto ngẫu nhiên

$$
\phi=\left\{\left(\phi_{t}^{0}, \phi_{t}^{1}, \ldots, \phi_{t}^{N}\right):=\phi_{t}\right\}_{t=0, \ldots, T}
$$

Với giá trị thuộc $R^{N+1}$, trong đó $\phi_{t}^{n}, n=1, \ldots, N$ là số đơn vị chứng khoán thứ $n$ mà nhà đầu tư đang giữ tù̀ thời gian t-1 tới thời gian $t$.

Giả sử $\phi_{0}^{n}$ là $F_{0}$ - đo được, $\phi_{t}^{n}$ là $F_{t-1}$ - đo được $(n=0, \ldots, N)$, điều đó có nghĩa là chiến lược $\phi_{t}$ tại thời điểm $\mathrm{t}$ được xây dựng dựa trên tất cả các thông tin cho đến thời điểm t-1 (ví dụ sự lên xuống của các loại chứng khoán cho đến thời điểm t-1).

Chiến lược $\phi$ được coi là chiến lược phân bố vốn đầu tư hoặc một danh mục đầu tư.

Định nghĩa 2.1.5:

Quá trình giá của chiến lược $\phi$ tại thời điểm t được cho bởi

$$
V_{t}(\phi)= \begin{cases}\phi_{1}^{0} B_{0}+\sum_{n=1}^{N} \phi_{1}^{n} S_{0}^{n}, & t=0 \\ \phi_{t}^{0} B_{t}+\sum_{n=1}^{N} \phi_{t}^{n} S_{t}^{n}, & t \geq 1\end{cases}
$$

Trong trường hợp $t \geq 1$, ta có thể viết $V_{t}(\phi)=\phi_{t}^{0} B_{t}+\sum_{n=1}^{N} \phi_{t}^{n} S_{t}^{n}=\left\langle\phi_{t}, S_{t}\right\rangle$. 
Trong đó $S_{t}=\left(B_{t}, S_{t}^{1}, \ldots, S_{t}^{N}\right)$ và $<., .>$ là tích vô hướng trong $R^{N+1}$

Ký hiệu $\Delta S_{t}^{n}=S_{t}^{n}-S_{t-1}^{n}$

Thì $\phi_{t}^{n} \Delta S_{t}^{n}$ đại diện cho tình trạng lời hay lỗ trong một chu kỳ mà nhà đầu tư phải trả cho việc giữ $\phi_{t}^{n}$ đơn vị chứng khoán thứ $\mathrm{n}$ giữa thời gian $\mathrm{t}-1$ tới thời gian $\mathrm{t}$. Khi đó $\sum_{u=1}^{t} \phi_{u}^{n} \Delta S_{u}^{n}$ đại diện cho tình trạng lời hay lỗ tích luỹ trong việc đầu tư vào chứng khoán thứ $\mathrm{n}$ tới thời gian $\mathrm{t}$.

Cuối cùng,

$$
G_{t}:=\sum_{n=0}^{N} \sum_{u=1}^{t} \phi_{u}^{n} \Delta S_{u}^{n}, \quad t=1, \ldots, T
$$

Đại diện cho tình trạng lời hay lỗ tích luỹ tới thời gian t của một danh mục đầu tư.

Ta định nghĩa quá trình $G=\left\{G_{t}, t=1, \ldots, T\right\}$ như trên là quá trình lời.

Trong trường hợp mọi hàng hoá trong thị trường phải chiết khấu thì quá trình giá chứng khoán và tài khoản ngân hàng đã chiết khấu là:

$$
\hat{S}_{t}^{n}=\frac{S_{t}^{n}}{B_{t}}, \quad n=1, \ldots, N, t=0,1, \ldots, T
$$

Khi đó quá trình giá chiết khấu là

$$
\hat{V}_{t}(\phi)=\frac{V_{t}(\phi)}{B_{t}}=\left\{\begin{array}{l}
\frac{1}{B_{0}}\left(\phi_{1}^{0} B_{0}+\sum_{n=1}^{N} \phi_{1}^{n} S_{0}^{n}\right), t=0 \\
\frac{1}{B_{t}}\left(\phi_{t}^{0} B_{t}+\sum_{n=1}^{N} \phi_{t}^{n} S_{t}^{n}\right), t \geq 1
\end{array}=\left\{\begin{array}{l}
\phi_{1}^{0}+\sum_{n=1}^{N} \phi_{1}^{n} \hat{S}_{0}^{n}, t=0 \\
\phi_{t}^{0}+\sum_{n=1}^{N} \phi_{t}^{n} \hat{S}_{t}^{n}, t \geq 1
\end{array}\right.\right.
$$

Trong trường hợp $t \geq 1$, ta có thể viết

$$
\hat{V}_{t}(\phi)=\phi_{t}^{0}+\sum_{n=1}^{N} \phi_{t}^{n} \hat{S}_{t}^{n}=\left\langle\phi_{t}, \hat{S}_{t}\right\rangle
$$

Trong đó

$$
\hat{S}_{t}=\left(1 ; \frac{S_{t}^{1}}{S_{t}^{0}} ; \ldots ; \frac{S_{t}^{N}}{S_{t}^{0}}\right)
$$


Quá trình lời chiết khấu $\widehat{G}=\left\{\widehat{G}_{t}, t=1, \ldots, T\right\}$ được định nghĩa như sau:

$$
\widehat{G}_{t}:=\sum_{n=1}^{N} \sum_{u=1}^{t} \phi_{u}^{n} \Delta \hat{S}_{u}^{n}, \quad t=1, \ldots, T
$$

Trong đó $\Delta \hat{S}_{u}^{n}=\hat{S}_{u}^{n}-\hat{S}_{u-1}^{n}$

\section{Định nghĩa 2.1.6:}

Chiến lược $\phi$ được gọi là chiến lược tụ tài trọ hoặc tụ điều chỉnh tài chính (selffinancing) nếu:

$$
V_{t}=\phi_{t+1}^{0} B_{t}+\sum_{n=1}^{N} \phi_{t+1}^{n} S_{t}^{n}, \quad t=1, \ldots, T-1
$$

\section{Mệnh đề 2.1.7:}

Một chiến lược đầu tu $\phi$ là tụ tài trọ khi và chỉ khi

$$
\widehat{V}_{t}=\widehat{V}_{0}+\widehat{G}_{t}, t=1, \ldots, T
$$

Chứng minh:

Với mọi $t=1, \ldots, T$ :

$$
\widehat{G}_{t}=\widehat{G}_{t-1}+\sum_{n=1}^{N} \phi_{t}^{n} \Delta \hat{S}_{t}^{n}
$$

Để thuận tiện ta định nghĩa $\widehat{G}_{0}=0$.

$(\Rightarrow)$ : Giả sử $\phi$ là chiến lược đầu tư tự tài trợ, thì sử dụng định nghĩa của quá trình giá và tính chất tự tài trợ, với $t=1, \ldots, T$, ta được:

$$
\begin{aligned}
& \widehat{V}_{t}-\widehat{G}_{t}=\phi_{t}^{0}+\sum_{n=1}^{N} \phi_{t}^{n} \hat{S}_{t}^{n}-\sum_{n=1}^{N} \phi_{t}^{n} \Delta \hat{S}_{t}^{n}-\widehat{G}_{t-1} \\
& =\phi_{t}^{0}+\sum_{n=1}^{N} \phi_{t}^{n}\left(\hat{S}_{t}^{n}-\Delta \hat{S}_{t}^{n}\right)-\widehat{G}_{t-1}=\phi_{t}^{0}+\sum_{n=1}^{N} \phi_{t}^{n} \hat{S}_{t-1}^{n}-\widehat{G}_{t-1} \\
& =\widehat{V}_{t-1}-\widehat{G}_{t-1}
\end{aligned}
$$

Tiếp tục quá trình trên, ta được: 


$$
\widehat{V}_{t}-\widehat{G}_{t}=\widehat{V}_{t-1}-\widehat{G}_{t-1}=\ldots=\widehat{V}_{0}-\widehat{G}_{0}=\widehat{V}_{0}
$$

$(\Leftarrow)$ : Giả sử $\widehat{V}_{t}=\widehat{V}_{0}+\widehat{G}_{t}, t=1, \ldots, T$, thì với mọi $t=1, \ldots, T-1$ :

$\widehat{V}_{t}=\hat{V}_{t+1}-\left(\widehat{G}_{t+1}-\widehat{G}_{t}\right)=\phi_{t+1}^{0}+\sum_{n=1}^{N} \phi_{t+1}^{n} \hat{S}_{t+1}^{n}-\sum_{n=1}^{N} \phi_{t+1}^{n} \Delta \hat{S}_{t+1}^{n}$

$=\phi_{t+1}^{0}+\sum_{n=1}^{N} \phi_{t+1}^{n} \hat{S}_{t}^{n}$

Do đó $\phi$ là tự tài trợ (điều phải chứng minh).

\subsection{Quá trình lọi tức (return)}

\subsubsection{Lọi tức với quá trình giá của chứng khoán.}

\section{Định nghĩa 2.2.1:}

Cho trước một quá trình giá $S^{n}, n=1, \ldots, N$ của chứng khoán thứ $n$. Ta định nghĩa một quá trình lọi tức $R^{n}=\left\{R_{t}^{n} ; t=0,1, \ldots, T\right\}$ tương úng với quá trình giá $S^{n} n h u$ sau:

(1) $\quad R_{0}^{n}=0$ và

(2) $\Delta R_{t}^{n}=\left\{\begin{array}{l}\frac{\Delta S_{t}^{n}}{S_{t-1}^{n}}, S_{t-1}^{n}>0 \\ 0, S_{t-1}^{n}=0\end{array} \forall t=1, \ldots, T\right.$

Quá trình lợi tức $R^{0}$ được định nghĩa trong quá trình tài khoản ngân hàng $\mathrm{B}$, cho bởi công thức:

$$
\Delta R_{t}^{0}=\frac{B_{t}-B_{t-1}}{B_{t-1}}=r_{t}
$$

\section{Nhận xét 1:}

$\Delta R_{t}^{n} \geq-1$, vì $S_{t}^{n} \geq 0, \forall t, n$. Hơn nữa, $\Delta R_{t}^{n}>-1, \forall t \Leftrightarrow S_{t}^{n}>0, \forall t$. Khi đó phương trình

(2) của định nghĩa $R^{n}$ tương đương với

$$
\Delta S_{t}^{n}=S_{t-1}^{n} \cdot \Delta R_{t}^{n}, \quad t=1, \ldots, T
$$


Từ (3), ta có hai biểu thức của $S_{t}^{n}$ sau:

$$
\begin{aligned}
& S_{t}^{n}=S_{0}^{n}+\sum_{u=1}^{t} S_{u-1}^{n} \Delta R_{u}^{n}, t=1, \ldots, T \\
& S_{t}^{n}=S_{0}^{n} \prod_{u=1}^{t}\left(1+\Delta R_{u}^{n}\right), \quad t=1, \ldots, T
\end{aligned}
$$

\section{Nhận xét 2:}

Hai phương trình $(4),(5)$ chỉ ra rằng bắt đầu với một quá trình lợi tức $R^{n}$ thoả mãn $\Delta R_{t}^{n}>-1$ kết hợp với giá ban đầu $S_{0}^{n}$, ta có thể định nghĩa một quá trình giá dương ngặt. Vì thế có một tương ứng 1-1 giữa quá trình giá (dương) và cặp gồm một giá ban đầu (dương) với một quá quá trình lợi tức thoả $\Delta R_{t}^{n}>-1$.

Quá trình lợi tức tương ứng với quá trình giá, quá trình giá chiết khấu, và vì thế có thể được định nghĩa cùng một cách, nghĩa là:

\section{Định nghĩa 2.2.2:}

Quá trình lợi tức $\widehat{R}^{n}=\left\{\widehat{R}_{t}^{n} ; t=0,1, \ldots, T\right\}$ tương ưng với quá trình giá đã chiết khấu $\hat{S}^{n}$ được định nghĩa nhur sau:

(1) $\widehat{R}_{0}^{n}=0$ và

(2) $\Delta \hat{R}_{t}^{n}=\left\{\begin{array}{l}\frac{\Delta \hat{S}_{t}^{n}}{\hat{S}_{t-1}^{n}}, \hat{S}_{t-1}^{n}>0 \\ 0, \hat{S}_{t-1}^{n}=0\end{array} \forall t=1, \ldots, T\right.$

Vì $\hat{S}_{t}^{n}=\frac{S_{t}^{n}}{B_{t}}, t=1, \ldots, T$, nên người ta tự hỏi $\hat{R}^{n}$ có quan hệ như thế nào với $R^{n}$ ?

Ta có thể tính toán như sau:

$$
\Delta \hat{S}_{t}^{n}=\hat{S}_{t}^{n}-\hat{S}_{t-1}^{n}=\frac{S_{t}^{n}}{B_{t}}-\hat{S}_{t-1}^{n}=\frac{S_{t-1}^{n}\left[1+\Delta R_{t}^{n}\right]}{B_{t-1}\left[1+\Delta R_{t}^{0}\right]}-\hat{S}_{t-1}^{n}=\hat{S}_{t-1}^{n}\left[\frac{\Delta R_{t}^{n}-\Delta R_{t}^{0}}{1+\Delta R_{t}^{0}}\right]
$$

Vì $\Delta \hat{S}_{t}^{n}=\hat{S}_{t-1}^{n} \Delta R_{t}^{n}$ do định nghĩa nên suy ra $\Delta \hat{R}_{t}^{n}=\frac{\Delta R_{t}^{n}-\Delta R_{t}^{0}}{1+\Delta R_{t}^{0}}$ 
Điều này thống nhất với

$$
\hat{S}_{t}^{n}=\hat{S}_{0}^{n} \prod_{u=1}^{t}\left[1+\Delta \hat{R}_{u}^{n}\right]=S_{0}^{n} \prod_{u=1}^{t}\left[\frac{1+\Delta R_{u}^{n}}{1+\Delta R_{u}^{0}}\right]=\frac{S_{t}^{n}}{B_{t}}
$$

\subsubsection{Lợi tức với quá trình giá và quá trình lời}

Vì $\phi_{t}^{n} \Delta S_{t}^{n}=\phi_{t}^{n} S_{t-1}^{n} \Delta R_{t}^{n}$ nên quá trình lời thoả mãn:

$$
G_{t}=\sum_{u=1}^{t} \phi_{u}^{0} B_{u-1} \Delta R_{u}^{0}+\sum_{n=1}^{N} \sum_{u=1}^{t} \phi_{u}^{n} S_{u-1}^{n} \Delta R_{u}^{n}=\sum_{u=1}^{t} M_{u}^{0} \Delta R_{u}^{0}+\sum_{n=1}^{N} \sum_{u=1}^{t} M_{u}^{n} \Delta R_{u}^{n}
$$

Trong đó $M_{t}^{n}= \begin{cases}\phi_{t}^{0} B_{t-1}, & n=0 \\ \phi_{t}^{n} S_{t-1}^{n}, & n=1,2, \ldots, N\end{cases}$

$M_{t}^{n}$ được hiểu như là tiền đầu tư vào chứng khoán thứ $\mathrm{n}$ bắt đầu tại thời gian $\mathrm{t}-1$.

Nói cách khác, $M=\left\{M^{0}, M^{1}, \ldots, M^{N}\right\}$ là một sự lựa chọn khác để xác định chiến lược kinh doanh.

\section{Nhận xét 3:}

$M^{n}=\left\{M_{t}^{n}, t=1, \ldots, T\right\}$ là quá trình ngẫu nhiên thích nghi.

Tiếp theo, xem quá trình lợi tức R tương ứng với quá trình giá V.

Vì $V_{t}=V_{t-1}+\phi_{t}^{0} \Delta B_{t}+\sum_{n=1}^{N} \phi_{t}^{n} \Delta S_{t}^{n}=V_{t-1}+M_{t}^{0} \Delta R_{t}^{0}+\sum_{n=1}^{N} M_{t}^{n} \Delta R_{t}^{n}$

Nên suy ra

$\Delta R_{t}=\frac{V_{t}-V_{t-1}}{V_{t-1}}=\frac{M_{t}^{0}}{V_{t-1}} \Delta R_{t}^{0}+\sum_{n=1}^{N}\left[\frac{M_{t}^{n}}{V_{t-1}} \Delta R_{t}^{n}\right]=\sum_{n=0}^{N} F_{t}^{n} \Delta R_{t}^{n}$

Trong đó $F_{t}^{n}=\frac{M_{t}^{n}}{V_{t-1}}, \quad(n=0,1, \ldots ., N)$

$F_{t}^{n}$ đại diện cho dạng phân số của tổng tài sản đầu tư vào chứng khoán thứ $n$ bắt đầu tại thời gian $\mathrm{t}-1$ và được mang tới trước thời gian $\mathrm{t}$.

\section{Nhận xét 4:}


$F_{t}=\left\{F_{t}^{n}, t=1, \ldots, T\right\}$ là một quá trình thích nghi. $F_{t}^{n}$ có thể âm với n,t $\omega$ nào đó nhưng ta luôn có $F_{t}^{0}=1-F_{t}^{1}-\ldots-F_{t}^{N}$. Vì thế $F=\left\{F^{1}, \ldots, F^{N}\right\}$ cũng là một dạng khác của chiến lược kinh doanh.

Tóm lại, chiến lược kinh doanh có thể được biểu diễn bằng 3 cách:

- Số đơn vị, $H^{n}$, đầu tư vào chứng khoán thứ n

- Lượng tiền, $M^{n}$, đầu tư vào chứng khoán thứ n.

- Dạng phân số của tổng tài sản, $F^{n}$, đầu tư vào chứng khoán thứ n.

Nếu ta biết quá trình lợi tức với mỗi chứng khoán, thì ta cũng có biểu thức quá trình giá như sau:

$$
V_{t}=V_{0} \prod_{u=1}^{t}\left[1+\Delta R_{u}\right]=V_{0} \prod_{u=1}^{t}\left[1+\sum_{n=0}^{N} F_{u}^{n} \Delta R_{u}^{n}\right]
$$

Do đó, bắt đầu với một chiến lược kinh doanh trong dạng phân số $F=\left\{F^{1}, \ldots, F^{N}\right\}$ kết hợp với quá trình lợi tức riêng biệt $\left\{R^{n}\right\}$ và giá ban đầu $V_{0}$, ta có thể tính $V_{t}$ Tiếp theo, ta định nghĩa quá trình $\widehat{R}=\left\{\widehat{R}_{t} ; t=0,1, \ldots, T\right\}$ là quá trình lợi tức tương ứng với quá trình giá chiết khấu $\widehat{V}$ được xác định tương tự như các định nghĩa lợi tức ở trên.

Một cách tương tự, ta có biểu thức chỉ mối quan hệ giữa $\widehat{R}$ và $R$ như sau:

$$
\Delta \hat{R}_{t}=\frac{\Delta R_{t}-\Delta R_{t}^{0}}{1+\Delta R_{t}^{0}}
$$

Vì thế

$$
\widehat{V}_{t}=\widehat{V}_{0} \prod_{u=1}^{t}\left[1+\Delta \widehat{R}_{u}\right]=V_{0} \prod_{u=1}^{t}\left[\frac{1+\Delta R_{u}}{1+\Delta R_{u}^{0}}\right]
$$

Biểu thức này thống nhất với $\widehat{V}=V / B$. 


\subsection{Quá trình cổ tức}

Nhiều loại chứng khoán khác nhau, như là chứng khoán trả bằng cổ tức.

Có hai cách để kết hợp thanh toán cổ tức: ngầm ẩn và rõ ràng.

- Với cách tiếp cận ngầm ẩn, thì $S_{t}^{n}$ được hiểu như giá của đầu tư, trong đó một đơn vị chứng khoán được mua tại thời điểm $\mathrm{t}=0$ và được giữ một cách mơ hồ. Các cố tức nhận được được tái đầu tư trong cùng một chứng khoán. Ví dụ: nếu 1 đơn vị tiền tệ cổ tức được nhận tại thời gian $\mathrm{t}=1$, thì giá không-cổ tức (ex-dividend) tại thời điểm đó là $S_{1}^{n}-1$ đơn vị tiền tệ.

Theo cách này ta đã thay chứng khoán trả cổ tức bằng chứng khoán mà không được trả bất kỳ cổ tức nào. Song chúng có cùng quá trình lợi tức.

- Với cách tiếp cận rõ ràng. Để mô tả cách này và xem quá trình lợi tức có vai trò gì đối với chứng khoán trả cổ tức thì:

Ta gọi $D^{n}=\left\{D_{t}^{n}: t=0, \ldots, T\right\}$ là quá trình cổ tức với chứng khoán thứ $n, n=1, \ldots, N$, trong đó $D_{0}^{n}=0$ và $\Delta D_{t}^{n}$ đại diện cho cổ tức mỗi đơn vị chứng khoán được trả tại thời điểm $\mathrm{t}$. Vì thế $D_{t}^{n}$ đại diện cho thanh toán cổ tức tích luỹ với một đơn vị của chứng khoán. Hơn nữa, $S_{t}^{n}$ đại diện cho giá không-cổ tức của chứng khoán. Ta giả sử rằng quá trình cổ tức là một quá trình thích nghi.

Bây giờ nhà đầu tư sở hữu một đơn vị chứng khoán thứ $\mathrm{n}$ tại thời gian $\mathrm{t}-1$ sẽ kiếm được một lợi nhuận $\Delta S_{t}^{n}+\Delta D_{t}^{n}$ trên chu kỳ theo sau, vì thế lợi tức một chu kỳ tương ứng (giả sử $S_{t-1}^{n}>0$ ) là:

$$
\Delta R_{t}^{n}=\frac{\Delta S_{t}^{n}+\Delta D_{t}^{n}}{S_{t-1}^{n}}, \quad t=1, \ldots, T ; n=1, \ldots, N
$$

Vì thế khi biết quá trình giá và quá trình cổ tức với một chứng khoán, ta có thể suy ra quá trình lợi tức của chứng khoán (đương nhiên là $R_{0}^{n}=0$ ) nhưng không ngược lại. Với một quá trình lợi tức cho trước, thì rõ ràng sẽ tồn tại một số vô hạn cặp quá trình giá và cổ tức có cùng quá trình lợi tức này, với một trong những các cặp đó thoã mãn $D^{n}=0$.

Với quá trình lợi tức khấu hao với một chứng khoán trả trả cổ tức được định nghĩa như sau: 
$\hat{R}_{0}^{n}=0$ và $\Delta \hat{R}_{t}^{n}=\frac{\Delta \hat{S}_{t}^{n}+\frac{\Delta D_{t}^{n}}{B_{t}}}{\hat{S}_{t-1}^{n}}, \quad t=1, \ldots, T ; n=1, \ldots, N$

Ta sẽ chứng minh biểu thức $\Delta \hat{R}_{t}^{n}=\frac{\Delta R_{t}^{n}-\Delta R_{t}^{0}}{1+\Delta R_{t}^{0}}$

Thật vậy, ta có:

$$
\begin{aligned}
& \Delta \hat{S}_{t}^{n}+\frac{\Delta D_{t}^{n}}{B_{t}}=\hat{S}_{t}^{n}-\hat{S}_{t-1}^{n}+\frac{\Delta D_{t}^{n}}{B_{t}}=\frac{S_{t}^{n}}{B_{t}}+\frac{\Delta D_{t}^{n}}{B_{t}}-\hat{S}_{t-1}^{n} \\
& =\frac{S_{t}^{n}+\Delta D_{t}^{n}}{B_{t}}-\hat{S}_{t-1}^{n}=\frac{\Delta S_{t}^{n}+\Delta D_{t}^{n}+S_{t-1}^{n}}{B_{t}}-\hat{S}_{t-1}^{n} \\
& =\frac{S_{t-1}^{n} \Delta R_{t}^{n}+S_{t-1}^{n}}{B_{t}}-\hat{S}_{t-1}^{n}=\frac{S_{t-1}^{n}\left(1+\Delta R_{t}^{n}\right)}{B_{t-1}\left(1+\Delta R_{t}^{0}\right)}-\hat{S}_{t-1}^{n} \\
& =\hat{S}_{t-1}^{n}\left[\frac{1+\Delta R_{t}^{n}}{1+\Delta R_{t}^{0}}-1\right] \\
& =\hat{S}_{t-1}^{n}\left[\frac{\Delta R_{t}^{n}-\Delta R_{t}^{0}}{1+\Delta R_{t}^{0}}\right]
\end{aligned}
$$

Vậy ta có điều phải chứng minh.

\subsection{Kỳ vọng điều kiện và martingale}

- Giống như trong mô hình một chu kỳ, mô hình thị trường chứng khoán nhiều chu kỳ không có cơ hội chênh lệch thị giá nếu và chỉ nếu có một độ đo xác suất trung tính rủi ro. Tuy nhiên trong trường hợp nhiều chu kỳ thì độ đo xác suất trung tính rủi ro được định nghĩa trong thuật ngữ khác, gọi là độ đo martingale, lần lượt được định nghĩa với kỳ vọng điều kiện. Mục đích của phần này là giới thiệu hai định nghĩa từ lý thuyết xác suất.

\subsubsection{Kỳ vọng có điều kiện}

Cho không gian xác suất $(\Omega, F, P)$. Cho hai biến cố $A, B \in F$ với $P(B)>0$.

Định nghĩa 2.4.1: 
Xác suất có điều kiện $B$ của biến cố $A$, ghi là $P(A \mid B)$ được định nghĩa:

$$
P(A \mid B):=\frac{P(A \cap B)}{P(B)}
$$

\section{Định nghĩa 2.4.2:}

Kỳ vọng có điều kiện B của biến ngẫu nhiên rời rạc $Y$, ghi là $E[Y \mid B]$ được định nghĩa bởi công thức:

$$
E[Y \mid B]=\sum_{y} y P\{Y=y \mid B\}
$$

$E[Y \mid B]$ là hàm tì̀ biến cố $B$ đến tập số thực.

Vì $P\{Y=y \mid B\}=\frac{P(\{Y=y\} \cap B)}{P\{B\}}$ nên ta có:

$$
E[Y \mid B]=\frac{\sum_{y} y P(\{Y(\omega)=x\} \cap B)}{P\{B\}}=\frac{\sum_{\omega \in A} Y(\omega) P\{\omega\}}{P\{B\}}
$$

\section{Định nghĩa 2.4.3:}

Cho F là một đại số và $P$ là phân hoạch tưong úng của $\Omega$. Thì ta định nghĩa kỳ vọng điều kiện $E[Y \mid F]$ bởi:

$$
E[Y \mid F]=\sum_{A \in P} E[Y \mid A] 1_{A}
$$

$E[Y \mid F]$ là một biến ngẫu nhiên $F$ - đo được và với mọi $\omega \in A$

$$
E[Y \mid F](\omega)=E[Y \mid A]
$$

\section{Tính chất 2.4.4:}

Cho biến ngẫu nhiên rời rạc $Y$, thì:

$$
E[E[Y \mid F]]=E[Y]
$$

Chứng minh: 
Ta có: $E[E[Y \mid F]]=E\left[\sum_{A \in P} E[Y \mid A] 1_{A}\right]$

$$
\begin{aligned}
& =\sum_{A \in P} P\{A\} E[Y \mid A]=\sum_{A \in P} P\{A\} \frac{\sum_{\omega \in A} Y(\omega) P\{\omega\}}{P\{A\}} \\
& =\sum_{A \in P} \sum_{\omega \in A} Y(\omega) P\{\omega\}=\sum_{\omega \in \Omega} Y(\omega) P\{\omega\} \\
& =E[Y]
\end{aligned}
$$

Ta có điều phải chứng minh.

\section{Tính chất 2.4.5:}

Nếu $F_{1} \subset F_{2}$ thì $E\left[E\left[Y \mid F_{2}\right] \mid F_{1}\right]=E\left[Y \mid F_{1}\right]$

Chứng minh:

Theo định nghĩa của kỳ vọng điều kiện, ta có:

$$
\begin{aligned}
& E\left[E\left[Y \mid F_{2}\right] \mid F_{1}\right]=E\left[\sum_{B \in P_{2}} E[Y \mid B] 1_{B} \mid F_{1}\right] \\
& =\sum_{B \in P_{2}} E[Y \mid B] \cdot E\left[1_{B} \mid F_{1}\right] \\
& =\sum_{B \in P_{2}} E[Y \mid B] \cdot \sum_{A \in P_{1}} E\left[1_{B} \mid A\right] 1_{A} \\
& =\sum_{A \in P_{1}} \sum_{B \in P_{2}} E[Y \mid B] \frac{P(A \cap B)}{P(A)} 1_{A}
\end{aligned}
$$

Vì phân hoạch $P_{2}$ "tốt hơn" $P_{1}$ nên với mọi $B \in P_{2}$ và $A \in P_{1}$ thì $B \subset A$ hoặc $A \cap B=\varnothing$. Do đó:

$$
\begin{aligned}
& E\left[E\left[Y \mid F_{2}\right] \mid F_{1}\right]=\sum_{A \in P_{1}} \sum_{B \in P_{2}, B \subset A} E[Y \mid B] \frac{P(B)}{P(A)} 1_{A} \\
& =\sum_{A \in P_{1}} \sum_{B \in P_{2}, B \in A} \sum_{\omega \in B} Y(\omega) \frac{P(\{\omega\})}{P(B)} \frac{P(B)}{P(A)} 1_{A}
\end{aligned}
$$


$=\sum_{A \in P_{1}} \sum_{\omega \in A} Y(\omega) \frac{P(\{\omega\})}{P(A)} 1_{A}$

$=\sum_{A \in P_{1}} E[Y \mid A] 1_{A}$

$=E\left[Y \mid F_{1}\right]$. Điều phải chứng minh.

\section{Tính chất 2.4.6:}

Cho $X, Y$ là các biến ngẫu nhiên; $X \in F$ thì ta có $E[X Y \mid F]=X E[Y \mid F]$.

Chứng minh:

Nếu biến ngẫu nhiên $X \in F$, ta có thể viết $X=\sum_{A \in P} x_{A} 1_{A}$.

Trong đó $\mathrm{P}$ là phân hoạch của $\Omega$ tương ứng với $\mathrm{F}$.

Vì thế $E[X Y \mid F]=\sum_{A \in P} E[X Y \mid A] 1_{A}$

$=\sum_{A \in P} E\left[x_{A} Y \mid A\right] 1_{A}$

$=\sum_{A \in P} x_{A} E[Y \mid A] 1_{A}$

$=X E[Y \mid F]$

Nhận xét: Tương tự ta cũng có $E\left[X_{1} Y_{1}+X_{2} Y_{2} \mid F\right]=X_{1} E\left[Y_{1} \mid F\right]+X_{2} E\left[Y_{2} \mid F\right]$

Trong đó $X_{1}, X_{2}, Y_{1}, Y_{2}$ là các biến ngẫu nhiên, $X_{1}, X_{2} \in F$.

\section{Tính chất 2.4.7:}

Nếu $X \in F$ thì $E[X \mid F]=X$

Chứng minh:

Nếu Y là một hằng số thì $E[Y \mid F]=Y$.

Cho $Y=1$ thì ta được $E[1 \mid F]=1$.

Từ $E[X Y \mid F]=X E[Y \mid F], \quad X \in F$ 
Cho $Y=1$, ta được $E[X \mid F]=X$.

\section{Tính chất 2.4.8:}

Với $\forall A \in F$, chúng minh: $E\left[1_{A} E[Y \mid F]\right]=E\left[Y 1_{A}\right]$

Chứng minh:

Ta có $A \in F \Rightarrow 1_{A} \in F$.

Do đó $1_{A} E[Y \mid F]=E\left[Y 1_{A} \mid F\right]$

Suy ra $E\left[1_{A} E[Y \mid F]\right]=E\left[E\left[Y 1_{A} \mid F\right]\right]=E\left[Y 1_{A}\right], \forall A \in F$.

(do ta áp dụng tính chất 1)

\section{Tính chất 2.4.9:}

Nếu Y độc lập với $F$, thì $E[Y \mid F]=E Y$

Chứng minh:

Ta có: $\forall A \in F \Rightarrow E[Y \mid A]=\sum_{y} y P(Y=y \mid A)=\sum_{y} y P(Y=y)=E Y$.

\subsubsection{Martingale}

Xét không gian xác suất hữu hạn $(\Omega, F, P)$ với bộ lộc $\left\{F_{t}: t=0, \ldots, T\right\}$. Dãy các biến ngẫu nhiên $\left\{X_{t}: t=0, \ldots, T\right\}$ được gọi là tưong thích (phù hợp) với bộ lộc $\left\{F_{t}: t=0, \ldots, T\right\}$ (viết tắt là $F_{t}-$ tương thích) nếu $X_{t}$ là $F_{t}$-đo được với mọi $t=0, \ldots, T$.

\section{Định nghĩa 2.4.10:}

Cho $X=\left\{X_{t}: t=0,1, \ldots, T\right\}$ là một quá trình tuoong thích với bộ lọc $\left\{F_{t}\right\}$. Quá trình $X$ được gọi là:

- Một martingale nếu:

$$
E\left[X_{t} \mid F_{t-1}\right]=X_{t-1}, \quad \forall t \geq 1(*)
$$

- Một martingale trên (supermartingale) nếu: 


$$
E\left[X_{t} \mid F_{t-1}\right] \leq X_{t-1}, \quad \forall t \geq 1
$$

- Một martingale dưới (submartingale) nếu:

$$
E\left[X_{t} \mid F_{t-1}\right] \geq X_{t-1}, \quad \forall t \geq 1
$$

\section{Tính chất 2.4.11:}

Một quá trình ngẫu nhiên thích nghi X là một martingale nếu và chỉ nếu:

$$
E\left[X_{t+s} \mid F_{t}\right]=X_{t}, \forall t, s \geq 0
$$

Chứng minh:

Rõ ràng nếu phương trình $E\left[X_{t+s} \mid F_{t}\right]=X_{t}, \forall t, s \geq 0$ đúng thì phương trình

$$
E\left[X_{t} \mid F_{t-1}\right]=X_{t-1}, \forall t \geq 1 \text { dúng. }
$$

Giả sử ta có $E\left[X_{t} \mid F_{t-1}\right]=X_{t-1}, \quad \forall t \geq 1$. Khi đó ta có:

$$
\begin{aligned}
& E\left[X_{t+s} \mid F_{t}\right]=E\left[E\left[X_{t+s} \mid F_{t+s-1}\right] \mid F_{t}\right](\text { do tính chất 2) } \\
& =E\left[X_{t+s-1} \mid F_{t}\right]=\ldots=E\left[X_{t} \mid F_{t}\right]=X_{t}
\end{aligned}
$$

\section{Mệnh đề 2.4.12:}

Trong không gian xác suất $(\Omega, F, P)$, cùng với lộc thông tin $\left\{F_{t}: t=0,1, \ldots, T\right\}$. Cho biến ngẫu nhiên $X$, đặt $M_{t}=E\left[X \mid F_{t}\right]$. Khi đó $M_{t}$ là một martingale.

Chứng minh:

Do $M_{t}=E\left[X \mid F_{t}\right]$ nên $M_{t}$ là $F_{t}$ - đo được.

Ta có:

$$
E\left[M_{t+1} \mid F_{t}\right]=E\left[E\left[X \mid F_{t+1}\right] \mid F_{t}\right]=E\left[X \mid F_{t}\right]=M_{t}
$$

Do đó $M_{t}$ là một martingale. Điều phải chứng minh. 


\subsection{Thị trường tài chính lành mạnh.}

Trong mô hình một chu kỳ ta có nguyên lý: "Mô hình tài chính không có cơ hội chênh lệch thị giá khi và chỉ khi tồn tại một độ đo xác suất rủi ro trung tính”. Nguyên lý này và hầu hết một số khái niệm và tính chất khác được phát triển từ mô hình một chu kỳ và vẫn đúng trong mô hình nhiều chu kỳ, chỉ có một vài chi tiết là khác.

Giả sử cho một chiến lược kinh doanh $\phi$. Ta không đặt điều kiện nào về dấu của các $\phi_{t}^{n}$. Ta hiểu $\phi_{t}^{0}<0$ nghĩa là cần phải vay một lượng $\phi_{t}^{0}$ để đầu tư vào chứng khoán không có rủi ro, còn $\phi_{t}^{n}<0$ đối với $n=1, \ldots, N$ có nghĩa là có một khoản nợ $\phi_{t}^{n}$ trên chứng khoán có rủi ro thứ n (có khi phải bán chứng khoán khác để trang trải). Người ta cho phép vay hoặc bán chứng khoán khác để trang trải nhưng đòi hỏi giá trị ứng với chiến lược $\phi$ tại thời điểm $t$ là $V_{t}(\phi) \geq 0, \forall t=0,1, \ldots, T$.

\section{Định nghĩa 2.5.1:}

Chiến lược $\phi$ gọi là chấp nhận được nếu nó là chiến lược tư điều chỉnh tài chính và $V_{t}(\phi) \geq 0, \forall t=0,1, \ldots, T$.

\section{Định nghĩa 2.5.2:}

Một co hội chênh lệch thị giá hay co lợi (arbitrage opportunity) là một chiến luợc đầu tu chấp nhận được $\phi$ sao cho các điều kiện sau thoả mãn:

$$
\begin{array}{ll}
\text { i. } & V_{0}(\phi)=0 \\
\text { ii. } & V_{T}(\phi) \geq 0 \\
\text { iii. } & E\left[V_{T}(\phi)\right]>0
\end{array}
$$

Tức là chiến lược không cần vốn ban đầu mà vẫn có thu nhập.

Do $\widehat{V}_{t}=\frac{V_{t}}{B_{t}}, \forall t=0,1, \ldots, T$ nên ta có

\section{Tính chất 2.5.3:}

Chiến lược kinh doanh chấp nhận được $\phi$ là một cơ hội chênh lệch thị giá nếu và chỉ nếu:

i. $\quad \hat{V}_{0}(\phi)=0$ 

ii. $\quad \widehat{V}_{T}(\phi) \geq 0$
iii. $\quad E\left[\widehat{V}_{T}(\phi)\right]>0$

Vì $\phi$ là chiến lược tự tài trợ nên $\widehat{V}_{t}=\widehat{V}_{0}+\widehat{G}_{t}, t=1,2, \ldots, T$. Do đó ta có tính chất sau:

\section{Tính chất 2.5.4:}

Chiến lược kinh doanh chấp nhận được $\phi$ là một co hội chênh lệch thị giá nếu và chinếu:
i. $\quad \widehat{G}_{T}(\phi) \geq 0$
ii. $\quad E\left[\widehat{G}_{T}(\phi)\right]>0$

\section{Định nghĩa 2.5.5:}

Một thị truờng tài chính là lành mạnh khi và chỉ khi không tồn tại danh muc đầu tur cơ lợi nào.

\section{Định nghĩa 2.5.6:}

Một độ đo martingale (hay độ đo xác suất trung tính rủi ro) là một độ đo xác xuất $Q$ sao cho:

i. $Q(\{\omega\})>0, \forall \omega \in \Omega$

ii. Quá trình giá khấu hao $\hat{S}^{n}$ là một martingale theo $Q$ với mọi $n=1,2, \ldots, N$ :

$$
E_{Q}\left[\hat{S}_{t+s}^{n} \mid \mathcal{F}_{t}\right]=\hat{S}_{t}^{n}, \quad \forall t, s \geq 0
$$

Ta có viết điều kiện ii. như sau:

$$
E_{Q}\left[\frac{S_{t+s}^{n}}{B_{t+s}} \mid \mathcal{F}_{t}\right]=\frac{S_{t}^{n}}{B_{t}}, \quad \forall t, s \geq 0
$$

\section{Tính chất 2.5.7:}

Nếu Q là một độ đo martingale và $\phi$ là một chiến lược kinh doanh tụ tài trọ', thì:

(a) Quá trình giá chiết khấu $\widehat{V}$ 
(b) Quá trình lò̀i chiết khấu $\widehat{G}$

là các martingale theo $Q$.

Chứng minh:

Ta phải chứng minh $E_{Q}\left[\widehat{V}_{t+1} \mid \mathcal{F}_{t}\right]=\widehat{V}_{t}$ với mọi $t \geq 1$. Việc này tương đương với việc chứng minh

$E_{Q}\left[\widehat{G}_{t+1} \mid \mathcal{F}_{t}\right]=\widehat{G}_{t}\left(\right.$ do $\left.\hat{V}_{t}=\hat{V}_{0}+\widehat{G}_{t}, \forall t=1,2, \ldots, T\right)$

Ta có $E_{Q}\left[\hat{G}_{t+1}-\hat{G}_{t} \mid \mathcal{F}_{t}\right]=E_{Q}\left[\sum_{n=1}^{N} \sum_{u=1}^{t+1} \phi_{u}^{n} \Delta \hat{S}_{u}^{n}-\sum_{n=1}^{N} \sum_{u=1}^{t} \phi_{u}^{n} \Delta \hat{S}_{u}^{n} \mid \mathcal{F}_{t}\right]$

$=E_{Q}\left[\sum_{n=1}^{N} \phi_{t+1}^{n} \Delta \hat{S}_{t+1}^{n} \mid \mathcal{F}_{t}\right]$

$=\sum_{n=1}^{N} \phi_{t+1}^{n} E_{Q}\left[\Delta \hat{S}_{t+1}^{n} \mid \mathcal{F}_{t}\right]$

(do $\phi^{n}$ là chiến lược kinh doanh nên đoán được, suy ra $\phi_{t+1}^{n}$ là $\mathcal{F}_{t}$-đo được)

Hơn nữa, $E_{Q}\left[\Delta \hat{S}_{t+1}^{n} \mid \mathcal{F}_{t}\right]=0, \forall t>0$.

Vì thế $\widehat{V}_{t}$ và $\widehat{G}_{t}$ là các martingale theo $Q$.

\section{Định lý 2.5.8: (Nguyên lý không cơ lọii)}

Thị trường tài chính không có cơ hội chênh lệch thị giá khi và chỉ khi tồn tại một độ đo martingale.

Chứng minh:

$(\Leftarrow)$ : Giả sử tồn tại một độ đo martingale $Q$.

Cho $\phi$ là một chiến lược kinh doanh tự tài trợ nào đó với $\widehat{V}_{T} \geq 0$ và $E\left[\widehat{V}_{T}\right]>0$, suy ra $E_{Q}\left[\hat{V}_{T}\right]>0$.

Vì $\widehat{V}$ là một martingale theo $Q$, nên $\widehat{V}_{0}=E_{Q}\left[\widehat{V}_{T}\right]>0$. 
Vì thế $\phi$ không thể là một cơ hội chênh lệch thị giá.

$(\Rightarrow)$ :Để chứng minh chiều này ta sử dụng tính chất sau:

\section{Tính chất 2.5.9:}

Nếu mô hình nhiều chu kỳ không có cơ hội chênh lệch thị giá thì không có mô hình một chu kỳ co bản nào có co hội chênh lệch thị giá.

Chứng minh:

Với mỗi $t<T$ và với mỗi $A \in \mathcal{P}_{t}$, có một mô hình một chu kỳ cơ bản:

- Giá chiết khấu tại “thời điểm 0 ” là: $\hat{S}_{t}^{n}(\omega), n=1,2, \ldots, N$ với bất kỳ $\omega \in A$ vì $\hat{S}_{t}^{n}(\omega)$ là hằng số trên $A$.

- Không gian mẫu: một trạng thái với mỗi $A^{\prime} \in \mathcal{P}_{t+1}$ và $A^{\prime} \subset A$.

- Giá chiết khấu tại thời điểm 1 là: $\hat{S}_{t+1}^{n}(\omega), n=1,2, \ldots, N, \omega \in A$.

Nếu bất kỳ mô hình một chu kỳ cơ bản nào có cơ hội chênh lệch thị giá theo kiểu mô hình một chu kỳ thì mô hình nhiều chu kỳ phải có cơ hội chênh lệch thị giá theo kiểu mô hình nhiều chu kỳ.

Để thấy điều này, ta giả sử tồn tại cơ hội chênh lệch thị giá $\hat{\phi}$ với mô hình chu kỳ đơn tương ứng với mỗi $A \in \mathcal{P}_{t}$ với $t<T$.

Điều này có nghĩa là lời chiết khấu $\hat{\phi}^{1} \Delta \hat{S}_{t+1}^{1}+\ldots+\hat{\phi}^{N} \Delta \hat{S}_{t+1}^{N}$ là không âm và $\exists \omega \in A$ sao cho $\hat{\phi}^{1} \Delta \hat{S}_{t+1}^{1}+\ldots+\hat{\phi}^{N} \Delta \hat{S}_{t+1}^{N}>0$

Bây giờ ta xây dựng một chiến lược kinh doanh $\phi$ có một cơ hội chênh lệch thị giá của mô hình $T$ chu kỳ như sau: 


$$
\phi_{s}^{n}(\omega)= \begin{cases}0, & s \leq t \vee \omega \notin A \\ \hat{\phi}^{n}, & s=t+1, \omega \in A, n=1, \ldots, N \\ -\sum_{n=1}^{N} \hat{\phi}^{n} \hat{S}_{t}^{n}, & s=t+1, \omega \in A, n=0 \\ \sum_{n=1}^{N} \hat{\phi}^{n} \Delta \hat{S}_{t+1}^{n}, & s>t+1, \omega \in A, n=0 \\ 0, & s>t+1, n>0\end{cases}
$$

Có thể kiểm tra chiến lược $\phi$ trên là cơ hội chênh lệch thị giá.

Trở lại chứng minh chiều $(\Rightarrow)$ của định lý không chênh lệch thị giá.

Giả sử không có cơ hội chênh lệch thị giá.

Theo tính chất trên ta có: Với mỗi $t<T$ và với mỗi $A \in \mathcal{P}_{t}$ thì tồn tại một độ đo xác suất trung tính rủi ro của mô hình một chu kỳ cơ bản, ký hiệu $Q_{(t, A)}$. Độ đo này thoả mãn các điều kiện sau:

i. $\quad Q_{(t, A)}\left(A^{\prime}\right)>0, \forall A^{\prime} \in \mathcal{P}_{t+1}, A^{\prime} \subset A$

ii. $\sum_{\substack{A^{\prime} \in \mathcal{P}_{t+1} \\ A \prime \subset A}} Q_{(t, A)}\left(A^{\prime}\right)=1$

iii. $E_{Q(t, A)}\left[\Delta \hat{S}_{t}^{n}\right]=0, \forall n=1,2, \ldots, N$

Để ý là $Q_{(t, A)}$ đặt một xác suất trên mỗi nhánh của cây thông tin.

Ta tính độ đo martingale cho mô hình đa chu kỳ bằng cách cho $Q(\{\omega\})$ bằng tích của tất cả các xác suất có điều kiện dọc đường dẫn từ nút $t=0$ tới nút tương ứng với $(T, \omega)$. Rõ ràng $\sum_{\omega \in \Omega} Q(\omega)=1$.

Hơn nữa $Q(\{\omega\})>0, \forall \omega \in \Omega$ vì tất cả các xác suất trung tính rủi ro điều kiện là dương.

Bây giờ ta chứng minh $Q$ thoả mãn điều kiện của độ đo martingale:

$$
E_{Q}\left[\hat{S}_{t+s}^{n} \mid \mathcal{F}_{t}\right]=\hat{S}_{t}^{n}, \forall t, s \geq 0
$$


Vì $E_{Q_{(t, A)}}\left[\Delta \hat{S}_{t+1}^{n}\right]=0$ với $n=1,2, \ldots, N ; A \in \mathcal{P}_{t} ; t<T$. nên $E_{Q}\left[\Delta \hat{S}_{t+1}^{n} \mid \mathcal{F}_{t}\right]=0, n=1,2, \ldots, N ; t<T$.

Với $t, s \geq 0$ và $n$ tuỳ ý, ta có:

$$
\begin{aligned}
& E_{Q}\left[\hat{S}_{t+s}^{n} \mid \mathcal{F}_{t}\right]=E_{Q}\left[\Delta \hat{S}_{t+s}^{n}+\ldots+\Delta \hat{S}_{t+1}^{n}+\hat{S}_{t}^{n} \mid \mathcal{F}_{t}\right] \\
& =E_{Q}\left[\Delta \hat{S}_{t+s}^{n} \mid \mathcal{F}_{t}\right]+\ldots+E_{Q}\left[\Delta \hat{S}_{t+1}^{n} \mid \mathcal{F}_{t}\right]+\hat{S}_{t}^{n} \\
& =E_{Q}\left[E_{Q}\left[\Delta \hat{S}_{t+s}^{n} \mid \mathcal{F}_{t+s-1}\right] \mid \mathcal{F}_{t}\right]+\ldots+E_{Q}\left[E_{Q}\left[\Delta \hat{S}_{t+1}^{n} \mid \mathcal{F}_{t}\right] \mid \mathcal{F}_{t}\right]+\hat{S}_{t}^{n} \\
& =E_{Q}\left[0 \mid \mathcal{F}_{t}\right]+\ldots+E_{Q}\left[0 \mid \mathcal{F}_{t}\right]+\hat{S}_{t}^{n} \\
& =\hat{S}_{t}^{n}
\end{aligned}
$$

Vì thế $\hat{S}^{n}$ là một martingale theo $Q$ và do đó $Q$ là một độ đo martingale.

\section{Ví dụ :}

Ta xem một mô hình với $N=1$ chứng khoán trên $T=2$ chu kỳ và $K=4$ trạng thái có thể xảy ra. Để đơn giản ta thay đổi ký hiệu của quá trình giá $S^{n}$ thay cho $S_{t}^{n}$. Quá trình trên được cho bởi bảng sau:

\begin{tabular}{|l|l|l|l|}
\hline$\omega_{k}$ & $t=0$ & $t=1$ & $t=2$ \\
\hline$\omega_{1}$ & $S_{0}=6$ & $S_{1}=9$ & $S_{2}=10$ \\
\hline$\omega_{2}$ & $S_{0}=6$ & $S_{1}=9$ & $S_{2}=7$ \\
\hline$\omega_{3}$ & $S_{0}=6$ & $S_{1}=3$ & $S_{2}=7$ \\
\hline$\omega_{4}$ & $S_{0}=6$ & $S_{1}=3$ & $S_{2}=1$ \\
\hline
\end{tabular}

- Ta giả sử tỷ suất lợi nhuận (interest rate) là r trong cả hai chu kỳ. Do đó quá trình tài khoản ngân hàng là:

$$
B_{t}=(1+r)^{t}
$$

- Bộ lọc sinh bởi quá trình giá là:

$$
\mathcal{F}_{0}=\{\varnothing, \Omega\}
$$


$\mathcal{F}_{1}=\left\{\varnothing,\left\{\omega_{1}, \omega_{2}\right\},\left\{\omega_{3}, \omega_{4}\right\}, \Omega\right\}$

$\mathcal{F}_{2}=\mathbb{P}(\Omega)$ (tập hợp tất cả các tập con của $\Omega$ )

- Nhắc lại chiến lược kinh doanh có các thành phần $\phi_{t}^{n}(\omega)$, là số lượng tài sản (asset) thứ $n$ được giữ từ thời gian $t-1$ đến thời gian $t$.

- Cho $\phi$ là một chiến lược kinh doanh tuỳ ý, thì quá trình giá mà ta có là:

$V_{0}(\omega)=\phi_{1}^{0}(\omega)+6 . \phi_{1}^{1}(\omega)$

$V_{1}(\omega)=\left\{\begin{array}{l}(1+r) \phi_{1}^{0}(\omega)+9 \phi_{1}^{1}(\omega), \omega=\left\{\omega_{1}, \omega_{2}\right\} \\ (1+r) \phi_{1}^{0}(\omega)+9 \phi_{1}^{1}(\omega), \omega=\left\{\omega_{3}, \omega_{4}\right\}\end{array}\right.$

$V_{2}(\omega)= \begin{cases}(1+r)^{2} \phi_{2}^{0}(\omega)+10 \phi_{2}^{1}(\omega), & \omega=\omega_{1} \\ (1+r)^{2} \phi_{2}^{0}(\omega)+7 \phi_{2}^{1}(\omega), & \omega=\omega_{2}, \omega_{3} \\ (1+r)^{2} \phi_{2}^{0}(\omega)+\phi_{2}^{1}(\omega), & \omega=\omega_{4}\end{cases}$

- Chiến lược kinh doanh là đoán được (predictable) vì thế $\phi_{1}^{n}(\omega)$ là hằng số với mọi $\omega$, và $\phi_{2}^{n}\left(\omega_{1}\right)=\phi_{2}^{n}\left(\omega_{2}\right)=\phi^{n}\left(\omega_{1}, \omega_{2}\right)$ (như đã nói) và $\phi_{2}^{n}\left(\omega_{3}\right)=\phi_{2}^{n}\left(\omega_{4}\right)=\phi^{n}\left(\omega_{3}, \omega_{4}\right)$ (như đã nói).

- Quá trình lời:

$$
G_{1}(\omega)= \begin{cases}r \phi_{1}^{0}+3 \phi_{1}^{1}, & \omega=\omega_{1}, \omega_{2} \\ r \phi_{1}^{0}-3 \phi_{1}^{1}, & \omega=\omega_{3}, \omega_{4}\end{cases}
$$

- Để đơn giản ta viết $\phi_{t}^{n}$ để thay cho $\phi_{t}^{n}(\omega)$ :

$$
G_{2}(\omega)= \begin{cases}r \phi_{1}^{0}+3 \phi_{1}^{1}+r(1+r) \phi_{2}^{0}+\phi_{2}^{1}, & \omega=\omega_{1} \\ r \phi_{1}^{0}+3 \phi_{1}^{1}+r(1+r) \phi_{2}^{0}-2 \phi_{2}^{1}, & \omega=\omega_{2} \\ r \phi_{1}^{0}-3 \phi_{1}^{1}+r(1+r) \phi_{2}^{0}+4 \phi_{2}^{1}, & \omega=\omega_{3} \\ r \phi_{1}^{0}-3 \phi_{1}^{1}+r(1+r) \phi_{2}^{0}-2 \phi_{2}^{1}, & \omega=\omega_{4}\end{cases}
$$

- Với chiến lược kinh doanh $\phi$ là tự tài trợ (self-financing), tại thời gian $t=1$, trạng thái $\omega=\omega_{1}, \omega_{2}$ :

$V_{1}=(1+r) \phi_{1}^{0}+9 \phi_{1}^{1}=(1+r) \phi_{2}^{0}+9 \phi_{2}^{1}$ 
Trạng thái $\omega=\omega_{3}, \omega_{4}$ :

$V_{1}=(1+r) \phi_{1}^{0}+3 \phi_{1}^{1}=(1+r) \phi_{2}^{0}+3 \phi_{2}^{1}$

- Bây giờ ta trình bày 2 cách tính một độ đo martingale tương đương (xác suất trung tính rủi ro).

Cách 1:

Đầu tiên ta viết lại điều kiện ii. của định nghĩa 2.5.6:

$$
E_{Q}\left[\frac{S_{t+s}^{n}}{B_{t+s}} \mid \mathcal{F}_{t}\right]=\frac{S_{t}^{n}}{B_{t}}, \forall t, s \geq 0
$$

Đặt $q_{i}=Q\left(\left\{\omega_{i}\right\}\right), i=1,2,3,4$. Ngoài phương trình $q_{1}+q_{2}+q_{3}+q_{4}=1$, từ biểu thức trên, ta có thêm các phương trình sau:

- Tại $t=0, s=1$, ta có:

$$
E_{Q}\left[\frac{S_{1}^{n}}{B_{1}} \mid \mathcal{F}_{0}\right]=\frac{S_{0}^{n}}{B_{0}} \Leftrightarrow \frac{9\left(q_{1}+q_{2}\right)+3\left(q_{3}+q_{4}\right)}{(1+r)}=6 \Leftrightarrow 6(1+r)=9\left(q_{1}+q_{2}\right)+3\left(q_{3}+q_{4}\right)
$$

- Tại $t=0, s=2$, ta có:

$$
E_{Q}\left[\frac{S_{2}^{n}}{B_{2}} \mid \mathcal{F}_{0}\right]=\frac{S_{0}^{n}}{B_{0}} \Leftrightarrow \frac{10 q_{1}+7 q_{2}+7 q_{3}+q_{4}}{(1+r)^{2}}=6 \Leftrightarrow 6(1+r)^{2}=10 q_{1}+7 q_{2}+7 q_{3}+q_{4}
$$

- Tại $t=1, s=1$, ta có:

$$
E_{Q}\left[\frac{S_{2}^{n}}{B_{2}} \mid \mathcal{F}_{1}\right]=\frac{S_{1}^{n}}{B_{1}} \Leftrightarrow E_{Q}\left[S_{2}^{n} \mid \mathcal{F}_{1}\right]=(1+r) S_{1}^{n}
$$

Nếu $\omega=\omega_{1}, \omega_{2}$, thì

$$
E_{Q}\left[S_{2}^{n} \mid \mathcal{F}_{1}\right]=(1+r) S_{1}^{n} \Leftrightarrow E_{Q}\left[S_{2}^{n} \mid S_{1}=9\right]=9(1+r) \Leftrightarrow \frac{10 q_{1}+7 q_{2}}{q_{1}+q_{2}}=9(1+r)
$$

Nếu $\omega=\omega_{3}, \omega_{4}$, thì

$$
E_{Q}\left[S_{2}^{n} \mid \mathcal{F}_{1}\right]=(1+r) S_{1}^{n} \Leftrightarrow E_{Q}\left[S_{2}^{n} \mid S_{1}=3\right]=3(1+r) \Leftrightarrow \frac{7 q_{3}+q_{4}}{q_{3}+q_{4}}=3(1+r) .
$$


Vậy ta được hệ gồm 5 phương trình. Giải hệ đó ta tìm được $q_{i}=Q\left(\left\{\omega_{i}\right\}\right), i=1,2,3,4$.

\section{Cách 2:}

Ta viết lại biểu thức $E_{Q(t, A)}\left[\Delta \hat{S}_{t+1}^{n}\right]=0$ hay $E_{Q(t, A)}\left[\frac{S_{t+1}^{n}}{B_{t+1}}\right]=E_{Q(t, A)}\left[\frac{S_{t}^{n}}{B_{t}}\right]$

Tại $t=0$, lấy $A \in \mathcal{P}_{0} \Rightarrow A=\Omega$. Đặt $p_{1}=Q_{(0, \Omega)}\left(S_{1}=9\right)$, từ biểu thức trên ta có:

$9 p_{1}+3\left(1-p_{1}\right)=6(1+r)$. Suy ra

$Q_{(0, \Omega)}\left(S_{1}=9\right)=p_{1}=\frac{1+2 r}{2} ; Q_{(0, \Omega)}\left(S_{1}=3\right)=1-p_{1}=\frac{1-2 r}{2}$

Tại $t=1$, lấy $A \in \mathcal{P}_{1} \Rightarrow\left[\begin{array}{l}A=\left\{\omega_{1}, \omega_{2}\right\} \\ A=\left\{\omega_{3}, \omega_{4}\right\}\end{array}\right.$. Ta chia ra hai trường hợp:

TH1: $A=\left\{\omega_{1}, \omega_{2}\right\}$. Đặt $p_{2}=Q_{(1, A)}\left(S_{2}=10\right)$. Từ biểu thức $(*)$, ta có:

$10 p_{2}+7\left(1-p_{2}\right)=9(1+r)$. Suy ra

$Q_{(1, A)}\left(S_{2}=10\right)=p_{2}=\frac{2+9 r}{3} ; Q_{(1, A)}\left(S_{2}=7\right)=1-p_{2}=\frac{1-9 r}{3}$

TH2: $A=\left\{\omega_{3}, \omega_{4}\right\}$. Đặt $p_{2}^{\prime}=Q_{(1, A)}\left(S_{2}=7\right)$. Từ biểu thức $(*)$, ta có:

$7 p_{2}^{\prime}+7\left(1-p_{2}^{\prime}\right)=3(1+r)$. Suy ra

$Q_{(1, A)}\left(S_{2}=7\right)=p_{2}^{\prime}=\frac{2+3 r}{6} ; Q_{(1, A)}\left(S_{2}=1\right)=1-p_{2}^{\prime}=\frac{4-3 r}{6}$.

- Bằng cách nhân các xác suất có điều kiện dọc cách đường dẫn tới 4 trạng thái trong $\Omega$, ta được:

$$
\begin{aligned}
& Q\left(\left\{\omega_{1}\right\}\right)=\frac{1}{6}(1+2 r)(2+9 r) \\
& Q\left(\left\{\omega_{2}\right\}\right)=\frac{1}{6}(1+2 r)(1-9 r) \\
& Q\left(\left\{\omega_{3}\right\}\right)=\frac{1}{12}(1-2 r)(2+3 r) \\
& Q\left(\left\{\omega_{4}\right\}\right)=\frac{1}{12}(1-2 r)(4-3 r)
\end{aligned}
$$


Trong đó do các xác suất dương nên $r<\frac{1}{9}$, do đó $0 \leq r<\frac{1}{9}$.

\subsection{Mô hình nhị thức}

Xét một mô hình nhị thức mô tả giá chứng khoán trong thời gian rời rạc, $T$ chu kỳ. Thời điểm $t=0$ là thời điểm hiện tại, bắt đầu giao dịch và thời điểm $t=T$ là thời điểm đáo hạn, kết thúc giao dịch. Nhà đầu tư có thể giao dịch tại mọi thời điểm $t=\{0,1, \ldots, T\}$.

Mỗi chu kỳ, thị trường tài chính chỉ xảy ra một trong hai kịch bản, hoặc tốt, hoặc xấu; giống như việc tung đồng xu hai mặt (một mặt ký hiệu là $\mathcal{H}$, mặt kia ký hiệu là $\mathcal{T}$ ). Nghĩa là: trong mỗi chu kỳ, không gian các kịch bản tài chính có dạng $\Omega:=\{\mathcal{H} ; \mathcal{T}\}$, trong đó $\mathcal{H}$ xuất hiện với xác suất $P(\mathcal{H})=p, 0<p<1$ và $\mathcal{T}$ xuất hiện với xác suất $P(\mathcal{T})=1-p$. Do đó thị trường với $T$ chu kỳ, có thể xem như phép thử lặp $T$ lần. Khi đó ta có không gian kịch bản tài chính (không gian mẫu) ký hiệu là tập tất cả các kịch bản có thể có sau $T$ lần tung đồng xu là:

$$
\Omega=\left\{\omega_{i}, i=1,2, \ldots, 2^{T}\right\}
$$

Trong đó với mỗi $\omega \in \Omega$ có dạng:

$$
\omega=\left(A_{1}, A_{2}, \ldots, A_{T}\right) \text { với } A_{j}=\mathcal{H} \text { hoặc } A_{j}=\mathcal{T}(j=1,2, \ldots, T) \text {. }
$$

Nó xuất hiện với xác suất $0<P(\omega)<1$.

Cho trước hai hằng số dương $u, d$. Giả sử trong mỗi chu kỳ, giá chứng khoán hoặc tăng một thừa số $u$, hoặc giảm một thừa số $d$, tuỳ theo vào một trong hai kịch bản tài chính xảy ra; cũng giống như việc tung đồng xu, mặt $\mathcal{H}$ xuất hiện hay mặt $\mathcal{T}$ xuất hiện, nghĩa là giá chứng khoán $S_{t}$ của chứng khoán $S$ tại thời điểm $t$ được cho bởi:

$$
S_{t+1}=\left\{\begin{array}{ll}
u S_{t}, & A_{t+1}=\mathcal{H} \\
d S_{t}, & A_{t+1}=\mathcal{T}
\end{array} \quad t=0,1, \ldots, T-1\right.
$$

Khi đó với mỗi $\omega \in \Omega$ thì $P(\omega)=p^{n}(1-p)^{T-n}$, trong đó $\omega \in \Omega$ là trạng thái có $n$ thành phần $\mathcal{H}$ và $(N-n)$ thành phần $\mathcal{T}$.

Vì thế mô hình nhị thức liên qua đến quá trình $N_{t}$ đại diện cho số lần xuất hiện mặt $\mathcal{H}$ sau $t$ lần tung đồng xu. 


\section{Định nghĩa 2.6.1:}

Khi $t=1,2, \ldots, T$, xét ánh $x a ̣ X_{t}: \Omega \rightarrow R$ xác định bởi:

$$
X_{t}(\omega)= \begin{cases}1, & A_{t}=\mathcal{H} \\ 0, & A_{t}=\mathcal{T}\end{cases}
$$

thì $\left\{X_{t}, t=1,2, \ldots, T\right\}$ được gọi là quá trình ngẫu nhiên Bernoulli với tham số p.

Khi đó $P\left(X_{t}=1\right)=P(\mathcal{H})=p$ và $P\left(X_{t}=0\right)=P(\mathcal{T})=1-p$

Ta nên hiểu $\left\{X_{t}=1\right\}$ có nghĩa là kết quả của tung đồng xu lần $t$ xuất hiện mặt $\mathcal{H}$.

\section{Định nghĩa 2.6.2:}

Với mọi $\omega \in \Omega$. Quá trình đếm Becnoulli $\left\{N_{t}: t=1,2, \ldots, T\right\}$ đự̛c định nghĩa:

$$
N_{t}(\omega)=X_{1}(\omega)+X_{2}(\omega)+\ldots+X_{t}(\omega)
$$

Dùng quá trình đếm Becnoulli thì quá trình giá chứng khoán trong mô hình nhị thức được xác định thông qua giá chứng khoán ban đầu $S_{0}$ là:

$$
S_{t}(\omega)=S_{t} u^{N_{t}(\omega)} d^{t-N_{t}(\omega)} \text { với mỗi } t=1,2, \ldots, T ; \omega \in \Omega .
$$

Vì $E\left[X_{t}\right]=p$ và $\operatorname{var}\left(X_{t}\right)=p(1-p)$ nên $E\left[N_{t}\right]=t p$ và $\operatorname{var}\left(N_{t}\right)=t p(1-p)$.

Sự xây dựng quá trình Becnoulli có ý tưởng là: tại thời điểm $t$, giá chứng khoán tăng nếu $X_{t}(\omega)=1$ và giảm nếu $X_{t}(\omega)=0$. Quá trình đếm $N_{t}$ chỉ số lần giá chứng khoán tăng cho đến thời điểm $t$ và $t-N_{t}$ chỉ số lần giá chứng khoán giảm cho đến thời điểm $t$. Sở dĩ mô hình tài chính đang xét được gọi là mô hình nhị thức, vì với mỗi $t$, biến ngẫu nhiên $N_{t}$ là biến ngẫu nhiên nhị thức với tham số $p, t$. Nghĩa là

Với mọi $k=1,2, \ldots t$ thì:

$$
P\left(N_{t}=n\right)=C_{t}^{n} p^{n}(1-p)^{t-n}
$$

Trong đó $C_{t}^{n}=\frac{t !}{n !(t-n) !}$

Phân phối giá chứng khoán tại thời điểm $t$, khi $n=1,2, \ldots, t$ được xác định bởi:

$$
P\left(S_{t}=S_{0} u^{n} d^{t-n}\right)=C_{t}^{n} p^{n}(1-p)^{t-n}
$$


Giả sử trong thị trường chỉ có một chứng khoán $S$ và một tài khoản tín dụng (trái phiếu không rủi ro) $B$. Trái phiếu không rủi ro với lãi suất không đổi trong mỗi chu kỳ là $r$.

Tại thời điểm $t=0$, NĐT có vốn ban đầu là $x=V_{0}$, mua $\phi_{1}^{1}$ đơn vị cổ phiếu chứng khoán $\mathrm{S}$, với giá cổ phiếu là $S_{0}$. Vậy số tiền của $\mathrm{NĐT} \mathrm{ở} \mathrm{chứng} \mathrm{khoán} \mathrm{là} \phi_{1}^{1} S_{0}$; số tiền còn lại sau khi mua chứng khoán $S$ là $\phi_{1}^{0}:=x-\phi_{1}^{1} S_{0}=V_{0}-\phi_{1}^{1} S_{0}$ sẽ được gửi vào tài khoản tín dụng để hưởng lãi suất không rủi ro $r$.

Tại thời điểm $t=1$, giá cổ phiếu có thể thay đổi tuỳ thuộc vào kịch bản tài chính nào xảy ra, giả sử giá cổ phiếu là $S_{1}$ thì nhà đầu tư có một số tiền ở chứng khoán là $\phi_{1}^{1} S_{1}$ và trong tài khoản tín dụng là $\left(V_{0}-\phi_{1}^{1} S_{0}\right)(1+r)$. Vậy tại thời điểm $t=1$, nhà đầu tư có tổng số tiền là:

$$
V_{1}=\left(V_{0}-\phi_{1}^{1} S_{0}\right)(1+r)+\phi_{1}^{1} S_{1}
$$

Tại thời điểm này, nhà đầu tư mua $\phi_{2}^{1}$ đơn vị cổ phiếu chứng khoán $S$, với giá cổ phiếu là $S_{1}$. Vậy số tiền mà nhà đầu tư ở chứng khoán là $\phi_{2}^{1} S_{1}$; số tiền còn lại sau khi mua chứng khoán $S$ là $V_{1}-\phi_{2}^{1} S_{1}$ sẽ được gửi vào tài khoản tín dụng để hưởng lãi suất không rủi ro $\mathrm{r}$.

Tại thời điểm $t=2$, giá cổ phiếu là $S_{2}$ thì nhà đầu tư có một số tiền ở chứng khoán là $\phi_{2}^{1} S_{2}$ và trong tài khoản tính dụng là $\left(V_{1}-\phi_{2}^{1} S_{1}\right)(1+r)$. Vậy tại thời điểm $t=2$, nhà đầu tư có tổng số tiền là:

$$
V_{2}=\left(V_{1}-\phi_{2}^{1} S_{1}\right)(1+r)+\phi_{2}^{1} S_{2}
$$

Tiếp tục quá trình trên ta có công thức truy hồi của quá trình giá của chiến lược đầu tư với $V_{0}$ là tổng tài sản ban đầu là:

$$
V_{t+1}=\left(V_{t}-\phi_{t+1}^{1} S_{t}\right)(1+r)+\phi_{t+1}^{1} S_{t+1}, t=0,1, \ldots, T-1
$$

Hay

$$
V_{t+1}=\phi_{t+1}^{0}(1+r)+\phi_{t+1}^{1} S_{t+1}, t=0,1, \ldots, T-1
$$

Vậy ta nói nhà đầu tư đã thực hiện một phương án đầu tư $(x, \phi)$, trong đó $x$ là tổng số vốn ban đầu và $\phi=\left(\phi_{t}^{0} ; \phi_{t}^{1}\right): t=1,2, \ldots, T$; trong đó $\phi_{t}^{0}$ là số tiền trong tài 
khoản tín dụng và $\phi_{t}^{1}$ là số đơn vị cổ phiếu chứng khoán được giữ từ thời điểm $t-1$ tới thời điểm $t$.

\section{Định nghĩa 2.6.3:}

- Quá trình giá tương úng với phương án đầu tur $(x, \phi)$ với $\phi=\left(\phi_{t}^{0} ; \phi_{t}^{1}\right): t=1,2, \ldots, T$ là quá trình ngẫu nhiên $V_{t}(\phi)$ được xác định bởi:

$$
V_{t}(\phi)=\phi_{t}^{0}(1+r)+\phi_{t}^{1} S_{t}
$$

- Quá trình giá chứng khoán đã chiết khấu là $\hat{S}_{t}=\frac{S_{t}}{B_{t}}$ và quá trình giá của phương án đầu tu đã chiết khấu là: $\widehat{V}_{t}(\phi)=\frac{V_{t}(\phi)}{B_{t}}$

\section{Định nghĩa 2.6.4:}

Một phương án đầu tư $\phi=\left(\phi_{t}^{0} ; \phi_{t}^{1}\right): t=1,2, \ldots, T$ được gọi là phwơng án tụ tài trọ̆ nếu NĐT điều chỉnh phuơng án đầu tu bằng cách thay đổi số đơn vị tài sản mà không là thay đổi vốn đầu tu, không bỏ thêm tiền đầu tư và cũng không rút bớt vốn ra khỏi phương án.

Gọi $\mathcal{I}$ là tập hợp tất cả các phương án tài trợ và thích nghi với lọc thông tin $\left\{\mathcal{F}_{t}: t=0,1, \ldots, T\right\}$.

\section{Định nghĩa 2.6.5:}

- Một quyền tài chính là một biến ngẫu nhiên Xxác định trên $\Omega$ biểu diễn một thu hoạch một thu hoạch tại thời điểm đáo hạn $t=T$.

- Một phương án đầu tu $(x, \phi)$ trong $\mathcal{I}$ bảo hộ cho quyền tài chính X là phương án mà giá của nó tại thời điểm đáo hạn bằng thu hoạch của quyền tài chính, nghĩa là $V_{T}(x, \phi)=X$.

\section{Định nghĩa 2.6.6:}

Thị trường tài chính được gọi là đầy đủ nếu mọi quyền tài chính X, đều tồn tại một phưong án thuộc $\mathcal{I}$, bảo hộ cho $X$.

Định nghĩa 2.6.7: 
Cho không gian xác suất $(\Omega, \mathcal{F}, P)$ và lọc thông tin $\left\{\mathcal{F}_{t}: t=0,1, \ldots, T\right\}$ sao cho: $\mathcal{F}_{t} \subset \mathcal{F}_{t+1} \subset \mathcal{F}, \forall t=0,1, \ldots, T-1$. Quá trình ngẫu nhiên $\left\{S_{t}: t=0,1, \ldots, T\right\}$ thích nghi với lọc $\left\{\mathcal{F}_{t}: t=0,1, \ldots, T\right\}$, được gọi là một quá trình Markov nếu $P\left(S_{t+1} \in B \mid \mathcal{F}_{t}\right)=P\left(S_{t+1} \in B \mid S_{t}\right)$, với mọi $t=0,1, \ldots, T-1$; và mọi tập Borel $B$.

Bây giờ ta xác định giá mô hình chứng khoán nhị thức. Mô hình này đặc trưng với 4 tham số: $p, u, d, S_{0}$. Trong đó $0<p<1,0<d<1<u, S_{0}>0$. Khi đó giá của chứng khoán tại thời điểm $t$ là $S_{t}$ và một tài khoản tín dụng $B$, mà số tiền trong tài khoản tại thời điểm $t$ là $\phi_{t+1}^{0}$. Lọc thông tin được giả sử là lọc $\left\{\mathcal{F}_{t} \equiv \mathcal{F}_{t}^{s}: t=0,1, \ldots, T\right\}$ sinh ra bởi $\left\{S_{t}: t=0,1, \ldots, T\right\}$ và $\mathcal{I}$ là tập hợp tất cả các phương án đầu tư tự tài trợ, thích nghi với lọc thông tin.

\section{Mệnh đề 2.6.8:}

Trong mô hình nhị thức tham số $p, u, d$ và $T$ chu kỳ, duoói giả thiết $d<1+r<u$, thì một độ đo xác suất $Q$ xác định trên $(\Omega, \mathcal{F}, P)$ là một độ đo xác suất trung hoà rủi ro nếu và chỉ nếu ba điều sau đây thoả mãn:

i. $\quad X_{1}, X_{2}, \ldots, X_{T}$ là độc lập với nhau theo độ đo $Q$.

ii. $\quad 0<q:=Q\left(X_{t}=1\right)<1, \forall 0 \leq t \leq T$

iii. $\quad q\left(\frac{u-1-r}{1+r}\right)+(1-q)\left(\frac{d-1-r}{1+r}\right)=0$

Trong đó $\left\{X_{t}: t=0, \ldots, T\right\}$ là quá trình Bernoulli tuoong úng trong mô hình.

Chứng minh:

Điều kiện (i) và (ii) của mệnh đề đảm bảo $Q$ là độ đo xác suất thông thường theo yêu cầu của phép thử Bernoulli. Để chứng minh $Q$ là độ đo martingale, ta cần chứng minh nó thoả điều kiện

$$
E_{Q}\left[\hat{S}_{t+1} \mid \mathcal{F}_{t}\right]=\hat{S}_{t} \text { với } t=1,2, \ldots, T-1 .
$$

Xét $\omega_{i} \in \mathcal{P}_{t}$ là phân hoạch của $\Omega$ tương ứng với $\mathcal{F}_{t}$ có dạng: $\omega_{i}=\left(A_{1}, A_{2}, \ldots, A_{t}\right)$ với $A_{j}=\mathcal{H}$ hoặc $A_{j}=\mathcal{T}$ với $j=1,2, \ldots, t$ thì 


$$
\begin{aligned}
& E_{Q}\left[\hat{S}_{t+1} \mid F_{t}\right]\left(\omega_{i}\right) \equiv E_{Q}\left[\frac{S_{t+1}}{B_{t+1}}\right]\left(\omega_{i}\right) \\
= & \frac{1}{(1+r)^{t+1}}\left[q S_{t+1}\left(A_{1}, A_{2}, \ldots, A_{t}, \mathcal{H}\right)+(1-q) S_{t+1}\left(A_{1}, A_{2}, \ldots, A_{t}, \mathcal{T}\right)\right] \\
= & \frac{1}{(1+r)^{t}} \cdot \frac{1}{1+r}\left[q u S_{t}\left(A_{1}, A_{2}, \ldots, A_{t}\right)+(1-q) d S_{t}\left(A_{1}, A_{2}, \ldots, A_{t}\right)\right] \\
= & \frac{S_{t}\left(A_{1}, A_{2}, \ldots, A_{t}\right)}{(1+r)^{t}} \cdot \frac{q u+(1-q) d}{1+r} \\
= & \frac{S_{t}}{B_{t}}\left(\omega_{i}\right) \equiv \hat{S}_{t}\left(\omega_{i}\right) \quad\left(\text { do điều kiện (iii) suy ra } \frac{q u+(1-q) d}{1+r}=1\right)
\end{aligned}
$$

Vậy $E\left[\hat{S}_{t+1} \mid \mathcal{F}_{t}\right]=\hat{S}_{t}$ với $t=1,2, \ldots, T-1$.

\section{Nhận xét 1:}

Từ cách chứng minh trên, rõ ràng quá trình giá chứng khoán đã chiết khấu $\left\{\hat{S}_{t}: t=1,2, \ldots, T\right\}$; cùng với lọc thông tin $\left\{\mathcal{F}_{t}: 0 \leq t \leq T\right\}$; là martingale dưới độ đo xác suất trung tính rủi ro $Q(\omega)=q^{N_{T}(\omega)}(1-q)^{T-N_{T}(\omega)}$ với $q=\frac{1+r-d}{u-d},(d<1+r<u)$, suy ra từ điều kiện iii. của mệnh đề trên.

Phân phối giá chứng khoán tại thời điểm $t$, khi $n=1,2, \ldots, t$ được xác định bởi:

$$
Q\left(S_{t}=S_{0} u^{N_{t}(\omega)} d^{t-N_{t}(\omega)}\right)=C_{t}^{N_{t}(\omega)} q^{N_{t}(\omega)}(1-q)^{t-N_{t}(\omega)}
$$

\section{Mệnh đề 2.6.9:}

Trong mô hình nhị thức tham số $p, u, d$ và T chu kỳ, dưới giả thiết $d<1+r<u$, thì quá trình giá chứng khoán $\left\{S_{t}: t=1,2, \ldots, T\right\}$; cùng với bộ lọc thông tin $\left\{\mathcal{F}_{t}: t=0,1, \ldots, T\right\}$ là một quá trình Markov dưới độ đo gốc $P$.

Chứng minh:

Lấy $\omega_{i}=\left(A_{1}, A_{2}, \ldots, A_{t}, A_{t+1}\right)$ với $A_{j}=\mathcal{H}$ hoặc $A_{j}=\mathcal{T} ; j=1,2, \ldots, t+1$. 
Ta có: $S_{t+1}\left(\omega_{i}\right)= \begin{cases}u S_{t}\left(A_{1}, A_{2}, \ldots, A_{t}\right) ; & A_{t+1}=\mathcal{H} \\ d S_{t}\left(A_{1}, A_{2}, \ldots, A_{t}\right) ; & A_{t+1}=\mathcal{T}\end{cases}$

Do đó $E\left[f\left(S_{t+1}\right)\right]\left(A_{1}, A_{2}, \ldots, A_{t}\right)=p f\left(u S_{t}\left(A_{1}, A_{2}, \ldots, A_{\tau}\right)\right)+(1-p) f\left(d S_{t}\left(A_{1}, A_{2}, \ldots, A_{t}\right)\right)$

Có vế phải chỉ phụ thuộc vào $\left(A_{1}, A_{2}, \ldots, A_{\tau}\right)$ qua giá trị $S_{t}\left(A_{1}, A_{2}, \ldots, A_{\tau}\right)$

Nên $E\left[f\left(S_{t+1}\right)\right]=g\left(S_{t}\right)$ với $g(x)=p f(u x)+(1-p) f(d x)$.

Vậy ta có điều phải chứng minh.

\section{Mệnh đề 2.6.10:}

Quá trình giá đã chiết khấu $\hat{V}_{t}=\frac{V_{t}}{B_{t}}$ của một phưong án đầu tu nào đó là một martingale theo độ đo $Q$.

Chứng minh.

Ta sẽ chứng minh $\hat{V}_{t}$ là $\mathcal{F}_{t}-$ đo được và

$$
E_{Q}\left[\frac{V_{t+1}}{B_{t+1}} \mid \mathcal{F}_{t}\right]=\frac{V_{t}}{B_{t}}, \forall t=0,1, \ldots, T-1
$$

Theo công thức truy hồi của $\left\{V_{t}: t=0,1, \ldots, T\right\}$, ta có:

$$
\begin{gathered}
V_{t+1}=\left(V_{t}-\phi_{t+1}^{1} S_{t}\right)(1+r)+\phi_{t+1}^{1} S_{t+1} \\
\Rightarrow \frac{V_{t+1}}{B_{t+1}}=\frac{V_{t}}{B_{t}}+\phi_{t+1}^{1} \frac{S_{t+1}}{B_{t+1}}-\phi_{t+1}^{1} \frac{S_{t}}{B_{t}} \quad\left(B_{t}=(1+r)^{t}\right) \\
\Rightarrow \frac{V_{t+1}}{B_{t+1}}=\frac{V_{t}}{B_{t}}+\phi_{t+1}^{1}\left(\frac{S_{t+1}}{B_{t+1}}-\frac{S_{t}}{B_{t}}\right)
\end{gathered}
$$

Do $S_{t}, \phi_{t+1}^{1}, V_{t}$ là $\mathcal{F}_{t}$-đo được và $\frac{S_{t}}{B_{t}}$ là Q-martingale nên $\frac{V_{t}}{B_{t}}$ cũng là Q-martingale.

Ta có điều phải chứng minh.

\section{Định lý 2.6.11:}

Mô hình định giá tài sản nhị thức là đầy đủ 
Chứng minh:

Điều cần chứng minh là: nếu $X$ là một quyền tài chính, thì tồn tại hằng số $V_{0}$ và một chiến lược đầu tư $\phi_{t}$ sao cho quá trình giá $V_{t}$ của chiến lược thoả mãn: $V_{T}(\phi)=X$. Nói cách khác, bắt đầu với $V_{0}$ đơn vị tiền tệ, ta có thể giao dịch cổ phiếu chứng khoán để đáp ứng chính xác kết quả cuối cùng của quyền phái sinh bất kỳ $X$.

Đặt $X_{t}=(1+r)^{t} E_{Q}\left[\frac{X}{(1+r)^{T}} \mid \mathcal{F}_{t}\right]$

Do tính chất.... nên $\frac{X_{t}}{(1+r)^{t}}$ là một Q-martingale.

Nếu $\omega=\left(A_{1}, \ldots, A_{T}\right)$, trong đó $A_{j}$ là $\mathcal{H}$ hoặc $\mathcal{T}$, đặt

$\phi_{t+1}(\omega)=\frac{V_{t+1}\left(A_{1}, \ldots, A_{t}, \mathcal{H}, A_{t+2}, \ldots, A_{T}\right)-V_{t+1}\left(A_{1}, \ldots, A_{t}, \mathcal{T}, A_{t+2}, \ldots, A_{T}\right)}{S_{t+1}\left(A_{1}, \ldots, A_{t}, \mathcal{H}, A_{t+2}, \ldots, A_{T}\right)-S_{t+1}\left(A_{1}, \ldots, A_{t}, \mathcal{T}, A_{t+2}, \ldots, A_{T}\right)}$

Đặt $V_{0}=X_{0}$, và ta sẽ chứng minh $V_{t}=X_{t}$.

Đầu tiên, ta sẽ chứng minh $\phi_{t+1}$ là $\mathcal{F}_{t}$-đo được. Cả $S_{t+1}$ và $V_{t+1}$ đều không phụ thuộc vào $A_{t+2}, \ldots, A_{T}$. Vì thế $\phi_{t+1}$ chỉ phụ thuộc vào $A_{1}, \ldots, A_{t}$, vì thế $\phi_{t+1}$ là $\mathcal{F}_{t}$-đo được.

Bây giờ $A_{t+2}, \ldots, A_{T}$ không có vai trò trong phần còn lại của chứng minh, và ta cho $A_{1}, \ldots, A_{t}$ cố định.

Để làm gọn ký hiệu, ta viết $V_{t+1}(\mathcal{H})$ để viết tắt cho $V_{t+1}\left(A_{1}, \ldots, A_{t}, \mathcal{H}, A_{t+2}, \ldots, A_{T}\right)$. Tương tự ta viết $V_{t+1}(\mathcal{T})$ để viết tắt $\operatorname{cho} V_{t+1}\left(A_{1}, \ldots, A_{t}, \mathcal{T}, A_{t+2}, \ldots, A_{T}\right)$

Ta biết $\frac{X_{t}}{(1+r)^{t}}$ là một martingale theo độ đo Q, nghĩa là:

$$
X_{t}=E_{Q}\left[\frac{X_{t+1}}{1+r} \mid \mathcal{F}_{t}\right]=\frac{1}{1+r}\left[q X_{t+1}(\mathcal{H})+(1-q) X_{t+1}(\mathcal{T})\right]
$$

Trong đó $q=\frac{(1+r)-d}{u-d}$.

Bây giờ ta giả sử $V_{t}=X_{t}$. Ta sẽ chứng minh $V_{t+1}(\mathcal{H})=X_{t+1}(\mathcal{H})$ và $V_{t+1}(\mathcal{T})=X_{t+1}(\mathcal{T})$, thì ta được $V_{T}=X_{T}=X$ theo yêu cầu. 
Ta có $V_{t+1}(\mathcal{H})=\phi_{t+1} S_{t+1}(\mathcal{H})+(1+r)\left(V_{t}-\phi_{t+1} S_{t}\right)$

$=\phi_{t+1} u S_{t}+(1+r) V_{t}-(1+r) \phi_{t+1} S_{t}$

$=\phi_{t+1}\left[u S_{t}-(1+r) S_{t}\right]+(1+r) X_{t} \quad\left(X_{t}=V_{t}\right)$

$=\frac{X_{t+1}(\mathcal{H})-X_{t+1}(\mathcal{T})}{(u-d) S_{t}} S_{t}[u-(1+r)]+q X_{t+1}(\mathcal{H})+(1-q) X_{t+1}(\mathcal{T})$

$=X_{t+1}(\mathcal{H})$

Tương tự ta cũng có $V_{t+1}(\mathcal{T})=X_{t+1}(\mathcal{T})$.

Vậy ta có điều phải chứng minh.

Nhận xét 3:

Từ chứng minh định lý trên cho ta kết quả là: Giá quyền phái sinh $X$ cũng chính là giá của phương án đầu tư $\phi$ đáp ứng cho $X$ và được xác định theo công thức:

$$
V_{t}(\phi)=X_{t}=(1+r)^{t} E_{Q}\left[\frac{X}{(1+r)^{T}} \mid \mathcal{F}_{t}\right]
$$

Hơn nữa:

$$
X_{0}=E_{Q}\left[\frac{X_{t}}{B_{t}} \mid \mathcal{F}_{t}\right], \quad t=1,2, \ldots, T
$$




\section{CHƯONG 3:}

\section{QUYỀN CHỌN VÀ HỢP ĐỒNG KÝ KẾT TRƯớC}

Các khái niệm và kết quả của chuơng này được trích tù tài liệu [6], [9], [10]

\subsection{Quyền phái sinh}

\section{Định nghĩa 3.1.1:}

Quyền phái sinh (hay quyền tài chính) là một biến ngẫu nhiên X xác định trên không gian xác suất $(\Omega, F, P)$ biểu diễn thu hoạch tại thời điểm đáo hạn $t=T$.

\section{Định nghĩa 3.1.2:}

Quyền phái sinh X được gọi là đạt được (attainable) hay mua bán được (marketable) nếu tồn tại một chiến lược chấp nhận được sao cho hàm giá trị uúng với chiến lược kinh doanh đó tại thời điểm $T$ là: $V_{T}(\phi)=X$.

Trong trường hợp này, ta cũng có thể nói $\phi$ bảo hộ (generates) cho $\mathrm{X}$ và $\phi$ được gọi là phuơng án đáp úng ( replicating portfolio).

\section{Mệnh đề 3.1.3: (Nguyên tắc xác định giá trị trung tính rủi ro)}

Cho $X$ là một quyền tài chinh đạt được và $Q$ là độ đo xác suất rủi ro trung tính xác định trên $\Omega$ thì giá tại thời điểm $t$ của $X$ là $V_{t}$ chính là giá tại thời điểm $t$ của phuơng án đáp úng cho $X$ và có thể được xác định bởi công thức:

$$
\hat{V}_{t}=\frac{V_{t}}{B_{t}}=E_{Q}\left[\frac{X}{B_{T}} \mid F_{t}\right], \quad t=0,1, \ldots, T
$$

Chứng minh:

Gọi $\phi$ là chiến lược kinh doanh đáp ứng cho $X$, nghĩa là: $V_{T}(\phi)=X$ 
- Cho $Q$ là một độ đo martingale tuỳ ý, thì với mọi $t<T$ ta có:

$\widehat{V}_{t}=E_{Q}\left[\widehat{V}_{T} \mid F_{t}\right]$ (vì $\hat{V}_{t}$ là một martingale)

- Hơn nữa, vì $\widehat{V}_{T}$ là giá chiết khấu của danh mục đầu tư đáp ứng cho $\mathrm{X}$ nên ta có:

$\widehat{V}_{T}=\frac{X}{B_{T}}$. Suy ra:

$E_{Q}\left[\hat{V}_{T} \mid F_{t}\right]=E_{Q}\left[\frac{X}{B_{T}} \mid F_{t}\right]$.

- Do đó $\widehat{V}_{t}=E_{Q}\left[\frac{X}{B_{T}} \mid F_{t}\right]$

Vậy mệnh đề đã được chứng minh.

- Câu hỏi tiếp theo là làm sao tính chiến lược kinh doanh bảo hộ $\phi$.

- Nếu chúng ta biết quá trình giá $\mathrm{V}$ với phương án đáp ứng, ta chứng minh với chiến lược kinh doanh $\phi$ sử dụng trong phương trình tuyến tính trong định nghĩa quá trình giá.

$V_{t}\left(\omega_{i}\right)=\phi_{t}^{0} B_{t}+\sum_{n=1}^{N} \phi_{t}^{n} S_{t}^{n}\left(\omega_{i}\right)$ với mỗi i.

Lưu ý là $\phi$ là đoán được.

- Nếu ta chỉ biết $\mathrm{X}$, để tính được $\mathrm{V}$ và $\phi$, làm theo các bước lùi theo thời gian như sau:

Vì $V_{T}=X$, nên

$$
X\left(\omega_{i}\right)=\phi_{T}^{0} B_{T}+\sum_{n=1}^{N} \phi_{T}^{n} S_{T}^{n}\left(\omega_{i}\right)
$$

Vì $\phi$ là tự tài trợ, nên ta được:

$$
V_{T-1}=\phi_{T}^{0} B_{T-1}+\sum_{n=1}^{N} \phi_{T}^{n} S_{T-1}^{n}\left(\omega_{i}\right)
$$


Vậy ta biết $V_{T-1}$.

Do đó bước tiếp, ta có:

$$
V_{T-1}=\phi_{T-1}^{0} B_{T-1}+\sum_{n=1}^{N} \phi_{T-1}^{n} S_{T-1}^{n}\left(\omega_{i}\right)
$$

Tính được các $\phi_{T-1}^{n}$ từ hệ phương trình trên, thì ta sẽ tính được $V_{T-2}$ và cứ tiếp tục quá trình như thế.

Ví dụ 3.13: (tiếp)

- Xem một quyền mua kiểu Châu âu với giá thực thi $K=5$.

- Quyền phái sinh tương ứng là:

$X=\left(S_{2}-5\right)^{+}= \begin{cases}5, & \omega=\omega_{1} \\ 2, & \omega=\omega_{2}, \omega_{3} \\ 0, & \omega=\omega_{4}\end{cases}$

- Giả sử $r=0$ thì $Q=\left(\frac{1}{3}, \frac{1}{6}, \frac{1}{6}, \frac{1}{3}\right)$.

- Tại $t=0$, ta có:

$V_{0}=E_{Q}[X]=5 \cdot \frac{1}{3}+2 \cdot \frac{1}{6}+2 \cdot \frac{1}{6}+0 \cdot \frac{1}{3}=\frac{7}{3}$

- Tại $t=1$, ta có:

$V_{1}=E_{Q}\left[X \mid F_{1}\right]$.

Khi $\omega \in\left\{\omega_{1}, \omega_{2}\right\}$, ta có:

$V_{1}(\omega)=E_{Q}\left[X \mid S_{2}=9\right]=\frac{\frac{1}{3} \cdot 5+\frac{1}{6} \cdot 2}{\frac{1}{2}}=4$.

Khi $\omega \in\left\{\omega_{3}, \omega_{4}\right\}$, ta có: 


$$
V_{1}(\omega)=E_{Q}\left[X \mid S_{2}=3\right]=\frac{\frac{1}{6} \cdot 2+\frac{1}{3} \cdot 0}{\frac{1}{2}}=\frac{2}{3}
$$

- Tại $t=2$, thì như đã nói, ta có: $V_{2}=X$.

- Để tìm một danh mục đầu tư, ta bắt đầu tại thời gian $t=2$ và thấy:

$$
\begin{aligned}
& V_{2}\left(\omega_{1}\right)=5=\phi_{2}^{0}\left(\omega_{1}, \omega_{2}\right) \cdot 1+\phi_{2}^{1}\left(\omega_{1}, \omega_{2}\right) \cdot 10 \\
& V_{2}\left(\omega_{2}\right)=2=\phi_{2}^{0}\left(\omega_{1}, \omega_{2}\right) \cdot 1+\phi_{2}^{1}\left(\omega_{1}, \omega_{2}\right) \cdot 7
\end{aligned}
$$

Giải hệ 2 phương trình trên ta được: $\phi_{2}^{0}\left(\omega_{1}, \omega_{2}\right)=-5 ; \phi_{2}^{1}\left(\omega_{1}, \omega_{2}\right)=1$

Tương tự, ta cũng có:

$$
\begin{aligned}
& V_{2}\left(\omega_{3}\right)=2=\phi_{2}^{0}\left(\omega_{3}, \omega_{4}\right) \cdot 1+\phi_{2}^{1}\left(\omega_{3}, \omega_{4}\right) \cdot 7 \\
& V_{2}\left(\omega_{4}\right)=0=\phi_{2}^{0}\left(\omega_{3}, \omega_{4}\right) \cdot 1+\phi_{2}^{1}\left(\omega_{3}, \omega_{4}\right) \cdot 1
\end{aligned}
$$

Suy ra: $\phi_{2}^{0}\left(\omega_{3}, \omega_{4}\right)=-\frac{1}{3} ; \phi_{2}^{1}\left(\omega_{3}, \omega_{4}\right)=\frac{1}{3}$

Bây giờ ta có 2 phương pháp để làm tiếp

Phương pháp 1:

Vì ta đã tính giá của quyền chọn tại thời điểm $\mathrm{t}=1$, nên ta có thể tiến hành trong chu kỳ thứ 2 .

$\phi_{1}^{0}\left(\omega_{1}, \ldots, \omega_{4}\right)$ và $\phi_{1}^{1}\left(\omega_{1}, \ldots, \omega_{4}\right)$ lần lượt được viết tắt là $\phi_{1}^{0}$ và $\phi_{1}^{1}$.

Ta có:

$$
\begin{array}{ll}
V_{1}(\omega)=4=\phi_{1}^{0} \cdot 1+\phi_{1}^{1} .9, & \omega=\omega_{1}, \omega_{2} \\
V_{1}(\omega)=\frac{2}{3}=\phi_{1}^{0} \cdot 1+\phi_{1}^{1} \cdot 3, & \omega=\omega_{3}, \omega_{4}
\end{array}
$$

Giải hệ hai phương trình, hai ẩn trên ta được: $\phi_{1}^{0}=-1$ và $\phi_{1}^{1}=\frac{5}{9}$.

Phương pháp 2: 
Ta sử dụng tính chất $\phi$ là chiến lược kinh doanh tự tài trợ, ta tính giá của danh mục đầu tư tại thời điểm $\mathrm{t}=1$.

Ta giả sử đã tính xong $\phi_{2}^{0}$ và $\phi_{2}^{1}$. Thì:

$$
V_{1}(\omega)=\phi_{2}^{0} .1+\phi_{2}^{1} .9=-5.1+1.9=4, \quad \omega=\omega_{1}, \omega_{2}
$$

Tương tự,

$$
V_{1}(\omega)=\phi_{2}^{0} \cdot 1+\phi_{2}^{1} \cdot 9=-\frac{1}{3} \cdot 1+\frac{1}{3} \cdot 3=\frac{2}{3}, \omega=\omega_{3}, \omega_{4}
$$

Tiến hành như trên, ta được: $\phi_{1}^{0}=-1$ và $\phi_{1}^{1}=\frac{5}{9}$.

\subsection{Quyền chọn kiểu châu Âu dưới mô hình nhị thức}

Xét mô hình nhị thức với $T$ chu kỳ.

\section{Định nghĩa 3.2.1: (quyền chọn kiểu châu Âu với thời điểm thụ̣c thi là là thời điểm đáo hạn $T$ )}

Cho biến ngẫu nhiên $X \geq 0, \mathcal{F}_{T}$-đo được, $X$ có thể coi là thu hoạch khi thưc thi quyền chọn mua hay bán trên một chứng khoán (thứ nhất chẳng hạn) với giá thực thi (hay quy định) là $K$. Ta có $X=\left(S_{T}^{1}-K\right)^{+}$cho quyền chọn mua và $X=\left(K-S_{T}^{1}\right)^{+}$ cho quyền chọn bán.

Trong hai ví dụ trên $X$ chỉ là hàm của $S_{N}$.

Ta nhắc lại mô hình nhị thức:

Giá của chứng khoán rủi ro tại thời điểm $t$ là:

$$
S_{t}=S_{0} u^{N_{t}} d^{t-N_{t}}, t=1,2, \ldots, N
$$

Trong đó $0<d<1<u$ và $N=\left\{N_{t}: t=1,2, \ldots, N\right\}$ là một quá trình đếm Becnoulli với tham số $p, 0<p<1$. Giả sử tỷ suất lợi nhuận $r$ là một hằng số với $d<1+r<u$, thì có một độ đo martingale $Q$, với:

$$
Q(\omega)=q^{N_{T}(\omega)}(1-q)^{T-N_{T}(\omega)}, \quad q=\frac{1+r-d}{u-d}
$$


Hay

$$
Q(\omega)=q^{n}(1-q)^{T-n}, \quad q=\frac{1+r-d}{u-d}
$$

Trong đó $n$ là số lần xuất hiện mặt $\mathcal{H}$ của $\omega$.

\section{Định lý 3.2.2: (công thức định giá quyền chọn kiểu châu Âu)}

Trong mô hình tài chính nhị thức lành mạnh, tham số $u=\frac{1}{d}, r, T$ chu kỳ, thì giá quyền chọn kiểu châu Âu $X=\left(S_{T}-K\right)^{+}=\max \left(0 ; S_{T}-K\right)$ với $K$ là giá thực thi, tại thời điểm $t=0$ được xác định bở:

$$
V_{0}=S_{0} \sum_{n=n_{0}}^{T} C_{T}^{n}\left(q_{0}\right)^{n}\left(1-q_{0}\right)^{T-n}-\frac{K}{(1+r)^{T}} \sum_{n=n_{0}}^{T} C_{T}^{n} q^{n}(1-q)^{T-n}
$$

Trong đó $q=\frac{1+r-d}{u-d}$ và $q_{0}=\frac{q u}{1+r}$ và $n_{0}$ là số nguyên nhỏ nhất thoả:

$$
n_{0}>\frac{\ln \left(\frac{K}{S_{0} d^{T}}\right)}{\ln \left(\frac{u}{d}\right)}
$$

Chứng minh:

Đối với quyền chọn kiểu châu Âu, $X=g\left(S_{T}\right)=\left(S_{T}-K\right)^{+}$, thì theo mệnh đề trên, giá của quyền chọn này tại thời điểm $t=0$ được xác định bởi:

$$
V_{0}=E_{Q}\left[\frac{X}{(1+r)^{T}}\right]=\frac{1}{(1+r)^{T}} \sum_{n=0}^{T} C_{T}^{n} q^{n}(1-q)^{T-n} \max \left(0 ; S_{0} u^{n} d^{T-n}-K\right)
$$

và

$$
S_{0} u^{n} d^{T-n}-K>0 \Leftrightarrow\left(\frac{u}{d}\right)^{n}>\frac{K}{S_{0} d^{T}} \Leftrightarrow n \ln \left(\frac{u}{d}\right)>\ln \left(\frac{K}{S_{0} d^{T}}\right) \Leftrightarrow n>\frac{\ln \left(\frac{K}{S_{0} d^{T}}\right)}{\ln \left(\frac{u}{d}\right)}
$$

Gọi $n_{0}$ là số nguyên nhỏ nhất trong các số nguyên thoả mãn bất đẳng thức sau cùng ở trên, thì nếu số bước tăng ít hơn $n_{0}$ thì sẽ không có cơ hội thực thi. Do đó: 


$$
\begin{aligned}
V_{0}=\frac{1}{(1+r)^{T}} \sum_{n=0}^{T} C_{T}^{n} q^{n}(1-q)^{T-n} \max \left(0 ; S_{0} u^{n} d^{T-n}-K\right) \\
=\frac{1}{(1+r)^{T}} \sum_{n=0}^{n_{0}-1} C_{T}^{n} q^{n}(1-q)^{T-n} .0+\frac{1}{(1+r)^{T}} \sum_{n=n_{0}}^{T} C_{T}^{n} q^{n}(1-q)^{T-n}\left(S_{0} u^{n} d^{T-n}-K\right) \\
=\frac{S_{0}}{(1+r)^{T}} \sum_{n=n_{0}}^{T} C_{T}^{n} q^{n}(1-q)^{T-n} u^{n} d^{T-n}-\frac{K}{(1+r)^{T}} \sum_{n=n_{0}}^{T} C_{T}^{n} q^{n}(1-q)^{T-n} \\
=S_{0} \sum_{n=n_{0}}^{T} C_{T}^{n}\left(\frac{q u}{1+r}\right)^{n}\left[\frac{(1-q) d}{1+r}\right]^{T-n}-\frac{K}{(1+r)^{T}} \sum_{n=n_{0}}^{T} C_{T}^{n} q^{n}(1-q)^{T-n} \\
=S_{0} \sum_{n=n_{0}}^{T} C_{T}^{n}\left(q_{0}\right)^{n}\left(1-q_{0}\right)^{T-n}-\frac{K}{(1+r)^{T}} \sum_{n=n_{0}}^{T} C_{T}^{n} q^{n}(1-q)^{T-n} .
\end{aligned}
$$

Vậy ta có điều phải chứng minh.

\subsection{Thị trường đầy đủ và không đầy đủ}

\section{Định nghĩa 3.3.1:}

Mô hình thị truò̀ng được gọi là đầy đủ nếu mọi quyền phái sinh là đạt được. Ngược lại ta goi mô hình không đầy đủ.

\section{Mệnh đề 3.3.2:}

Mô hình thị trường nhiều chu kỳ là đầy đủ khi và chỉ khi mọi mô hình một chu kỳ co bản là đầy đủ.

Chứng minh:

$(\Rightarrow)$ : Giả sử mô hình nhiều chu kỳ là đầy đủ. Cho một quyền phái sinh X bất kỳ thì ta luôn tính được chiến lược kinh doanh $\phi$ bảo hộ cho $\mathrm{X}$ theo thời gian lùi dần (mục 3.1). Khi đó, tất cả các ma trận $\mathrm{A}$ của mỗi mô hình một chu kỳ cơ bản có số cột độc lập cần thiết. Suy ra tất cả các mô hình một chu kỳ cơ bản là đầy đủ.

$(\Leftarrow)$ : Giả sử mọi mô hình một chu kỳ cơ bản là đầy đủ. Lấy X là một quyền phái sinh bất kỳ. Ta chứng minh $\mathrm{X}$ là đạt được. 
Giả sử X là không đạt được. Khi đó, ta tính chiến lược kinh doanh $\phi$ sao cho: $V_{T}(\phi)=X$.

Do X không đạt được nên việc tính chiến lược kinh doanh theo thời gian lùi dần sẽ bị "phá vỡ” tại một mô hình một chu kỳ cơ bản nào đó. Nghĩa là mô hình một chu kỳ cơ bản đó là không đầy đủ. Điều này trái với giả thiết. Do đó $\mathrm{X}$ là đạt được hay mô hình nhiều chu kỳ là đầy đủ.

\section{Định lý 3.3.3:}

Mô hình nhiều chu kỳ đầy đủ khi và chi khi độ đo xác suất rủi ro trung tính là duy nhất.

Chứng minh:

Áp dụng mệnh đề trên ta có:

Mô hình nhiều chu kỳ đầy đủ khi và chỉ khi mỗi mô hình một chu kỳ cơ bản có một độ đo xác suất rủi ro trung tính duy nhất.

Quan sát cách xây dựng và phát triển trong mục 2.5 của độ đo xác suất rủi ro trung tính với mô hình nhiều chu kỳ thì tính duy nhất của độ đo martingale $Q$ tương đương với tính duy nhất của các độ đo martingale của các mô hình chu kỳ đơn cơ bản. Ta có điều phải chứng minh.

\section{Định lý 3.3.4:}

Quyền phái sinh X là đạt được nếu và chỉ nếu $E_{Q}\left[\frac{X}{B_{T}}\right]$ mang cùng một giá trị với mọi $Q \in \mathrm{M}$.

Chứng minh:

Ở đây ta xét mô hình không đầy đủ.

$(\Rightarrow)$ : Giả sử quyền phái sinh $X$ là đạt được, thì khi đó tồn tại chiến lược kinh doanh đáp ứng cho $\mathrm{X}$, và giá của nó tại thời gian $t=0$ là $V_{0}=E_{Q}\left[\frac{X}{B_{T}}\right]$. Vì $V_{0}=E_{Q}\left[\frac{X}{B_{T}}\right]$ với mọi độ đo xác suất rủi ro trung tính $Q$ nên khi $X$ là quyền phái sinh đạt được thì $E_{Q}\left[\frac{X}{B_{T}}\right]$ là một hằng số với mọi $Q \in \mathrm{M}$. 
$(\Leftarrow)$ : Để chứng minh chiều ngược lại, ta sẽ chứng minh bằng phản chứng.

Giả sử quyền phái sinh $\mathrm{X}$ không đạt được, ta sẽ chứng minh $E_{Q}\left[\frac{X}{B_{T}}\right]$ mang nhiều giá trị với mọi $Q \in \mathrm{M}$.

Giả sử ta thử tính chiến lược kinh doanh đáp ứng cho $\mathrm{X}$ theo thời gian lùi dần. Do quyền phái sinh $\mathrm{X}$ không đạt được nên việc tính chiến lược kinh doanh này sẽ bị "phá vỡ" tại một mô hình một chu kỳ cơ bản nào đó. Giả sử mô hình một chu kỳ cơ bản này tương ứng với thời gian $t<T, A \in P_{t}$. Khi đó tồn tại ít nhất hai độ đo xác suất điều kiện rủi ro trung tính $Q_{(A, t)}$ và $\widetilde{Q}_{(A, t)}$ sao cho:

$$
\begin{aligned}
& E_{Q_{(A, t)}}\left[\frac{V_{t+1}}{B_{1}}\right] \neq E_{\widetilde{Q}_{(A, t)}}\left[\frac{V_{t+1}}{B_{1}}\right] \\
& \Leftrightarrow E_{Q_{(A, t)}}\left[B_{t} E_{Q}\left[\frac{X}{B_{T}}\right]\right] \neq E_{\tilde{Q}_{(A, t)}}\left[B_{t} E_{\tilde{Q}}\left[\frac{X}{B_{T}}\right]\right] \\
& \Leftrightarrow E_{Q}\left[\frac{X}{B_{T}}\right] \neq E_{\tilde{Q}}\left[\frac{X}{B_{T}}\right]
\end{aligned}
$$

Trong đó $Q$ và $\widetilde{Q}$ là các độ đo rủi ro trung tính của mô hình nhiều chu kỳ tương ứng với $Q_{(A, t)}$ và $\widetilde{Q}_{(A, t)}$.

Vậy ta có điều phải chứng minh.

\subsection{Quyền chọn kiểu Mỹ:}

Mục tiêu của chương này là việc định giá và xây dựng chiến lược đảm bảo quyền tài chính quyền chọn châu Mỹ. Để thực hiện điều đó ta cần có khái niệm về dừng tối ưu mà nó cho phép xác định chiến lược thực thi của quyền chọn kiểu Mỹ. Ta cũng cần có khái niệm về bao hình Snell mà nó là chìa khoá để giải quyết bài toán dừng tối ưu.

\subsubsection{Thò̀i gian dùng (stopping time)}

Xét không gian xác suất $(\Omega, F, P)$ với bộ lọc $\left\{F_{t}: t=0,1, \ldots, T\right\}$. 


\section{Định nghĩa 3.4.1:}

Giả sử $\tau: \Omega \rightarrow\{0,1, \ldots, T\} \cup\{\infty\}$ là biến ngẫu nhiên. Ta nói rằng $\tau$ là thời điểm dù̀ng đối với bộ lọc $\left\{F_{t}: t=0,1, \ldots, T\right\}$, nếu

$$
\{\omega: \tau(\omega)=t\} \in F_{t}, \forall t=0,1, \ldots, T \text { và }
$$

(ii)

$$
P(\tau<\infty)=1
$$

Nhận xét 1:

- Điều kiện (i) trong định nghĩa tương đương với điều kiện $\{\omega: \tau(\omega) \leq t\} \in F_{t}, \forall t$.

Thật vậy, chứng minh suy ra từ các đẳng thức sau:

$$
\begin{aligned}
& \{\omega: \tau(\omega) \leq t\}=\bigcup_{k=0}^{t}\{\omega: \tau(\omega)=k\} \in F_{t} \\
& \{\omega: \tau(\omega)=t\}=\{\omega: \tau(\omega) \leq t\} \backslash\{\omega: \tau(\omega) \leq t-1\} \in F_{t}
\end{aligned}
$$

- Định nghĩa cho phép quyết định xem liệu biến cố $\{\tau \leq t\}$ xuất hiện hay không bằng cách kiểm tra thông tin có sẵn tại thời gian $\mathrm{t}$.

- Giá trị œ cho phép biến cố không bao giờ xảy ra.

- Chỉ sẽ được cho phép sử dụng luật giao dịch dựa vào thời gian dừng.

\section{Định lý 3.4.2:}

- Cho $\tau$ là một thời gian dìng ràng buộc và $X=\left\{X_{t}: t=0,1, \ldots, T\right\}$ là một martingale, thì

$$
E\left[X_{\tau}\right]=E\left[X_{0}\right]
$$

- Nếu $\tau$ là một thời gian dùng ràng buộc và X là một supermartingale, thì

$$
E\left[X_{\tau}\right] \leq E\left[X_{0}\right]
$$

Chứng minh:

Giả sử $\tau \leq T$ và viết $X_{\tau(\omega)}(\omega)=\sum_{t=0}^{T} X_{t}(\omega) 1_{\{\tau(\omega)=t\}}$, thì 


$$
\begin{aligned}
& E\left[X_{\tau}\right]=\sum_{t=0}^{T} E\left[X_{t} 1_{\{\tau=t\}}\right]=\sum_{t=0}^{T} E\left[E\left[X_{T} \mid F_{t}\right] 1_{\{\tau=t\}}\right] \\
& =\sum_{t=0}^{T} E\left[X_{T} 1_{\{\tau=t\}} \mid F_{t}\right] \\
& =\sum_{t=0}^{T} E\left[X_{T} 1_{\{\tau=t\}} \mid F_{t}\right]=E\left[X_{T} \sum_{t=0}^{T} 1_{\{\tau=t\}}\right]=E\left[X_{T}\right] \\
& =E\left[X_{0}\right]
\end{aligned}
$$

(*) có được do $\tau$ là thời gian dừng, $\{\tau=t\}$ là $F_{t}$ - đo được, vì thế $E\left[X_{T} \mid F_{t}\right] 1_{\{\tau=t\}}=E\left[X_{T} 1_{\{\tau=t\}} \mid F_{t}\right]$

\subsubsection{Quyền chọn kiểu Mỹ.}

Với quyền chọn kiều châu Âu, đó là quyền phái sinh $\mathrm{X}$ biểu diễn thanh toán chỉ xuất hiện tại thời gian đáo hạn T. Quyền chọn kiểu Mỹ cũng tương tự, thanh toán chỉ xuất hiện tại một thời điểm $\tau$ nào đó trước hoặc tại thời gian đáo hạn $\mathrm{T}$.

Quyền chọn kiểu châu Mỹ như là một hợp đồng giữa hai bên, bên mua và bên bán. Dữ kiện được xác định là một quá trình ngẫu nhiên thích nghi, không âm $Y=\left\{Y_{t}: t=0,1, \ldots, T\right\}$. Nếu họ ký một thoả thuận tại thời gian $\mathrm{t}$, thì tại thời gian đó người mua phải trả cho người bán một lượng $W_{t}$ bằng với giá của quyền chọn tại thời gian $\mathrm{t}$. Sau đó người mua phải thực thi quyền chọn tại một thời gian $\tau$ nào đó, trong đó $t \leq \tau \leq T$

Nếu quyền chọn thực thi tại thời gian $\tau$ thì người bán phải trả $Y_{\tau}$ cho người mua. Một quyền chọn kiểu châu Mỹ chỉ được thực thi một lần. Đương nhiên vấn đề ở đây là ta phải đi xác định giá của quyền chọn. Đó là quá trình giá $W=\left\{W_{t}: t=0,1, \ldots, T\right\}$ của quyền chọn kiểu Mỹ $Y$.

Với sự mô tả quyền chọn kiểu Mỹ như trên, ta có một số định nghĩa sau:

\section{Định nghĩa 3.4.3:}

Cho quyền phái sinh $\mathrm{X}$, một quá trình ngẫu nhiên $\left\{Y_{t}: t=0,1, \ldots, T\right\}$ mô tả thu hoạch của $\mathrm{X}$ nếu thực thi tại thời điểm $\mathrm{t}$ thì được gọi là quá trình thu hoạch của quyền phái $\sinh \mathrm{X}$. 


\section{Định nghĩa 3.4.4:}

Thời gian dừng $\tau$ đại diện cho thời điểm thực thi thì được gọi là chiến lược thực thi.

\section{Định nghĩa 3.4.5:}

Quyền phái sinh $Y_{\tau}$ cùng với quá trình thu hoạch $\left\{Y_{t}: t=0,1, \ldots, T\right\}$ và chiến lược thục thi thì được gọi là quyền phái sinh kiểu Mỹ.

\section{Định nghĩa 3.4.6:}

- Một quyền chọn kiểu Mỹ được gọi là đạt được khi tồn tại một chiến lược kinh doanh tụ tài trọ̆ sao cho giá danh muc đầu tư tương ứng thoả mãn: $V_{\tau}(\phi)=Y_{\tau}$.

- Một quá trình thanh toán kiểu $M \tilde{y}\left\{Y_{t}: t=0,1, \ldots, T\right\}$ được gọi là đạt được nếu với mọi thời gian dùng $\tau$, thì quyền chọn kiểu $M \tilde{y} Y_{\tau}$ là đạt được.

\section{Định lý 3.4.7:}

Nếu mô hình là đầy đủ thì mọi quyền chọn kiểu châu Mỹ đều đạt được.

Chứng minh:

Cho quá trình thanh toán $\left\{Y_{t}: t=0,1, \ldots, T\right\}$ và chiến lược thực thi $\tau$.

Ta phải tìm một chiến lược kinh doanh tự tài trợ sao cho $V_{\tau}=Y_{\tau}$.

Ta xem một chiến lược kinh doanh, viết là $\hat{\phi}$, bắt đầu tại thời gian $\tau$ với giá $\widehat{V}_{\tau}(\hat{\phi})=Y_{\tau}$. Tất cả lượng tài sản này được đầu tư vào trong tài khoản ngân hàng cho tới thời gian T. Với chiến lược này, sẽ có $\frac{Y_{\tau} B_{T}}{B_{\tau}}$ tại thời điểm T. Trong khi đó, vì mô hình là đầy đủ, nên có một chiến lược kinh doanh đáp ứng $\phi$ bắt đầu từ thời gian $t=0$ sao cho $V_{T}(\phi)=\frac{Y_{\tau} B_{T}}{B_{\tau}}$.

Vì tại thời điểm $t=T$, giá của hai danh mục đầu tư là trùng nhau nêngiá của hai danh mục đầu tư trên tại thời điểm $t=\tau$ phải trùng nhau. Tức là $V_{\tau}(\phi)=\widehat{V}_{\tau}(\hat{\phi})=Y_{\tau}$. (ĐPCM)

Nếu thị trường không đầy đủ, thì một quyền chọn kiểu Mỹ bất kỳ có thể đạt được hoặc không đạt được. 


\section{Định lý 3.4.8:}

Quyền chọn kiểu Mỹ Y là đạt được nếu và chỉ nếu với mối thời gian dìng $\tau$ thì $E_{Q}\left[\frac{Y_{\tau}}{B_{\tau}}\right]$ mang cùng giá trị với mọi $Q \in \mathrm{M}$.

Điều kiện này không dễ kiểm tra trong nhiều trường hợp riêng lẻ.

\section{Định nghĩa 3.4.9:}

Với một quá trình ngẫu nhiên cho trước $\left\{X_{t}, t=0,1, \ldots, T\right\}$. Bao hình Snell của X là quá trình ngẫu nhiên $\left\{Z_{t}, t=0,1, \ldots, T\right\}$ được định nghĩa bởi:

$$
Z_{t}= \begin{cases}X_{T}, & t=T \\ \max \left\{X_{t}, E\left[Z_{t+1} \mid F_{t}\right]\right\}, & t<T\end{cases}
$$

\section{Định lý 3.4.10:}

Bao hình Snell $Z$ của $X$ là supermatingale nhỏ nhất của $X$ và thoả mãn: $Z_{t} \geq X_{t}, \forall t$ Chứng minh:

Đầu tiên, theo định nghĩa của $Z_{t}$, rõ ràng ta có $Z_{t} \geq X_{t}, \forall t$. Hơn nữa $Z_{t} \geq E\left[Z_{t+1} \mid F_{t}\right]$, do đó $Z$ là một supermatingale.

Tiếp theo, đặt $U=\left\{U_{t}: t=0,1, \ldots, T\right\}$ là một supermatingale khác và $U_{t} \geq X_{t}, \forall t$.

Vì $U_{t} \geq X_{t}, \forall t$ và $Z_{T}=X_{T}$ nên $U_{T} \geq Z_{T}$. Ta sử dụng bước lùi thời gian. Giả sử quy nạp rằng $U_{t} \geq Z_{t}$. Khi đó, vì $U$ là một supermatingale nên $U_{t-1} \geq E\left[U_{t} \mid F_{t-1}\right] \geq E\left[Z_{t} \mid F_{t-1}\right]$

Mặt khác, vì $U_{t-1} \geq X_{t-1}$ nên ta được $U_{t-1} \geq \max \left\{X_{t-1}, E\left[Z_{t} \mid F_{t-1}\right]\right\}=Z_{t-1}$.

Do đó $U_{t} \geq Z_{t}, \forall t$.

\section{Định lý 3.4.11:}


Cho $\left\{X_{t}, t=0,1, \ldots, T\right\}$ là một quá trình ngẫu nhiên thích nghi với bộ lọc $\left\{F_{t}: t=0,1, \ldots, T\right\}$ và cho $Z_{t}$ là bao hình Snell của $\left\{X_{t}\right\}$. Vói $t=0,1, \ldots, T$ ta định nghĩa một thời gian dìng sau: $\tau(t)=\min \left\{s \geq t: X_{s}=Z_{s}\right\}$. Thì khi đó, ta có:

$Z_{t}=E\left[X_{\tau(t)} \mid F_{t}\right]=\max \left\{E\left[X_{\tau} \mid F_{t}\right]: \tau \in \varsigma(t, T)\right\}$ vói mọi $t=0,1, \ldots, T$

Trong đó $\varsigma(t, T)$ là tập hợp các thời gian dìng mang giá trị trong đoạn $[t, T]$.

Mặt khác,

$$
Z_{0}=E\left[X_{\tau(0)}\right]=\max \left\{E\left[X_{\tau}\right]: \tau \in \varsigma(0, T)\right\}
$$

Chứng minh:

- Ta sẽ chứng minh với thời gian lùi dần.

- Nhận xét là đúng với $t=T$ vì theo định nghĩa $Z_{T}=X_{T}$ và do đó thời gian dừng $\tau(T)$ dừng tại $\mathrm{T}$.

- Giả sử (3.2) đúng với $t<T$. Đặt $\tau \in \varsigma(t-1, T)$. Ta định nghĩa thêm thời gian dừng khác: $\tilde{\tau}=\max \{\tau, t\}$, thì

$$
\begin{aligned}
& E\left[X_{\tau} \mid F_{t-1}\right]=E\left[1_{\{\tau=t-1\}} X_{t-1}+1_{\{\tau z t\}} X_{\tau} \mid F_{t-1}\right] \\
& =E\left[1_{\{\tau=t-1\}} X_{t-1}+1_{\{\tau z t\}} X_{\tilde{\tau}} \mid F_{t-1}\right](\text { vì } \tau \geq t \Rightarrow \tau=\tilde{\tau}) \\
& =1_{\{\tau=t-1\}} X_{t-1}+1_{\{\tau \geq t\}} E\left[X_{\tilde{\tau}} \mid F_{t-1}\right] \\
& =1_{\{\tau t-1\}} X_{t-1}+1_{\{\tau z t\}} E\left[E\left[X_{\tilde{\tau}} \mid F_{t}\right] \mid F_{t-1}\right]
\end{aligned}
$$

Ta có: $\tilde{\tau} \in \varsigma(t, T)$. Theo điều giả sử thì ta được $E\left[X_{\tilde{\tau}} \mid F_{t}\right] \leq Z_{t}$.

- Theo định nghĩa của $Z_{t-1}: Z_{t-1}=\max \left\{X_{t-1}, E\left[Z_{t} \mid F_{t-1}\right]\right\} \Rightarrow X_{t-1} \leq Z_{t-1}$. Do đó:

$$
\begin{aligned}
& E\left[X_{\tau} \mid F_{t-1}\right] \leq 1_{\{\tau t-1\}} X_{t-1}+1_{\{\tau z t\}} E\left[Z_{t} \mid F_{t-1}\right] \\
& \leq 1_{\{t=t-1\}} Z_{t-1}+1_{\{\tau z t\}} E\left[Z_{t} \mid F_{t-1}\right] \leq E\left[Z_{t-1} \mid F_{t-1}\right]=Z_{t-1}
\end{aligned}
$$


- Trong trường hợp này, ta có: $\tau(t-1)= \begin{cases}t-1, & Z_{t-1}=X_{t-1} \\ \tau(t), & Z_{t-1}>X_{t-1}\end{cases}$

Do đó:

$$
\begin{aligned}
& E\left[X_{\tau(t-1)} \mid F_{t-1}\right]=1_{\left\{Z_{t-1}=X_{t-1}\right\}} X_{t-1}+1_{\left\{Z_{t-1}>X_{t-1}\right\}} E\left[X_{\tau(t)} \mid F_{t-1}\right] \\
& =1_{\left\{Z_{t-1}=X_{t-1}\right\}} X_{t-1}+1_{\left\{Z_{t-1}>X_{t-1}\right\}} E\left[E\left[X_{\tau(t)} \mid F_{t}\right] \mid F_{t-1}\right] \\
& =1_{\left\{Z_{t-1}=X_{t-1}\right\}} Z_{t-1}+1_{\left\{Z_{t-1}>X_{t-1}\right\}} E\left[Z_{t} \mid F_{t-1}\right] \text { (do giả thiết quy nạp } E\left[X_{\tau(t)} \mid F_{t}\right]=Z_{t} \text { ) } \\
& =Z_{t-1} .
\end{aligned}
$$

Vậy (3.2) đúng với thời gian t-1.

\section{Mệnh đề 3.4.12:}

Xem một thị truòng tài chính với một độ đo xác suất trung tính rủi ro Q và quá trình thu hoạch kiểu Mỹ $\left\{Y_{t}\right\}$ mà nó được bảo hộ. Thì bao hình Snell Z của quá trình thu hoạch chiết khấu $\frac{Y}{B}$ là quá trình giá chiết khấu của $Y$.

Chứng minh:

$Z$ là bao hình Snell của $\frac{Y}{B}$ nên $Z_{t}= \begin{cases}\frac{Y_{T}}{B_{T}}, & t=T \\ \max \left\{\frac{Y_{t}}{B_{t}}, E\left[Z_{t+1} \mid F_{t}\right]\right\}, & t<T\end{cases}$

Theo định lý 3.22 thì $Z_{t}=E\left[\frac{Y_{\tau(t)}}{B_{\tau(t)}} \mid F_{t}\right]=\max \left\{E\left[\frac{Y_{\tau}}{B_{\tau}} \mid F_{t}\right]: \tau \in \varsigma(t, T)\right\}$ với mọi $t=0,1, \ldots, T$

Trong đó $\varsigma(t, T)$ là tập hợp các thời gian dừng mang giá trị trong đoạn $[t, T]$

Gọi $W=\left\{W_{t}: t=0,1, \ldots, T\right\}$ là quá trình giá của $Y$. Ta sẽ chứng minh $Z=\frac{W}{B}$. 
- Tại thời điểm $\mathrm{T}$, giá chiết khấu của quá trình thu hoạch kiểu châu Mỹ bằng $\frac{W_{T}}{B_{T}}=\frac{Y_{T}}{B_{T}}$ (do định nghĩa quyền chọn kiểu Mỹ). Suy ra $Z_{T}=\frac{W_{T}}{B_{T}}$

- Giả sử ta đã chứng minh được $Z_{s}=\frac{W_{s}}{B_{s}}$ với mọi $s \geq t>0$.

- Ta sẽ chứng minh $Z_{t-1}=\frac{W_{t-1}}{B_{t-1}}$.

- Nếu $\tau(t-1)=t-1$ thì ta thực thi quyền chọn ngay lập tức và $Z_{t-1}=\frac{Y_{t-1}}{B_{t-1}}=\frac{W_{t-1}}{B_{t-1}}$.

- Nếu $\tau(t-1)>t-1$ thì ta thực thi quyền chọn tại thời gian $\tau(t-1)$. Ta xem quá trình Y bắt đầu tại thời gian $\mathrm{t}-1$, thực thi tại thời gian $\tau(t-1)$. Do quá trình thu hoạch kiểu châu Mỹ Y là thực thi nên với thời gian dừng $\tau(t-1)$ thì quyền $Y_{\tau(t-1)}$ là thực thi. Do đó tồn tại một chiến lược kinh doanh tự tài trợ sao cho giá của danh mục đầu tư tương ứng có giá $W_{\tau(t-1)}=Y_{\tau(t-1)}$. Khi đó giá chiết khấu của của danh mục đầu tư bảo hộ tại thời gian t-1 là: $\frac{W_{t-1}}{B_{t-1}}=E\left[\frac{Y_{\tau(t-1)}}{B_{\tau(t-1)}} \mid F_{t-1}\right]=Z_{t-1}$ (Theo nguyên tắc xác định giá trung tính rủi ro).

\section{Ví dụ:}

Ta xét một mô hình với $\mathrm{N}=1$ chứng khoán trên $\mathrm{T}=2$ chu kỳ và $\mathrm{k}=4$ trạng thái có thể xảy ra. Để đơn giản ta thay đổi ký hiệu của quá trình giá $S^{n}$ thay cho $S_{t}^{n}$. Quá trình trên được cho bởi bảng sau:

\begin{tabular}{|l|l|l|l|}
\hline$\omega_{k}$ & $t=0$ & $t=1$ & $t=2$ \\
\hline$\omega_{1}$ & $S_{0}=6$ & $S_{1}=9$ & $S_{2}=10$ \\
\hline$\omega_{2}$ & $S_{0}=6$ & $S_{1}=9$ & $S_{2}=7$ \\
\hline$\omega_{3}$ & $S_{0}=6$ & $S_{1}=3$ & $S_{2}=7$ \\
\hline$\omega_{4}$ & $S_{0}=6$ & $S_{1}=3$ & $S_{2}=1$ \\
\hline
\end{tabular}


Trong trường hợp $r=0$, ta có $Q=\left(\frac{1}{3} ; \frac{1}{6} ; \frac{1}{6} ; \frac{1}{3}\right)$.

Ta xem một quyền chọn kiểu châu Mỹ với giá thực thi $K=5$. Quá trình thu hoạch là:

\begin{tabular}{|l|l|l|l|}
\hline$\omega_{k}$ & $t=0$ & $t=1$ & $t=2$ \\
\hline$\omega_{1}$ & $Y_{0}=1$ & $Y_{1}=4$ & $Y_{2}=5$ \\
\hline$\omega_{2}$ & $Y_{0}=1$ & $Y_{1}=4$ & $Y_{2}=2$ \\
\hline$\omega_{3}$ & $Y_{0}=1$ & $Y_{1}=0$ & $Y_{2}=2$ \\
\hline$\omega_{4}$ & $Y_{0}=1$ & $Y_{1}=0$ & $Y_{2}=0$ \\
\hline
\end{tabular}

Tại thời gian $t=2$, ta có $Z_{2}=Y_{2}$.

Tại thời gian $t=1$.

Trong các trạng thái $\omega_{1}$ và $\omega_{2}$ thì giá

$$
Z_{1}=\max \left\{Y_{1} ; E_{Q}\left[Z_{2} \mid F_{1}\right]\right\}=\max \left\{4 ; 5 \cdot \frac{2}{3}+2 \cdot \frac{1}{3}\right\}=\max \{4 ; 4\}=4
$$

Rõ ràng $Z_{1}\left(\omega_{1}, \omega_{2}\right)=V_{1}\left(\omega_{1}, \omega_{2}\right)$ là giá của quyền chọn kiểu châu Âu ở ví dụ trước.

Trong các trạng thái $\omega_{3}$ và $\omega_{4}$ thì giá

$$
. Z_{1}=\max \left\{Y_{1} ; E_{Q}\left[Z_{2} \mid F_{1}\right]\right\}=\max \left\{0 ; 2 . \frac{1}{3}+0 . \frac{1}{3}\right\}=\max \left\{0 ; \frac{2}{3}\right\}=\frac{2}{3}
$$

Tương tự $Z_{1}\left(\omega_{3}, \omega_{4}\right)=V_{1}\left(\omega_{3}, \omega_{4}\right)$.

Tại thời gian $t=0$ thì giá

$$
Z_{0}=\max \left\{Y_{0} ; E_{Q}\left[Z_{1} \mid F_{0}\right]\right\}=\max \left\{1 ; 4 \cdot \frac{1}{2}+\frac{2}{3} \cdot \frac{1}{2}\right\}=\max \left\{1 ; \frac{7}{3}\right\}=\frac{7}{3}\left(Z_{0}=V_{0}\right) \text {. }
$$

Bây giờ ta xem một quyền chọn kiểu châu Mỹ khác với quá trình thu hoạch được thay đổi bởi $Y_{1}\left(\omega_{1}\right)=Y_{1}\left(\omega_{2}\right)=5$. Quá trình thu hoạch là:

\begin{tabular}{|l|l|l|l|}
\hline$\omega_{k}$ & $t=0$ & $t=1$ & $t=2$ \\
\hline$\omega_{1}$ & $Y_{0}=1$ & $Y_{1}=5$ & $Y_{2}=5$ \\
\hline$\omega_{2}$ & $Y_{0}=1$ & $Y_{1}=5$ & $Y_{2}=2$ \\
\hline
\end{tabular}




\begin{tabular}{|l|l|l|l|}
\hline$\omega_{3}$ & $Y_{0}=1$ & $Y_{1}=0$ & $Y_{2}=2$ \\
\hline$\omega_{4}$ & $Y_{0}=1$ & $Y_{1}=0$ & $Y_{2}=0$ \\
\hline
\end{tabular}

Tại thời gian $t=2$, ta có $Z_{2}=Y_{2}$.

Tại thời gian $t=1$.

Trong các trạng thái $\omega_{1}$ và $\omega_{2}$ thì giá

$$
Z_{1}=\max \left\{Y_{1} ; E_{Q}\left[Z_{2} \mid F_{1}\right]\right\}=\max \left\{5 ; 6 \cdot \frac{2}{3}+3 \cdot \frac{1}{3}\right\}=\max \{4 ; 5\}=5 \text {. }
$$

Trong các trạng thái $\omega_{3}$ và $\omega_{4}$ thì giá

$$
Z_{1}=\max \left\{Y_{1} ; E_{Q}\left[Z_{2} \mid F_{1}\right]\right\}=\max \left\{0 ; 2 \cdot \frac{1}{3}+0 \cdot \frac{2}{3}\right\}=\max \left\{0 ; \frac{2}{3}\right\}=\frac{2}{3}
$$

Tại thời gian $t=0$ thì giá

$$
Z_{0}=\max \left\{Y_{0} ; E_{Q}\left[Z_{1} \mid F_{0}\right]\right\}=\max \left\{1 ; 5 \cdot \frac{1}{2}+\frac{2}{3} \cdot \frac{1}{2}\right\}=\max \left\{1 ; \frac{17}{6}\right\}=\frac{17}{6}
$$

- Chiến lược thự thi tối ưu là:

$$
\tau(0)(\omega)=\tau(1)(\omega)= \begin{cases}1, & \omega=\omega_{1}, \omega_{2} \\ 2, & \omega=\omega_{3}, \omega_{4}\end{cases}
$$

Và $\tau(2)(\omega)=2, \forall \omega \in \Omega$

\subsubsection{Mối quan hệ của quyền chọn kiểu Mỹ và quyền chọn kiểu châu Âu.}

Ta biết giá chiết khấu của một quyền chọn kiểu châu Âu là một martingale theo độ đo $Q$ và của châu Mỹ là một supermartingale theo độ đo $Q$. Bây giờ ta có một số kết quả so sánh hai loại quyền chọn này.

\section{Mệnh đề 3.4.13:}

Xem $Y=\left\{Y_{t}: t=0,1, \ldots, T\right\}$ là một quyền chọn kiểu Mỹ và quyền chọn kiểu châu Âu tuoong úng với thu hoạch tại thời gian $T$ là $X=Y_{T}$. Ký hiệu $V_{t}$ là giá tại thời điểm $t$ 
của quyền chọn kiểu châu Âu. Khi đó nếu $V_{t} \geq Y_{t}, \forall t, \omega$ thì $V_{t}=W_{t}, \forall t, \omega$. Trong đó $W_{t}$ là giá của quyền chọn kiều châu Mỹ tại thời điểm $t$.

Chứng minh:

Vì $\widehat{W}_{t}$ là một supermartingale theo độ đo $\mathrm{Q}$, ta có:

$$
\begin{aligned}
& \widehat{W}_{t} \geq E_{Q}\left[\widehat{W}_{T} \mid F_{t}\right]=E_{Q}\left[\widehat{V}_{T} \mid F_{t}\right]=\widehat{V}_{t} \\
& \Rightarrow W_{t} \geq V_{t}
\end{aligned}
$$

Nếu ta có $V_{t} \geq Y_{t}, \forall t, \omega$. Vì $\widehat{V}_{t}$ là martingale theo độ đo $Q$ nên nó cũng là supermatingale vượt trội $\hat{Y}_{t}$ nên ta có $\widehat{V}_{t} \geq \widehat{W}_{t}$ (vì $\widehat{W}_{t}$ là supermartingale nhỏ nhất vượt trội $\hat{Y}_{t}$ ). Từ đó suy ra $V_{t} \geq W_{t}$.

Vậy $V_{t}=W_{t}, \forall t, \omega$. (đpcm).

\section{Nhận xét:}

Bất đẳng thức $W_{t} \geq V_{t}$ là lẽ tự nhiên vì quyền chọn kiểu châu Mỹ cho nhiều lựa chọn hơn so với quyền chọn kiểu châu Âu.

\section{Ví dụ:}

Cho một thị trường với một tài sản rủi ro với giá là $S_{t} ; t=0,1, \ldots, T$ và một tài khoản ngân hàng với lãi suất là $r \geq 0$ và $B_{t}=(1+r)^{t}$. Với các ký hiệu tương tự mệnh đề trên. Quyền chọn kiểu Mỹ được mô tả bởi dãy $Y_{t}=\left(S_{t}-K\right)^{+}$trên một đơn vị của tài sản rủi ro, thì $V_{t}=W_{t}, \forall t=0,1, \ldots, T$. Thật vậy, khi đó ta có:

$$
\begin{aligned}
& \hat{V}_{t}=\frac{1}{(1+r)^{T}} E_{Q}\left[\left(S_{T}-K\right)^{+} \mid F_{t}\right] \geq \frac{1}{(1+r)^{T}} E_{Q}\left[\left(S_{T}-K\right) \mid F_{t}\right] \\
& =E_{Q}\left[\left(\hat{S}_{T}-\frac{K}{(1+r)^{T}}\right) \mid F_{t}\right]=\hat{S}_{t}-\frac{K}{(1+r)^{T}} \geq \hat{S}_{t}-\frac{K}{(1+r)^{t}} \\
& \Rightarrow V_{t} \geq S_{t}-K \text {. Mặt khác, ta có: } V_{t} \geq 0 \text {, suy ra } V_{t} \geq \max \left(S_{t}-K ; 0\right)=Y_{t} .
\end{aligned}
$$

Vậy $V_{t}=W_{t}$. 


\section{Mệnh đề 3.4.14:}

Nếu Y là một quyền chọn kiểu châu Mỹ và $\frac{Y}{B}$ là một submartingale theo độ đo $Q$ thì $\tau=T$ luôn là một chiến luợc thực thi tối uu, và giá của quyền chọn kiểu châu Mỹ trùng với giá của quyền chọn kiểu châu Âu $X=Y_{T}$.

Chứng minh:

Theo định lý mẫu tối ưu: Nếu $\frac{Y}{B}$ là một submartingale theo độ đo Q, thì $E_{Q}\left[\frac{Y_{\tau}}{B_{\tau}}\right] \leq E_{Q}\left[\frac{Y_{T}}{B_{T}}\right]$ với mọi thời gian dừng $\tau \leq T$. Do đó $\tau=T$ luôn là một chiến lược thực thi tối ưu.

Mặt khác theo định lý ta được: $W_{0}=E_{Q}\left[\frac{Y_{T}}{B_{T}}\right]$, suy ra $W_{0}=V_{0}$ là giá của quyền chọn kiểu châu Âu $X=Y_{T}$.

\section{Nhận xét:}

Tính chất trên là điều kiện mà đôi khi nó tiện cho việc kiểm tra giá của hai quyền chọn có trùng nhau hay không.

\section{Ví dụ}

Trong không gian của lãi suất không âm và không có cổ tức, một hợp đồng mua trước kiểu Mỹ được viết trên một tài sản rủi ro riêng sẽ không được thực thi sớm. Thật vậy:

Ta cần chứng minh $\frac{\left(S_{t}-K\right)^{+}}{B_{t}}=\left(\frac{S_{t}}{B_{t}}-\frac{K}{B_{t}}\right)^{+}$là submartingale. Tức là kiểm tra:

Với $s, t \geq 0:\left(\frac{S_{t}}{B_{t}}-\frac{K}{B_{t}}\right)^{+} \leq E_{Q}\left[\left(\frac{S_{t+s}}{B_{t+s}}-\frac{K}{B_{t+s}}\right)^{+} \mid F_{t}\right]$

Thật vậy, ta có $E_{Q}\left[\left(\frac{S_{t+s}}{B_{t+s}}-\frac{K}{B_{t+s}}\right)^{+} \mid F_{t}\right] \geq E_{Q}\left[\left(\frac{S_{t+s}}{B_{t+s}}-\frac{K}{B_{t+s}}\right) \mid F_{t}\right]$ 


$$
\begin{aligned}
& =E_{Q}\left[\frac{S_{t+s}}{B_{t+s}} \mid F_{t}\right]-K E_{Q}\left[\frac{1}{B_{t+s}} \mid F_{t}\right] \\
& =\frac{S_{t}}{B_{t}}-K E_{Q}\left[\frac{1}{B_{t+s}} \mid F_{t}\right] \text { (do } \frac{S_{t}}{B_{t}} \text { là Q-martingale) }
\end{aligned}
$$

Vì $B_{t+s} \geq B_{t} \Rightarrow \frac{1}{B_{t+s}} \leq \frac{1}{B_{t}}$ nên $E_{Q}\left[\left(\frac{S_{t+s}}{B_{t+s}}-\frac{K}{B_{t+s}}\right)^{+} \mid F_{t}\right] \geq \frac{S_{t}}{B_{t}}-K E_{Q}\left[\frac{1}{B_{t}} \mid F_{t}\right]=\frac{S_{t}}{B_{t}}-\frac{K}{B_{t}}$

Mặt khác, vì $E_{Q}\left[\left(\frac{S_{t+s}}{B_{t+s}}-\frac{K}{B_{t+s}}\right)^{+} \mid F_{t}\right] \geq 0$ nên

$E_{Q}\left[\left(\frac{S_{t+s}}{B_{t+s}}-\frac{K}{B_{t+s}}\right)^{+} \mid F_{t}\right] \geq \max \left\{\frac{S_{t}}{B_{t}}-\frac{K}{B_{t}} ; 0\right\}$.

Vậy đi đến điều phải chứng minh.

\subsection{Giá hợp đồng ký kết trước (forward contract) Định nghĩa 3.5.1:}

Đó là loại hợp đồng ký kết truớc giữa hai bên đối tác $A$ và $B$ (thưòng là các công ty tài chính hay các nhà môi giới đầu tu, hay các nhà đầu tu tài chính...) tại thời điểm ký hợp đồng là t với các quy ước sau:

i. Đến thời điểm đáo hạn $\tau \leq T$ của hợp đồng, bên A phải giao cho bên B một khối luợng sản phẩm tài chính (cổ phiếu, ngoại tệ,...) hoặc mọt khối lượng hàng hoá đặc biệt nào đó (dầu mó, lúa,...) có giá trị thị truoòng là $X$ tại thời điểm $\tau$.

ii. Đến thời điểm đáo hạn $\tau$ đó, bên $B$ phải trả cho bên A một khoản tiền $O_{t}(O$ bắt nguồn tù fOrward) định truớc tù lý ký kết (thời điểm t)

iii. Không có bất kỳ một chi phí giao dịch nào truớc thời điểm $\tau$.

iv. Đến thời điểm $\tau$, hai bên bắt buộc phải thực thi các quy uớc đó, theo một số điều khoản cu thế.

Vấn đề của ta bây giờ là đi xác định giá của hợp đồng ký kết trước $O_{t}$.

Đầu tiên ta có kết quả sau, trong trường hợp S là chứng khoán không trả cổ tức. 


\section{Mệnh đề 3.5.2:}

Giá ký kết truớc của chứng khoán không trả cổ tức S tại thời gian t là $O_{t}$ được nhận và trả tại thời gian $\tau>t$ là:

$$
O_{t}=\frac{S_{t}}{E_{Q}\left[\frac{B_{t}}{B_{\tau}} \mid F_{t}\right]}
$$

Chứng minh:

Ý tưởng của việc giữ hợp đồng ký kết trước và trả $O_{t} \$$ tại thời điểm $\tau$ giống với việc giữ một đơn vị chứng khoán $\mathrm{S}$ tại cùng thời điểm $\mathrm{t}$ và bán chứng khoán đó với giá tại thời điểm $t=\tau$ là $O_{t}$. Ta có thể xem đó là quyền phái sinh. Khi đó giá của danh mục đầu tư đáp ứng cho quyền phái sinh đó tại thời điểm $\mathrm{t}$ là:

$$
E_{Q}\left[O_{t} \frac{B_{t}}{B_{\tau}} \mid \mathcal{F}_{t}\right]=O_{t} E_{Q}\left[\frac{B_{t}}{B_{\tau}} \mid \mathcal{F}_{t}\right]
$$

Giá của chứng khoán $\mathrm{S}$ đó tại thời điểm $\mathrm{t}$ là $S_{t}$, nên:

$$
S_{t}=O_{t} E_{Q}\left[\frac{B_{t}}{B_{\tau}} \mid \mathcal{F}_{t}\right] .
$$

Điều này dẫn đến kết quả trên.

Tuy nhiên trong trường hợp $\mathrm{S}$ là chứng khoán trả cổ tức thì kết quả trên không còn đúng.

Ta xét chứng khoán $\mathrm{S}$ mà người mua nó tại thời điểm $\mathrm{t}$ sẽ được nhận $\Delta D_{t+1}, \ldots, \Delta D_{\tau}$ đơn vị tiền tệ lần lượt tại các thời điểm $t+1, \ldots, \tau$. Khi đó ta có kết quả sau:

\section{Mệnh đề 3.5.3:}

Giá ký kết truớc của chúng khoán trả cổ tức $S$ tại thời gian t là $O_{t}$ được nhận và trả tại thời gian $\tau>t$ là:

$$
O_{t}=\frac{1}{E_{Q}\left[\frac{B_{t}}{B_{\tau}} \mid \mathcal{F}_{t}\right]}\left[S_{t}-\sum_{s=t+1}^{\tau} E_{Q}\left[\frac{\Delta D_{s} B_{t}}{B_{s}} \mid \mathcal{F}_{t}\right]\right]
$$


Chứng minh:

Khi ta giữ hợp đồng ký kết trước và trả $O_{t} \$$ tại thời điểm $\tau$, thì tương tự như trên, giá của quyền phái sinh thời gian $\tau$ đó tại thời điểm $\mathrm{t}$ là:

$$
O_{t} E_{Q}\left[\frac{B_{t}}{B_{\tau}} \mid \mathcal{F}_{t}\right]
$$

Công việc trên cũng giống như việc ta mua chứng khoán $\mathrm{S}$ tại thời điểm $\mathrm{t}$ bằng cách trả $S_{t}$, mà:

- Tại thời điểm $\mathrm{t}+1$, ta nhận một lượng tiền là $\Delta D_{t+1}$, đây thực ra quyền phái sinh thời gian $\mathrm{t}+1$, do đó giá của danh mục đầu tư đáp ứng cho nó tại thời điểm $\mathrm{t}$ là:

$$
E_{Q}\left[\frac{\Delta D_{t+1} B_{t}}{B_{t+1}} \mid \mathcal{F}_{t}\right]
$$

- Tại thời điểm $\mathrm{t}+2$, ta nhận một lượng tiền là $\Delta D_{t+2}$, đây thực ra quyền phái sinh thời gian $\mathrm{t}+2$, do đó giá của danh mục đầu tư đáp ứng cho nó tại thời điểm $\mathrm{t}$ là:

$$
E_{Q}\left[\frac{\Delta D_{t+2} B_{t}}{B_{t+2}} \mid \mathcal{F}_{t}\right]
$$

- Tại thời điểm $\tau$, ta nhận một lượng tiền là $\Delta D_{\tau}$, đây thực ra quyền phái sinh thời gian $\tau$, do đó giá của danh mục đầu tư đáp ứng cho nó tại thời điểm $\mathrm{t}$ là:

$$
E_{Q}\left[\frac{\Delta D_{\tau} B_{t}}{B_{\tau}} \mid \mathcal{F}_{t}\right]
$$

Vậy giá của danh mục đầu tư tại thời gian t (lượng tiền phải trả) là:

$$
S_{t}-\sum_{s=t+1}^{\tau} E_{Q}\left[\frac{\Delta D_{s} B_{t}}{B_{s}} \mid \mathcal{F}_{t}\right]
$$

Do đó ta được:

$$
S_{t}-\sum_{s=t+1}^{\tau} E_{Q}\left[\frac{\Delta D_{s} B_{t}}{B_{s}} \mid \mathcal{F}_{t}\right]=O_{t} E_{Q}\left[\frac{B_{t}}{B_{\tau}} \mid \mathcal{F}_{t}\right]
$$


Hay

$$
O_{t}=\frac{1}{E_{Q}\left[\frac{B_{t}}{B_{\tau}} \mid \mathcal{F}_{t}\right]}\left[S_{t}-\sum_{s=t+1}^{\tau} E_{Q}\left[\frac{\Delta D_{s} B_{t}}{B_{s}} \mid \mathcal{F}_{t}\right]\right]
$$

Vậy ta có điều phải chứng minh. 


\section{KẾT LUẬN}

Mặc dù nội dung nghiên cứu của đề tài không có nhiều mới mẻ, nhưng tôi cảm thấy kiến thức của mình được củng cố và mở rộng hơn nhiều, cảm thấy tâm huyết mình bỏ ra trong thời gian qua thật sự xứng đáng. Tuy vậy cũng sẽ khó tránh những sai sót mà tôi không nhận ra, rất mong quí thầy cô tận tình góp ý để tôi có thể chỉnh sửa cho luận văn của mình hoàn chỉnh hơn. Xin chân thành cám ơn quí thầy cô rất nhiều. 


\section{TÀI LIỆU THAM KHẢO}

[1] Nguyễn Văn Hữu, Vương Quân Hoàng (2007), Các phương pháp toán học trong tài chính, NXB Đại học Quốc Gia Hà Nội

[2] Nguyễn Chí Long (2008), Xác suất thống kê và quá trình ngẫu nhiên, NXB Đại học Quốc gia TPHCM.

[3] Nguyễn Chí Long (2010), "Nguyên lý căn bản định giá tài sản trong thị trường tài chính", Tap chi khoa hoc ĐHSP TPHCM, 21(55), tr.38-51

[4] Nguyễn Chí Long (2011), "Bổ đề Fakas và áp dụng trong thị trường tài chính", Tap chi khoa hoc ĐHSP TPHCM, 27(61), tr.41-53

[5] Nguyễn Chí Long (2011), "Mô hình định giá tài sản tư bản", Tạp chí khoa hoc ĐHSP TPHCM, 30(64), tr.25-41

[6] Nguyễn Chí Long (2011), "Định giá tài sản trong mô hình nhị thức", Số chuyên đề của ĐHSG: Hội thảo Quốc tế Giải tích và Toán ứng dụng, ĐHSG TPHCM, tr 513-525

[7] Trần Hùng Thao (2004), Nhập môn toán học Tài chính, NXB Khoa học kỹ thuật Hà Nội.

[8] Trần Trọng Nguyên (2009), Cơ sơ Toán tài chính, NXB Khoa học kỹ thuật Hà Nội.

[9] Stanley R. Pliska (1997), Introduction to Mathematical Finance (Discrete Time Models), Blackwell Publishers Inc.

[10] Nick Whiteley (2011), Financial Maths, University of Bristol. 